GUSTAVO DA SILVA PIRES MARTINS

FILTROS INTERFERENCIAIS CONSTRUÍDOS COM DIELÉTRICOS DEPOSITADOS PELA TÉCNICA DE PECVD 
GUSTAVO DA SILVA PIRES MARTINS

\title{
FILTROS INTERFERENCIAIS CONSTRUÍDOS COM DIELÉTRICOS DEPOSITADOS PELA TÉCNICA DE PECVD
}

\author{
Dissertação apresentada à Escola \\ Politécnica da Universidade de São \\ Paulo para a obtenção do título de \\ Mestre em Engenharia
}

\section{São Paulo}


GUSTAVO DA SILVA PIRES MARTINS

FILTROS INTERFERENCIAIS CONSTRUÍDOS COM DIELÉTRICOS DEPOSITADOS PELA TÉCNICA DE PECVD

Dissertação apresentada à Escola

Politécnica da Universidade de São

Paulo para a obtenção do título de Mestre em Engenharia

Área de Concentração:

Microeletrônica

Orientador: Professor Doutor Marco Isaías Alayo Chávez

\section{São Paulo}


Este exemplar foi revisado e alterado em relação à versão original, sob responsabilidade única do autor e com a anuência de seu orientador.

São Paulo, 15 de julho de 2008.

Assinatura do autor

Assinatura do orientador

\section{FICHA CATALOGRÁFICA}

Martins, Gustavo da Silva Pires

Filtros interferenciais construídos com dielétricos depositados pela técnica de PECVD / G.S.P. Martins. -- ed.rev. --São Paulo, 2008.

$103 \mathrm{p}$.

Dissertação (Mestrado) - Escola Politécnica da Universidade de São Paulo. Departamento de Engenharia de Sistemas Eletrônicos.

1.Plasma (Microeletrônica) 2.Óptica 3.Filmes finos I.Universidade de São Paulo. Escola Politécnica. Departamento de Engenharia de Sistemas Eletrônicos II.t. 


\section{DEDICATÓRIA}

Dedico este trabalho aos meus Pais. 


\section{AGRADECIMENTOS}

Ao professor doutor Marco Isaías Alayo Chávez, pela orientação e pelo constante estímulo transmitido durante todo o trabalho.

Ao CNPq (Conselho Nacional de Desenvolvimento Científico e Tecnológico).

Aos técnicos do Laboratório de Microeletrônica da Universidade de São Paulo.

Aos meus amigos Alexandre Martin Mina, Hector Baez Medina e Mirele

Stochero e a todos que colaboraram direta ou indiretamente, na execução deste trabalho. 
A imaginação é mais importante que o conhecimento.

(Albert Einstein) 


\section{RESUMO}

Neste trabalho são apresentadas as simulações, fabricações e caracterizações de filtros interferenciais empregando películas dielétricas amorfas depositadas pela técnica de deposição a vapor assistida por plasma (PECVD) sobre substratos de silício e de Corning Glass (7059). Os dispositivos ópticos foram construídos usandose processos padrões de microeletrônica e consistiram em camadas periódicas com espessura e índice de refração apropriados para produzir picos da atenuação na transmitância da luz na região visível. Simulações numéricas precedentes foram realizadas baseando-se nas características ópticas das películas dielétricas. Para a caracterização dos filtros interferenciais, uma luz monocromática de um laser de He$\mathrm{Ne}$, foi injetada nos filtros e a luz obtida na saída foi conduzida então a um detector. O filtro depositado sobre Corning Glass (chamado de filtro vertical) e o filtro depositado sobre silício com cavidades (chamado de filtro suspenso) foram montados sobre dispositivos térmicos e angulares de modo a medir suas respostas à variação angular e térmica. Também, o filtro depositado sobre silício (chamado de filtro horizontal) foi montado sobre um dispositivo térmico, a fim de medir sua resposta à temperatura. Quando os filtros são submetidos a uma mudança na temperatura, uma variação do índice de refração devido ao efeito termo-óptico produz um deslocamento nos picos da atenuação, que podem ser previstos por simulações numéricas. Esta característica permite que estes dispositivos sejam usados como sensores termo-ópticos. Por outro lado, quando o filtro vertical e o filtro suspenso são submetidos a variações angulares entre a normal ao plano do filtro e o feixe de laser, uma variação na potência da luz de saída é produzida. Esta característica permite que estes dispositivos sejam usados como sensores angulares.

Palavras-chave: Deposição química a vapor assistida por plasma, Filtros Interferenciais, Filtros ópticos, Filtros Multicamada, Óptica integrada. 


\begin{abstract}
In this work, we present the simulation, fabrication and characterization of filters employing amorphous dielectric films deposited by Plasma Enhanced Chemical Vapor Deposition (PECVD) technique on crystalline silicon $<100>$ and Corning Glass (7059) substrates. The optical devices were fabricated using standard microelectronic processes and consisted of periodic layers with appropriated thickness and refractive indexes to produce transmittance attenuation peaks in the visible region. For this, previous numerical simulations were realized based in the optical parameters of the dielectric films. For the characterization of the optical interferential filters, a monochromatic light, a He-Ne laser, was projected onto the filters and the transmitted output light was then conducted to a detector. The optical filters were produced on Corning Glass (here called vertical filter) and on silicon substrates. The silicon substrate was etch in $\mathrm{KOH}$ solution to form cavities and suspend part of the filter (here called suspended filter). The vertical and suspended filters were mounted on thermo and angular devices that allowed the measurement of the optical power as a function of temperature and angle changes. A second type of filter deposited over a silicon substrate (here called horizontal filter) was mounted on thermoelectric device, in order to control the temperature responses. When the filters are submitted to a change in temperature, a variation of the refractive index is originated in the dielectric film due to the thermo-optic effect (TOE), producing a shift in the attenuation peaks, which can be well predicted by numerical simulations. This characteristic allows these devices to be used as thermo-optic sensors. On the other hand, when the vertical filter and the suspended filter were subjected to an angular shift between the filter's normal and the laser, a variation of the output optical power is originated. This characteristic allows these devices to be used as angular sensors.
\end{abstract}

Keywords: Plasma enhanced chemical vapor deposition, Interferential filters, Optical filters, Multilayer Filters, Integrated optics. 


\section{LISTA DE ILUSTRAÇÕES}

Figura 2.1 - Onda eletromagnética com as polarizações p e s vinda de um meio com índice de refração "a" e incidindo em um meio com índice de refração "b".

Figura 2.2 - Diagrama esquemático da estrutura multicamada usada para o calculo da transmitância total.

Figura 2.3 - Diagrama esquemático da estrutura usada para o calculo da matriz de multicamadas.

Figura 2.4 - Diagrama esquemático da estrutura usada para o calculo da matriz da interface.

Figura 2.5 - Diagrama esquemático da estrutura usada para o calculo da matriz de camada.

Figura 2.6 - Esquerda: Reflexão e transmissão (ou refração) de uma onda plana na interface entre dois meios (ab). Direita: a direção de propagação da onda transmitida assumindo-se a propagação reversa.

Figura 2.7 - Esquema da estrutura simulada

Figura 2.8 - Simulação 1, filtro de 7 camadas com $\lambda v=633 \mathrm{~nm}, \mathrm{CP}=1,46, \mathrm{Cl}=$ 1,91 e $\mathrm{m}=1$, para luz incidente de $300 \mathrm{~nm}$ a $1100 \mathrm{~nm}$.

Figura 2.9 - Simulação 2, filtro de 15 camadas com $\lambda v=633 n m, C P=1,46, C l$ $=1,91$ e $\mathrm{m}=1$ para luz incidente de $300 \mathrm{~nm}$ a $1100 \mathrm{~nm}$.

Figura 2.10 - Simulação 3, filtro de 7 camadas com $\lambda v=633 n m, C P=1,5, C l=$ 1,7 e $\mathrm{m}=1$, para luz incidente de $300 \mathrm{~nm}$ a $1100 \mathrm{~nm}$. .39

Figura 2.11 - Simulação 4, filtro de 7 camadas com $\lambda v=633 \mathrm{~nm}, \mathrm{CP}=1,46, \mathrm{Cl}=$ 1,91 e $\mathrm{m}=5$, para luz incidente de $300 \mathrm{~nm}$ a $1100 \mathrm{~nm}$.

Figura 2.12 - Simulação 5, filtro de 7 camadas com $\lambda v=633 \mathrm{~nm}, \mathrm{CP}=1,46, \mathrm{Cl}=$ 1,91 e $m=1$ com ângulos de incidência variando de $0^{\circ}$ a $50^{\circ}$, para luz incidente de 350nm a 750 $\mathrm{nm}$. 
Figura 2.13 - Simulação 6 , filtro de 9 camadas com $\lambda v=633 \mathrm{~nm}, \mathrm{CP}=1,46, \mathrm{Cl}=$ 1,91 e $m=1$ com ângulos de incidência variando de $0^{\circ}$ a 50ㅜㄹ para luz incidente de 350nm à 750 nm.

Figura 2.14 - Simulação 7, filtro de 7 camadas com $\lambda v=633 \mathrm{~nm}, \mathrm{CP}=1,46, \mathrm{Cl}=$ 1,91 e $\mathrm{m}=1$ com ângulos de incidência variando de $0^{\circ}$ a $80^{\circ}$ para luz incidente de 633nm.

Figura 2.15 - Simulação 8, filtro de 9 camadas com $\lambda v=633 \mathrm{~nm}, \mathrm{CP}=1,46, \mathrm{Cl}=$ 1,91 e $\mathrm{m}=1$ com ângulos de incidência variando de $0^{\circ}$ a $80^{\circ}$ para luz incidente de 633nm.

Figura 2.16 - Simulação 9, filtro de 13 camadas com $\lambda v=634 \mathrm{~nm} \quad \mathrm{CP}=1,46, \mathrm{Cl}$ $=1,91$ e $m=10.25$, variação com a temperatura para luz incidente de $633 \mathrm{~nm}$.

Figura 2.17 - Simulação 10, filtro de 13 camadas com $\lambda v=634 \mathrm{~nm} \quad \mathrm{CP}=1,46, \mathrm{Cl}$ $=1,91$ e $m=10.25$, variação com a temperatura para luz incidente de 630nm até 640nm. Pela legenda: gráfico vermelho o filtro se encontra a $375^{\circ} \mathrm{C}$ e gráfico em preto o filtro está à $25^{\circ} \mathrm{C}$ e centrado em $634 \mathrm{~nm}$.

Figura 3.1 - Transmitância (\%) em função do comprimento de onda para o Corning Glass (7059)........................................................... 46

Figura 3.2 - Diagrama esquemático do reator de PECVD................................. 48

Figura 3.3 - Índice de refração em função do fluxo dos gases nitrogênio $\left(N_{2}\right)$ e óxido nitroso $\left(\mathrm{N}_{2} \mathrm{O}\right)$ em sccm que entram no reator de PECVD........50

Figura 3.4 - Reator de PECVD do Laboratório de Microeletrônica da Escola Politécnica da Universidade de São Paulo.

Figura 3.5 - Arranjo experimental da medida de índice de refração por elipsometria.

Figura 3.6 - Concentração de silício, nitrogênio e oxigênio no filme depositado em função do fluxo gasoso que entra no reator durante a deposição.

Figura 3.7 - Taxa de deposição em função da composição dos gases que entram no reator. 
Figura 3.8 - Filtro sobre vidro Corning Glass (7059) com a luz passando no sentido vertical.

Figura 3.9 - Filtro sobre silício com a luz passando no sentido horizontal. 56

Figura 3.11 - Reator de sputtering (pulverização catódica) da sala do reator do Laboratório de Microeletrônica da Escola Politécnica da Universidade de São Paulo.

Figura 3.13 - Taxa de corrosão dos filmes de Oxinitreto de silício em função da composição usada de gases no reator de PECVD.

Figura 3.14 - Reator de RIE (reactive ion etching) para a corrosão dos filmes de oxinitreto e se encontra na sala limpa do Laboratório de Microeletrônica da Escola Politécnica da Universidade de São Paulo. 59

Figura 3.13 - (a) llustração da lâmina de 1"x1"; (b) Deposição em PECVD de 1,5 $\mu \mathrm{m}$ de óxido de silício (cladding); (c) Deposição em PECVD de 3 $\mu \mathrm{m}$ de nitreto de silício (núcleo); (d) Deposição de 1,5 $\mu \mathrm{m}$ de óxido de silício (cobertura); (e) Deposição da camada de cromo; (f) deposição de fotoresiste; (g) Fotogravação; (h) corrosão do cromo;

(i) Corrosão por RIE dos dielétricos; (j) Corrosão do cromo. 61

Figura 3.14 - (a)Máscaras utilizadas para definição de filtros horizontais; (b) máscara utilizada na definição dos filtros

Figura 3.18 - Dimensões dos filtros horizontais.................................................63

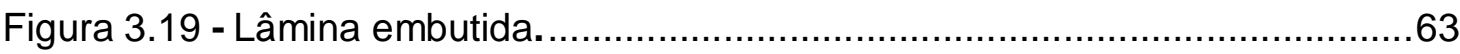

Figura 3.20 - Lâmina embutida sendo lixada....................................................64

Figura 3.21 - Acima na caixa branca: Pasta de diamante de 1 micrometro. No centro: Polimetriz MINIMET 1000. À direita: solução de sílica de 0,1 micrometros.

Figura 3.22 - (a) Deposição de filtro multicamada; (b) Deposição da camada de cromo; (c) Deposição de fotoressiste; (d) Fotogravação; (e) Corrosão do cromo; (f) Corrosão do substrato de silício por $\mathrm{KOH}$.....66

Figura 4.1 - Transmitância (\%) em função do comprimento de onda para o filtro 1. 
Figura 4.2 - Foto do filtro 1 onde se pode perceber a reflexão da luz branca sobre sua superfície e seu colorido característico e as regiões onde foram colocadas as garras para que o substrato fosse preso ao reator.

Figura 4.3 - Foto do filtro 2 onde se pode perceber a reflexão da luz branca sobre sua superfície.

Figura 4.4 - Transmitância (\%) em função do comprimento de onda para o filtro 2.

Figura 4.5 - Foto do filtro 3 onde se pode perceber a reflexão da luz branca sobre sua superfície.

Figura 4.6 - Transmitância (\%) em função do comprimento de onda para o filtro 3. .74

Figura 4.7 - Transmitância (\%) em função do comprimento de onda para o filtro 4. .77

Figura 4.8 - Foto do filtro 4 onde se pode perceber a reflexão da luz branca sobre sua superfície, o colorido se limita ao laranja e ao vermelho e se estabiliza ao se distanciar da marca da garra, tendo-se uma área útil muito maior para a realização de testes.

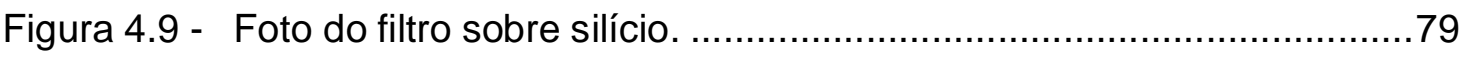

Figura 4.10 - Filtro suspenso sobre base de apoio....................................... 81

Figura 4.11 - Filtro suspenso, devidos às menores perdas deste filtro, as curvas experimental e simulada são praticamente idênticas, pois a luz passa apenas pela fina camada de filme fino PECVD.

Figura 4.12 - Estrutura que permite realizar a mudança angular do filtro, em cima de esboço do circulo trigonométrico.

Figura 4.13 - Estrutura que permite realizar a mudança angular do filtro, dentro do espectrofotômetro.

Figura 4.14 - Dados experimentais da transmitância do filtro 4 sob diferentes ângulos de incidência da luz. 
Figura 4.15 - Simulação da transmitância do filtro 4 em função do ângulo entre a normal para um feixe de luz monocromático de $633 \mathrm{~nm}$.

Figura 4.16 - Montagem para teste angular; à esquerda fotodetector; no centro, o filtro depositado sobre Corning Glass sobre o hot plate; à direita, o espelho; acima no centro, display óptico PTS-OPM-1 e acima à direita, o canhão do laser de 633nm.

Figura 4.17-Dados experimentais obtidos pelo teste angular, para 0 comprimento de onda de $633 \mathrm{~nm}$ no filtro 4 .

Figura 4.18 - Potência luminosa medida pelo fotodiodo em função da temperatura do filtro 4 .

Figura 4.19-Dados experimentais da transmitância do filtro suspenso sob diferentes ângulos de incidência da luz utilizando-se 0 espectrofotômetro. .89

Figura 4.20 - Simulação da transmitância do filtro suspenso em função do ângulo entre a normal e o feixe de luz monocromático de $633 \mathrm{~nm}$.

Figura 4.21-Dados experimentais obtidos pelo teste angular, para 0 comprimento de onda de $633 \mathrm{~nm}$ no filtro suspenso.

Figura 4.22 - Potência luminosa medida pelo fotodiodo em função da temperatura do filtro suspenso.

Figura 4.23 - Montagem para teste térmico do filtro sobre silício.

Figura 4.24 - Potência luminosa medida pelo fotodiodo em função da temperatura do filtro horizontal.

Figura 4.25 - Simulação da transmitância em função da temperatura do filtro horizontal.

Figura 4.26 - Comparação entre o gráfico simulado e o gráfico experimental normalizado. 


\section{LISTA DE TABELAS}

Tabela 3.1 - Características das lâminas de Corning Glass (7059) utilizadas........................................................................... 46

Tabela 3.2 - Descrição da limpeza inicial realizada após a clivagems nas lâminas.

Tabela 3.3 - Descrição da limpeza realizada após cada etapa de processamento.

Tabela 4.1 - Características da deposição em PECVD do filtro 1................68

Tabela 4.2 - Características da deposição em PECVD do filtro 2..................71

Tabela 4.3 - Características da deposição em PECVD do filtro 3.................75

Tabela 4.4 - Características da deposição em PECVD do filtro 4.................78

Tabela 4.5 - Características da deposição do filtro sobre silício com a luz passando no sentido horizontal. .........................................80

Tabela 4.6 - Características da deposição do filtro suspenso........................81 


\section{LISTA DE ABREVIATURAS E SIGLAS}

$\begin{array}{ll}\text { B-PON } & \text { Broadband Passive Optical Network } \\ \text { Cl's } & \text { Circuitos Integrados } \\ \text { FTTH } & \text { Fiber To The Home } \\ \text { GE-PON } & \text { Gigabit Ethernet-Passive Optical Network } \\ \text { G-PON } & \text { Gigabit Passive Optical Network } \\ \text { ITU } & \text { International Telecomunication Union } \\ \text { LPCVD } & \text { Low-pressure Chemical Vapor Deposition } \\ \text { LVDT } & \text { Linear Variable Differential Transformer } \\ \text { MOS } & \text { Metal-Óxido-Semicondutor } \\ \text { OTS } & \text { Optical temperature sensors } \\ \text { PECVD } & \text { Plasma Enhanced Chemical Vapor Deposition } \\ \text { RF } & \text { Rádio Freqüência } \\ \text { RIE } & \text { Reactive lon Etching } \\ \text { SOI } & \text { Silicon-On-Insulator } \\ \text { WDM } & \text { Wave Division Multiplex }\end{array}$




\section{SUMÁRIO}

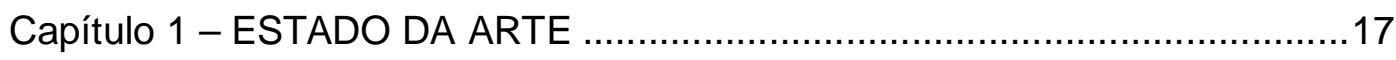

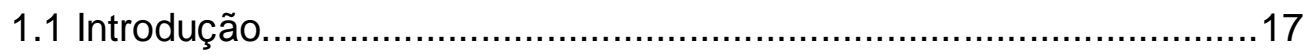

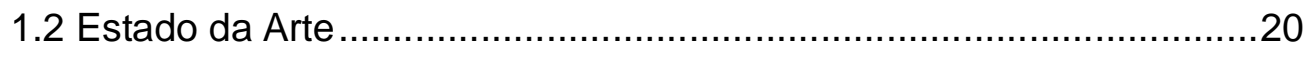

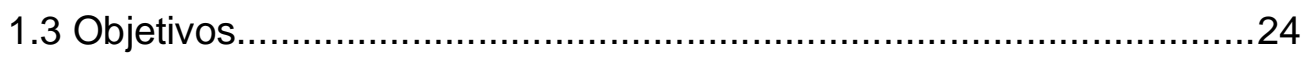

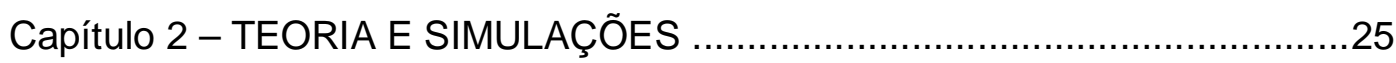

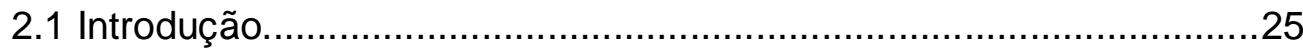

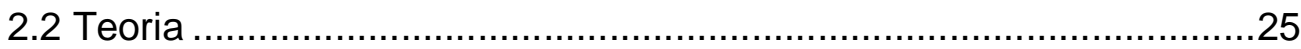

2.2.1 Reflexão e Refração em uma Interface Plana entre Dois Meios

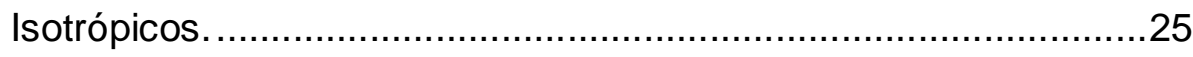

2.2.2 Reflexão e Transmissão por uma Estrutura Isotrópica Planar e

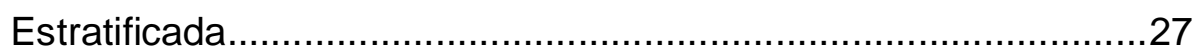

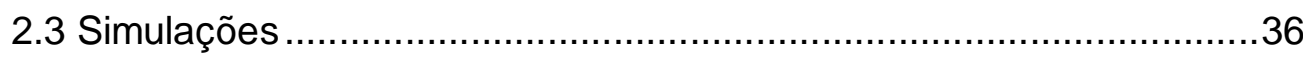

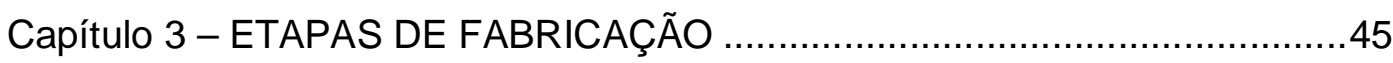

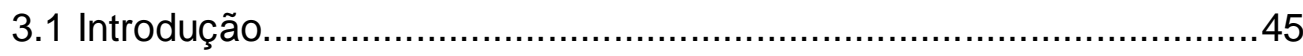

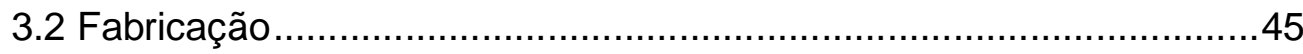

Capítulo 4 - RESULTADOS EXPERIMENTAIS E DISCUSSÕES....................67

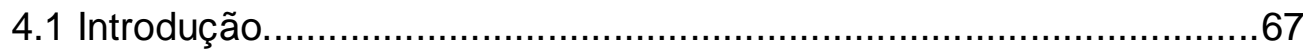

4.2 Filtros depositados sobre Corning Glass (7059).............................67

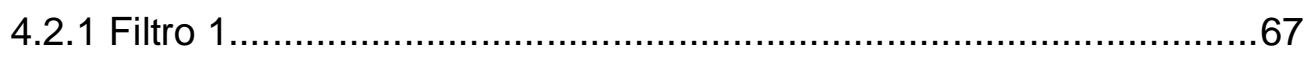

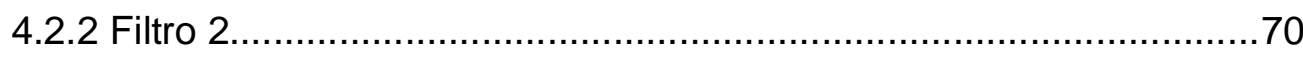

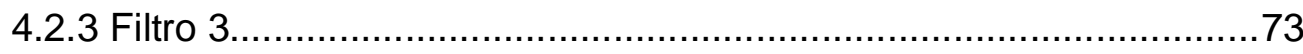

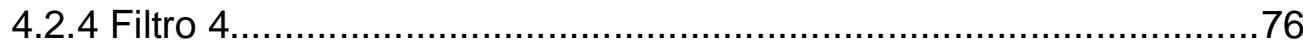

4.3 Filtro depositado sobre silício (Filtro Horizontal) ................................79

4.4 Filtro Depositado sobre Silício Fino (Filtro Suspenso) .........................80

4.4 Montagens Experimentais e Resultados ……………………........ 82

4.4.1 Filtro Vertical como Sensor Angular ............................................... 83

4.4.2 Filtro Vertical como Sensor de Temperatura ..................................87

4.4.3 Filtro Suspenso como Sensor de Angular ......................................89

4.4.4 Filtro Suspenso como Sensor de Temperatura ..............................91

4.4.5 Filtro Horizontal como Sensor de Temperatura ..............................92 


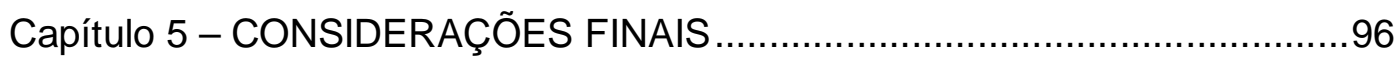

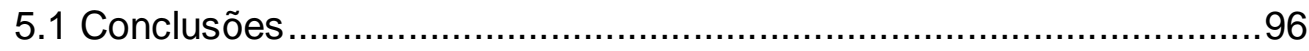

5.2 Sugestões para Trabalhos Futuros ……………..........................97

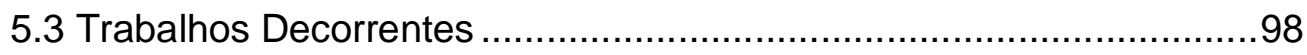




\section{Capítulo 1 - ESTADO DA ARTE}

\subsection{INTRODUÇÃO}

Desde o início do desenvolvimento dos circuitos integrados (Cl's), há aproximadamente 40 anos, nenhuma outra tecnologia teve uma evolução tão abrupta quanto a dos Cl's e atualmente os equipamentos mais modernos de hoje tem suas características mais atraentes graças à incorporação da microeletrônica. Além desta rápida evolução da tecnologia, a história da microeletrônica apresenta outros fatores incomparáveis relacionados com outras áreas, como por exemplo, um crescimento de mercado de aproximadamente $15 \%$ anuais durante as suas 4 décadas de existência tornando assim esta tecnologia a maior do mercado mundial [1]. Em resumo, a microeletrônica produziu uma nova revolução na história humana, alterando profundamente todas as atividades e por este motivo a nossa era é chamada de "idade do silício", referenciando à prática da história de classificar as eras pela habilidade humana em manipular e usar predominantemente um dado material (idade da pedra, do bronze, etc.).

Porém, estamos chegando a certas limitações com esta tecnologia como por exemplo: o limite de empacotamento, os problemas com as altas dissipações térmicas dos Cl's e as limitações físicas e elétricas dos materiais usados. Acreditase, por exemplo, que os dispositivos que serão projetados entre 2010 e 2018 estarão começando a entrar no limite útil de miniaturização da tecnologia de metalóxido-semicondutor (MOS) [2,3]. Isto levou a procurar outras tecnologias que visem eliminar estas barreiras. Dentro deste contexto, a tecnologia óptica tem assumido uma importância relevante.

Atualmente a óptica se mostra mais firmemente no setor de telecomunicações onde a fibra óptica, o qual é um meio barato e eficiente de enviar informações, abre um novo caminho para a transmissão de dados. Neste caso, o envio de informações com esta tecnologia se dá pelo uso de pulsos de luz o qual tem a vantagem de sofrer menos interferências eletromagnéticas que os sinais elétricos usados na 
microeletrônica. Ademais, esta tecnologia tem permitido a transmissão de dados a maiores velocidades (10Gb/s) e com maiores larguras de banda $(100 \mathrm{GHz})$ [4].

Porém, um importante desafio a ser enfrentado no desenvolvimento de sistemas de transmissão por fibras ópticas é a "barreira eletrônica". Essa "barreira" reflete o fato da limitação dos sistemas não ser causada pela banda passante da fibra óptica e da fonte luminosa utilizada, mas sim pelos componentes eletrônicos usados para o processamento de sinais. Entretanto, com o crescente desenvolvimento da tecnologia de óptica integrada, na realização de dispositivos ópticos de processamento de sinais, espera-se superar satisfatoriamente essa limitação [1].

O conceito de óptica integrada foi criado no fim da década de 60 e propunha essencialmente a integração em um único substrato de diversas funcionalidades de processamento de sinal óptico, mediante a integração híbrida ou monolítica.

Atualmente um sinal óptico que é propagado a grandes distâncias através de fibras ópticas é convertido depois para sinais elétricos e finalmente é processado eletronicamente [1].

Com a óptica integrada, algumas etapas do processamento passam a ser efetuadas no domínio óptico, ou seja, o sinal é transmitido e também processado opticamente. Assim, as funções que podem ser efetuadas com esta tecnologia incluem entre outras, divisão de potência óptica, chaveamento, multiplexação e demultiplexação óptica [5].

Tudo isto leva também à fabricação de dispositivos ópticos e microeletrônicos num mesmo chip, o qual vem se destacando como uma área de pesquisa de grande interesse e de rápido desenvolvimento pois se mostra como a solução para romper a "barreira eletrônica". Esta tecnologia pode trazer ademais, para o campo das telecomunicações e do sensoriamento, inúmeras vantagens como por exemplo, aumento da densidade de empacotamento dos circuitos ópticos e microeletrônicos, o aumento de taxa de transmissão de dados em telecomunicações (devido à redução do retardo de propagação), além de apresentar baixa sensibilidade às radiações eletromagnéticas $[1,7]$.

Por outro lado, no campo dos sensores, devido ao alto grau de conhecimento que se tem da tecnologia do silício, recentes desenvolvimentos para a fabricação de pequenos sensores opto - eletrônicos usando o silício e/ou compostos de silício como material padrão, estão sendo realizados com extrema precisão e custos 
aceitáveis Estes novos dispositivos ópticos baseiam-se em uma série de princípios para monitorar um grande número de parâmetros físicos (temperatura, pressão, fluxo) [6].

Particularmente no que concerne aos sensores de temperatura (esquema simplificado mostrado na Figura 1. 1), a dependência da temperatura em um transistor base-emissor bipolar e o efeito termo resistivo em filmes de metal (termopares) foram bastante explorados e devido a isso, tem surgido novas alternativas e pesquisas que pudessem apresentar novas soluções mais simplificadas, melhores e complementares aos sensores convencionais $[7,10]$. Entre elas está a optoeletrônica que tem buscado uma integração cada vez maior, onde o uso da parte elétrica (corrente, tensão) é substituído pelo sensoriamento óptico dependente da temperatura, através do efeito termo-óptico (variação do índice de refração com a temperatura). Isso por que as técnicas que utilizam a variação de uma corrente ou uma voltagem possuem certas desvantagens quando comparadas com as técnicas de sensoriamento óptico. Um sensor óptico, por exemplo, teria características peculiares como: insensibilidade a ruídos eletromagnéticos, inexistência de curtos-circuitos, segurança em ambientes hostis, vantagens de integração e miniaturização, maior confiabilidade e baixo custo [7]. Ademais disso, a tecnologia de óptica integrada abre as portas para o desenvolvimento de uma nova lógica computacional óptica [8], com aplicações em WDM (Wave Division Multiplex), filtros interferenciais e redes ópticas passivas.

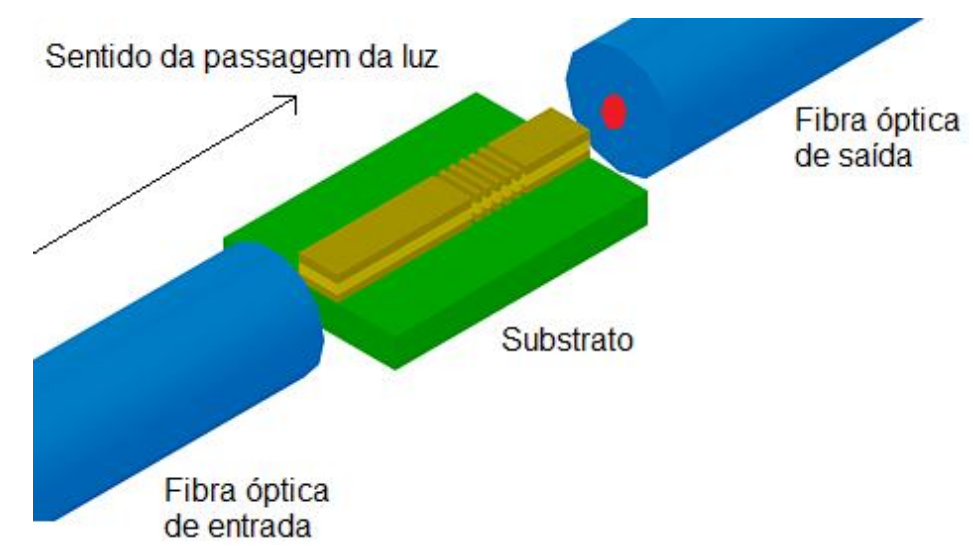

Figura 1. 1 - Esquema de um sensor termo-óptico sobre um substrato, a luz entra através da fibra de entrada, fica confinada entre as camadas do sensor e é captada na fibra óptica de saída, o aquecimento em alguma parte ou todo o sensor pode ser realizada de diversas formas com objetivo de sensoriamento. 


\subsection{ESTADO DA ARTE}

Com as grandes conquistas e a grande difusão da tecnologia da fibra óptica, sensores ópticos têm recebido mais e mais atenção. Atualmente esta se fabricando, estudando e simulando $[9,24]$ filtros multi e mono camada que utilizam o princípio de cavidades ressonantes, para diversos tipos de aplicações como por exemplo, sensores termo-ópticos $[6,10,11,12,13,14,15]$ mostrado na Figura 1.2. As razões do sucesso destes tipos de sensores são muitas e principalmente fundadas sobre o fato que eles usualmente têm desempenhos e características complementares aos outros sensores. Em particular, o desenvolvimento dos sensores de temperatura óptico, ou OTS (Optical temperature sensors), se baseiam no efeito termo-óptico e apresentam a vantagem da imunidade intrínseca ao ruído eletromagnético e de uma vasta gama de temperaturas mensuráveis, geralmente excedendo varias centenas de graus celsius. Ademais disto, estes dispositivos possuem quase total ausência de efeito de aquecimento (que os transistores de silício apresentam quando submetidos à corrente) e a habilidade de medida sem contato, que é particularmente útil para aplicações "in vivo" ou quando se está monitorando o movimento de objetos. Em $[6,10,14]$ foi realizada a construção de cavidades simples sobre silício definidas geometricamente através de corrosões secas com equipamentos de corrosão por plasma e onde foram variados os comprimentos das cavidades para se obter diferentes resoluções de temperatura. Estas pesquisas mostraram bons resultados, mas também mostraram as limitações de trabalhar com materiais com altas perdas ópticas. Em [12] mostra-se também um estudo de cavidades múltiplas e simples utilizando-se o efeito termo-óptico. 


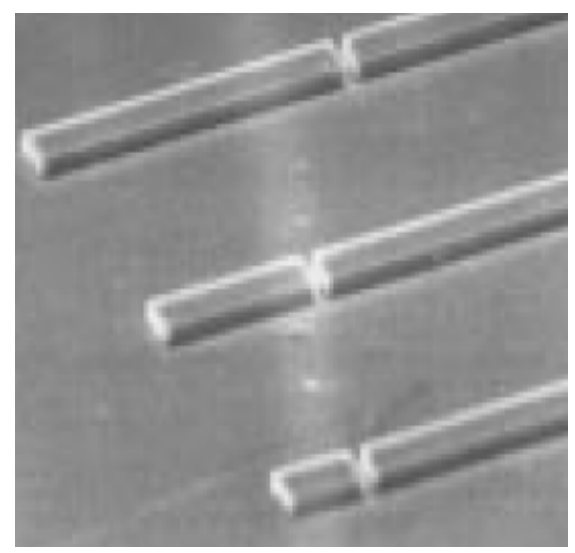

Figura 1.2 - Referência 10 imagem de cavidades utilizadas como sensores termo ópticos.

Um modelo diferente foi proposto por $[11,13,15]$ com a luz atravessando o filtro e o substrato que o sustenta. Em [11] um filtro ajustável termicamente foi construído sobre SOI (silicon-on-insulator) que foi posteriormente corroído e onde foram depositadas multicamadas de Si e óxido de silício $\left(\mathrm{SiO}_{2}\right)$ pela técnica de deposição química a vapor assistida por plasma (PECVD - Plasma Enhanced Chemical Vapor Deposition). A tudo isso se uniu um sistema de aquecimento mostrando resultados promissores onde é possível ajustar o filtro através de mudanças na temperatura. Em [13] os autores mostram um filtro de filmes dielétricos (pentóxido de tântalo, $\mathrm{Ta}_{2} \mathrm{O}_{5}$ e óxido de silício, $\mathrm{SiO}_{2}$ ) combinados com filmes de silício amorfo hidrogenado (a-Si:H) e nitreto de silício $\left(\mathrm{Si}_{3} \mathrm{~N}_{4}\right)$. Esses últimos servem como camada termo sensível de forma a otimizar a "sintonização" térmica do filtro. Em [15] uma corrosão em uma lâmina de silício com corrosão úmida em Hidróxido de Potásio $(\mathrm{KOH})$ foi realizada, utilizando-se para isso de uma máscara de óxido térmico e $\mathrm{Si}_{3} \mathrm{~N}_{4}$ depositado pela técnica de deposição química a vapor em baixa pressão (LPCVD - Low-pressure Chemical Vapor Deposition) de forma a deixar uma fina camada suspensa. Essa camada é formada de vários filmes finos depositados por PECVD de forma a constituir um filtro. 


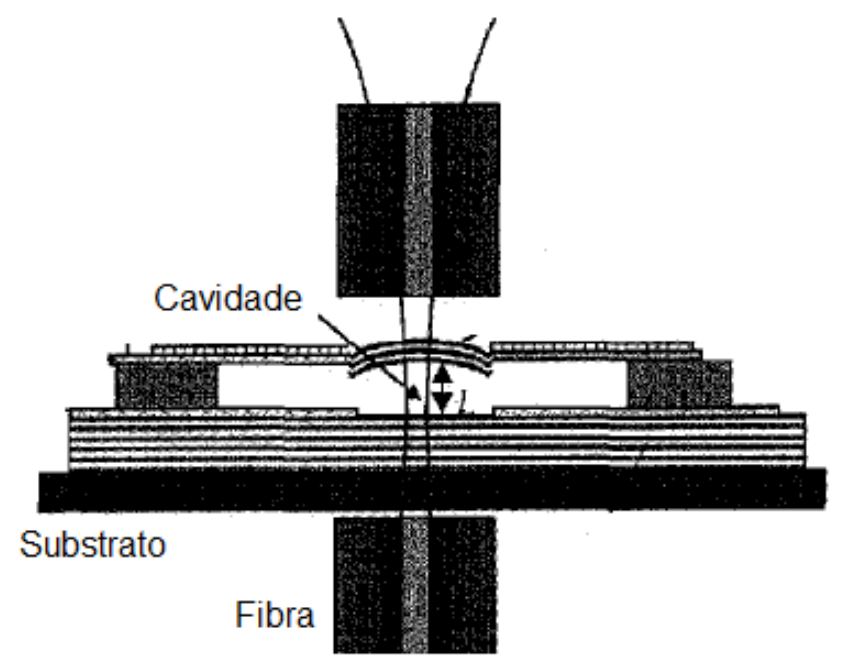

Figura 1.3 - Figura da referência 21 esquema do filtro micro eletromecânico.

Outro tipo de aplicação seriam os filtros interferenciais [16,17,18]. Estes filtros ópticos sintonizáveis são componentes importantes na seleção de comprimentos de onda, e estão sendo pesquisados em diversos modelos como por exemplo: filtros eletro-ópticos [19], acusto-ópticos [20] mostrado na Figura 1.4 e microeletromecânicos [21] que tem o esquema mostrado na Figura 1. 3. Esta pesquisa tem tido desenvolvimento rápido nos últimos anos, devido à tecnologia já desenvolvida e pouco dispendiosa da microeletrônica que permite uma efetiva integração com os dispositivos ópticos. Em [16] é mostrado um desenvolvimento e otimização de um filtro utilizando cristais fotônicos com espaçamento variado para captar diferentes comprimentos de onda em posições diferentes do dispositivo de forma que ocorra uma filtragem seletiva por região. Na referência [17] é mostrada a fabricação de filtros de camadas de $\mathrm{SiO}_{x} / \mathrm{Si}$ e $\mathrm{SiO}_{x} / \mathrm{SiN}_{\mathrm{x}}$ feitos por PECVD e o estudo do crescimento destes filmes para a aplicação em micro espelhos que seriam partes de dispositivos utilizados em circuitos optoeletrônicos. Outro estudo de otimização para as limitações de crosstalk (interferência entre canais de comunicação) de filtros feitos de cavidades Fabry-Perot, em aplicações para redes, é apresentado em [18] mostrando também outra forma de aplicação destes filtros que seria a multiplexação através da divisão dos comprimentos de onda (WDM - Wave Division Multiplex) $[22,23,24]$ onde os filtros ópticos são dispositivos centrais provendo seleção ao sinal óptico transmitido em um comprimento de onda específico. 


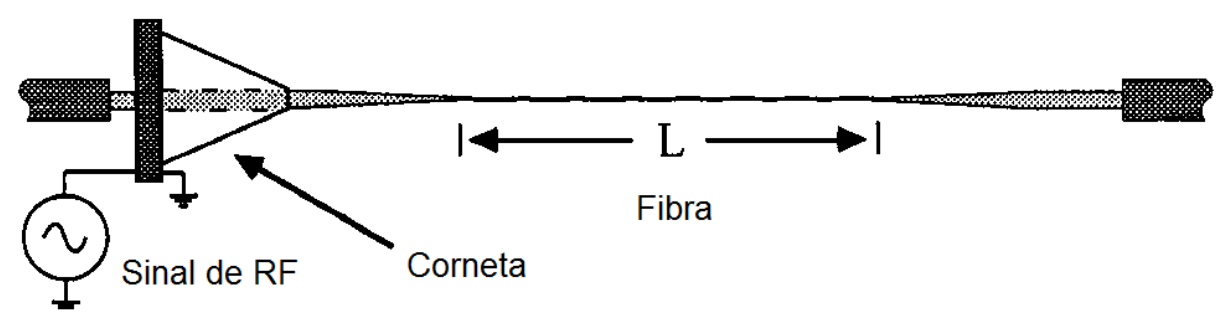

Figura 1.4 - Esquema da referência 20 filtro acusto-óptico.

A maior flexibilidade destes sistemas ópticos é obtida devido à propriedade de sintonia dos filtros que são colocados em frente aos dispositivos receptores. Estes filtros devem ter uma larga banda de sintonia compatível com a janela da fibra óptica, e uma banda ajustável que garanta baixo crosstalk. Em [22] tem-se uma análise da aplicação de filmes finos para a utilização em WDM onde se conclui que filtros sintonizáveis eficientes com banda de passagem estreita podem ser desenvolvidos com o uso de efeitos térmicos em camadas de $\mathrm{Si} / \mathrm{SiO}_{2}$ depositadas sobre substratos de vidro. Temos também aplicações que envolvem WDM usando efeito de pressão [23] para realizar a mudança da banda de passagem do filtro. Cálculos e simulações teóricas que permitem o desenho de filtros multicamada Fabry-Perot para aplicações em redes WDM são realizados em [24], o que mostra a importância dos filtros em redes ópticas passivas modernas. Ademais, as propriedades dos filtros ópticos influenciam o desempenho de todos os sistemas de comunicações ópticas, pois estão diretamente ligados à de-multiplexação.

Em particular, nas redes ópticas passivas modernas [25] está ocorrendo a migração da alta velocidade e alta capacidade para redes de acesso óptico ideais como a FTTH (Fiber To The Home). A B-PON (Broadband Passive Optical Network) definida na ITU-T G983.3 (ITU - International Telecomunication Union) diz que não somente os sinais digitais, representados pelos serviços de internet, mas também sinais de vídeo analógicos de serviços de TV a cabo irão migrar para o sistema óptico. Os próximos sistemas B-PON, G-PON e GE-PON irão fornecer mais benefícios em uma sociedade de banda larga, e para isso, baixo custo e produção em massa de dispositivos ópticos são essenciais em uma rede de acesso óptica mundial.

Como conclusão, filtros feitos de filmes finos são necessários para atender aos requerimentos destas redes ópticas e tem tido larga aplicação até então, apresentando baixas perdas de inserção e baixo coeficiente térmico de menos de 
0,001nm/ํㅜ o que é necessário para manter a estabilidade do filtro evitando desajustes da banda filtrada em função da temperatura.

\subsection{OBJETIVOS}

Acompanhando a tendência das pesquisas com relação à óptica integrada, foram desenvolvidos neste mestrado dispositivos que buscam atender necessidades de sensoriamento, construindo-se conversores termo-ópticos, filtros e sensores angulares ópticos, baseados em múltiplas cavidades ressonantes feitas de camadas dielétricas depositadas por Deposição Química a Vapor Assistida por Plasma (Plasma Enhanced Chemical Vapor Deposition, PECVD). Foi utilizado para isto a teoria de cavidades ressonantes e a tecnologia de fabricação da microeletrônica, já amplamente conhecida, juntamente com técnicas de pesquisas anteriores já desenvolvidas [26,27,28,29,30,31,32].

Este trabalho introduz uma nova técnica de sensoriamento angular com o uso de filtros de filme fino para a obtenção de WDM e uso de substratos transparentes na deposição de filtros facilitando a aplicação e diminuindo o número de processos. 


\section{Capítulo 2 - TEORIA E SIMULAÇÕES}

\subsection{INTRODUÇÃO}

Neste capítulo serão discutidas a teoria e as simulações realizadas para o desenvolvimento de filtros feitos de filmes finos depositados por PECVD. Inicialmente será mostrada a teoria de matrizes para a resolução de problemas de propagação em multicamadas e em seguida serão mostrados os parâmetros utilizados e os resultados obtidos com as simulações realizadas pelo programa desenvolvido no software de cálculo Mathematica. O desenvolvimento da teoria foi retirado da referência [33].

\subsection{TEORIA}

2.2.1 Reflexão e Refração em uma Interface Plana entre doIs Meios ISOTRÓPICOS.

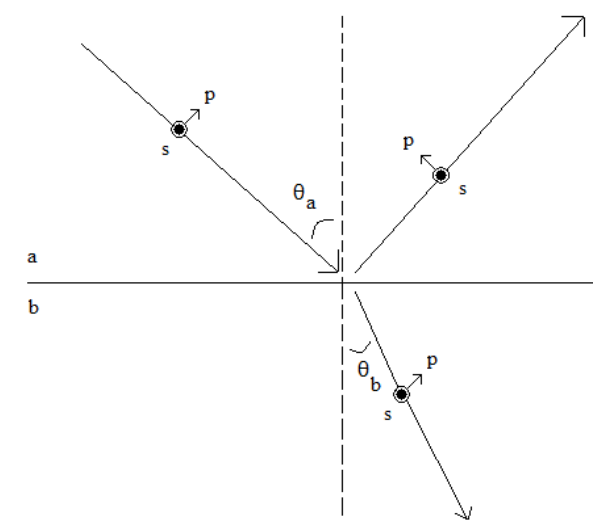

Figura 2.1 - Onda eletromagnética com as polarizações $p$ e s vinda de um meio com índice de refração "a" e incidindo em um meio com índice de refração "b". 
Vamos a considerar a reflexão e a transmissão de uma onda plana em uma interface plana entre dois meios semi-infinitos homogêneos e isotrópicos (que são aproximadamente os meios dos materiais que foram utilizados neste mestrado) a e $b$, com índices de refração complexos $\mathrm{N}_{a}$ e $\mathrm{N}_{b}$, respectivamente. Igualmente, é assumida uma mudança abrupta de índice na interface.

A onda incidente do meio a dá origem a uma onda refletida no mesmo meio e uma onda transmitida no meio $b$. Também, o ângulo de incidência $\theta_{\mathrm{a}} \mathrm{e}$ o ângulo de refração $\theta_{b}$ são medidos a partir da direção da normal da interface. Os campos totais dentro do meio a e do meio $b$ obedecem às equações de Maxwell e às condições de contorno das ondas eletromagnéticas na interface. Para as condições de contorno das ondas eletromagnéticas serem satisfeitas, as direções de propagação das ondas incidente, refletida e transmitida devem todas estar no mesmo plano de incidência (o plano do papel), perpendicular à interface. Ademais, o ângulo de incidência deve ser igual ao ângulo de reflexão, e os ângulos de incidência e refração devem se relacionar através da lei de Snell:

$$
N_{a} \operatorname{sen} \theta_{a}=N_{b} \operatorname{sen} \theta_{b}
$$

Se os meios $a$ e $b$ são transparentes de forma que $\mathrm{N}_{a}$ e $\mathrm{N}_{b}$ (índices de refração) sejam ambos números reais, os ângulos $\theta_{a}$ e $\theta_{b}$ são também reais e a Figura 2.1 é simples. Contudo, quando algum ou ambos os meios são absorventes, os ângulos $\theta_{\mathrm{a}}$ e $\theta_{\mathrm{b}}$ se tornam em geral, complexos e a discussão continua somente formalmente, mas fisicamente a figura dos campos se torna mais complicada. No caso dos materiais utilizados no mestrado, os índices de refração são números reais e os meios transparentes.

Para uma dada amplitude e polarização da onda incidente, a amplitude e a polarização das ondas refletida e transmitida podem ser determinadas pela continuidade dos componentes tangenciais dos vetores campo elétrico e campo magnético através da interface. Pode ser mostrado que quando a onda incidente é linearmente polarizada com o vetor campo elétrico vibrando paralelo ( $p$ ) ao plano de incidência, as ondas, refletida e transmitida são similarmente polarizadas com seus vetores campo elétrico também vibrando paralelos ao plano de incidência. Do mesmo modo, quando a onda incidente é linearmente polarizada 
perpendicularmente (s) ao plano de incidência, as ondas refletida e transmitida são também linearmente polarizadas perpendicularmente ao mesmo plano.

Sendo $E_{i p}, E_{i s}, E_{r p}, E_{r s}, E_{t p}$ e $E_{t s}$, as amplitudes complexas dos componentes, paralela ( $p$ ) e perpendicular (s), dos vetores campo elétrico das ondas incidente, refletida e transmitida, respectivamente, em pontos imediatamente acima e abaixo da interface, teremos:

$$
\begin{aligned}
& \frac{E_{r p}}{E_{i p}}=r_{p}=\frac{N_{b} \cos \theta_{a}-N_{a} \cos \theta_{b}}{N_{b} \cos \theta_{a}+N_{a} \cos \theta_{b}} \\
& \frac{E_{r s}}{E_{i s}}=r_{s}=\frac{N_{a} \cos \theta_{a}-N_{b} \cos \theta_{b}}{N_{a} \cos \theta_{a}+N_{b} \cos \theta_{b}} \\
& \frac{E_{t p}}{E_{t p}}=t_{p}=\frac{2 N_{a} \cos \theta_{a}}{N_{b} \cos \theta_{a}+N_{a} \cos \theta_{b}} \\
& \frac{E_{t s}}{E_{i s}}=t_{s}=\frac{2 N_{a} \cos \theta_{a}}{N_{a} \cos \theta_{a}+N_{b} \cos \theta_{b}}
\end{aligned}
$$

Onde $r_{p}$ e $r_{s}$ são os coeficientes de reflexão de Fresnel; e $t_{s}$ e $t_{p}$ são os coeficientes de transmissão de Fresnel.

\subsubsection{Reflexão e transmissão por uma Estrutura Isotrópica planar e}

\section{ESTRATIFICADA}

O método de adição de múltiplas reflexões torna-se impraticável quando consideramos a reflexão e transmissão de luz polarizada em uma incidência obliqua em um filme de múltiplas camadas entre dois ambientes semi-infinitos. Uma aproximação mais elegante é tratar como uma transformação de matrizes lineares que emprega matrizes $2 \times 2$ e é baseada no fato de que as equações que governam a 
propagação da luz são lineares e que existe continuidade dos campos tangenciais através da interface entre dois meios isotrópicos [33].

Vamos considerar uma estrutura estratificada que consiste em uma seqüência de $1,2,3,4, \ldots, j, \ldots$ m camadas paralelas umas sobre as outras entre dois ambientes semi-infinitos $(0)$ e $(m+1)$, sendo todos os meios homogêneos e isotrópicos, e sendo o índice de refração complexo da j-ésima camada $\mathrm{N}_{\mathrm{j}}$ e sua espessura $\mathrm{d}_{\mathrm{j}}$. Por outro lado, $\mathrm{N}_{0}$ e $\mathrm{N}_{\mathrm{m}+1}$ representam os índices de refração complexos dos ambientes semiinfinitos.

Uma onda incidente monocromática plana vinda do meio 0 gera uma resultante refletida no mesmo meio e uma resultante transmitida no meio $m+1$. O campo total dentro da j-ésima camada, que sofre a incidência da onda plana, consiste de duas ondas planas: uma viajando no sentido positivo (de esquerda para a direita, vide Figura 2.2) e outra no sentido negativo (de direita para a esquerda, vide Figura 2.2) que serão denotadas por (+) e (-), respectivamente. Os vetores de onda de todas as ondas planas estão no mesmo plano (o plano de incidência), e os vetores de onda das duas ondas planas da j-ésima camada fazem ângulos iguais com o eixo $Z$ que são perpendiculares às superfícies do plano (Figura 2.2).

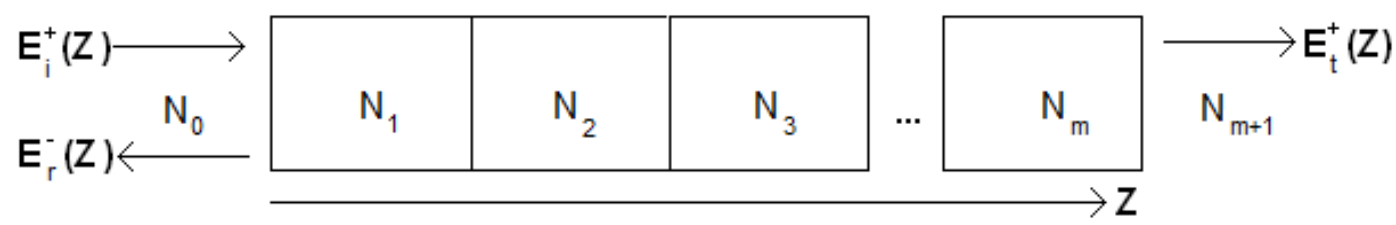

Figura 2.2 - Diagrama esquemático da estrutura multicamada usada para o calculo da transmitância total.

Quando a onda incidente é linearmente polarizada, com o seu vetor campo elétrico vibrando paralelamente ou perpendicularmente ao plano de incidência, todas as ondas planas que surgem da onda plana incidente nas várias camadas da estrutura estratificada serão polarizadas da mesma forma, paralela ou perpendicularmente ao plano de incidência. Assim, para as deduções seguintes será assumido que as ondas estão polarizadas ou paralelamente ou perpendicularmente.

$E^{+}(z)$ e $E^{-}(z)$ denotam as amplitudes complexas das ondas propagantes no sentido positivo e no sentido negativo respectivamente em um eixo arbitrário $Z$. $O$ campo total em $Z$ pode ser descrito por uma matriz $2 \times 1$ : 


$$
E(z)=\left[\begin{array}{c}
E^{+}(z) \\
E^{-}(z)
\end{array}\right]
$$

Se forem considerados os campos em dois planos diferentes z' e z" paralelos aos contornos das camadas (Figura 2.3) então $E\left(z^{\prime \prime}\right)$ e $E\left(z^{\prime}\right)$ podem ser relacionados por uma transformação matricial 2x2:

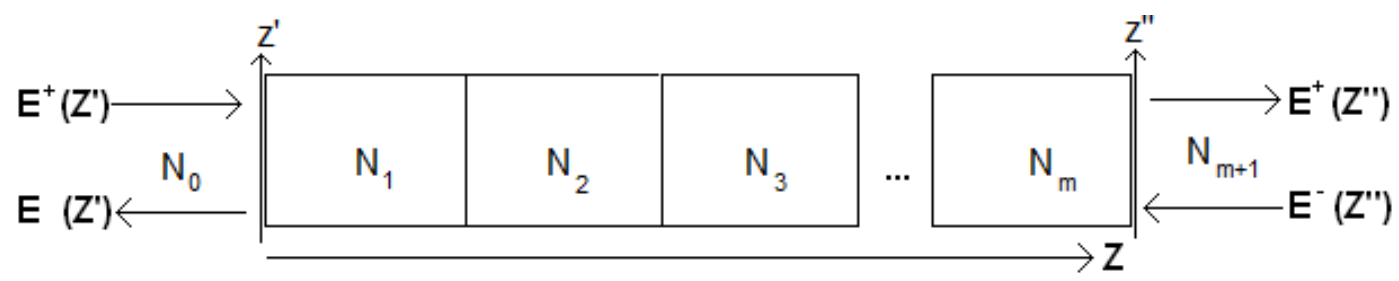

Figura 2.3 - Diagrama esquemático da estrutura usada para o calculo da matriz de multicamadas.

$$
\left[\begin{array}{l}
E^{+}\left(z^{\prime}\right) \\
E^{-}\left(z^{\prime}\right)
\end{array}\right]=\left[\begin{array}{ll}
S_{11} & S_{12} \\
S_{21} & S_{22}
\end{array}\right]\left[\begin{array}{l}
E^{+}\left(z^{\prime \prime}\right) \\
E^{-}\left(z^{\prime \prime}\right)
\end{array}\right]
$$

A equação (7) também pode ser escrita de forma mais concisa como:

$$
E\left(z^{\prime}\right)=S E\left(z^{\prime \prime}\right)
$$

Onde

$$
S=\left[\begin{array}{ll}
S_{11} & S_{12} \\
S_{21} & S_{22}
\end{array}\right]
$$

Nota-se que $S$ caracteriza a parte da estrutura estratificada confinada entre dois planos paralelos z' e z".

Escolhendo-se z' e z" localizados imediatamente em lados opostos da interface (j-1)j em $z_{j}$ entre as camadas j-1 e j (Figura 2.4), então se tem que a equação (8) pode ser escrita na forma:

$$
E\left(z_{j}-0\right)=I_{(j-1) j} E\left(z_{j}+0\right)
$$




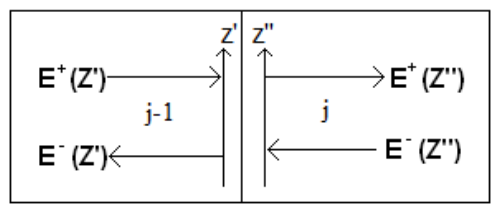

Figura 2.4 - Diagrama esquemático da estrutura usada para o calculo da matriz da interface.

Onde $\mathrm{I}_{(\mathrm{j}-1) \mathrm{j}}$ é uma matriz $2 \times 2$ que contém as características da interface $(\mathrm{j}-1) \mathrm{j}$. Por outro lado se z' e z" são escolhidos dentro da j-ésima camada em suas extremidades (Figura 2.5), a equação (8) pode ser escrita como:

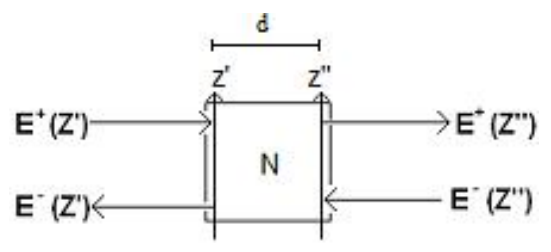

Figura 2.5 - Diagrama esquemático da estrutura usada para o calculo da matriz de camada.

$$
E\left(z_{j}+0\right)=L_{j} E\left(z_{j}+d_{j}-0\right)
$$

Onde $L_{j}$ é uma matriz $2 \times 2$ que contém as características da j-ésima camada cuja espessura é $\mathrm{d}_{\mathrm{j}}$. Somente a onda refletida e a onda transmitida pela estrutura estratificada são possíveis de serem medidas, por isso é necessário relacionar seus campos com aqueles da onda incidente [33]. Tomando-se os planos z' e z" nas extremidades imediatamente adjacentes às interfaces 01 e $\mathrm{m} /(\mathrm{m}+1)$ tem-se:

$$
E\left(z_{1}-0\right)=S E\left(z_{m+1}+0\right)
$$

Esta equação define a matriz de dispersão $S$, que representa as propriedades de reflexão e transmissão totais da estrutura estratificada. S pode ser expressa como um produto das matrizes de interface e das matrizes de camadas de toda a estrutura estratificada, tomada na devida ordem, como se segue:

$$
S=I_{01} L_{1} I_{12} L_{2} I_{23} L_{3} I_{34} L_{4} \ldots I_{(j-1)} L_{j} \ldots L_{m} I_{m(m+1)}
$$


A equação acima pode ser provada pela repetida aplicação da equação (8) para sucessivas interfaces e camadas de uma estrutura estratificada, começando com a primeira interface $(01)$ e terminando com a última interface $[m(m+1)]$.

Da equação (13) é evidente que para determinar a matriz de espalhamento da estrutura estratificada, a interface individual e as matrizes I e $\mathrm{L}$ tem de ser calculadas.

A matriz I da interface entre dois meios $a$ e $b$ relaciona os campos em ambos os lados como:

$$
\left[\begin{array}{c}
E_{a}^{+} \\
E_{a}^{-}
\end{array}\right]=\left[\begin{array}{ll}
I_{11} & I_{12} \\
I_{21} & I_{22}
\end{array}\right]\left[\begin{array}{l}
E_{b}^{+} \\
E_{b}^{-}
\end{array}\right]
$$

Vamos considerar os casos especiais quando a onda plana é incidente na interface $a b$ vindo do meio $a$. Em termos da amplitude complexa $E_{a}^{+}$da onda plana incidente no meio $a$, a amplitude complexa das ondas planas transmitidas $\mathrm{e}$ refletidas no meio $b$ e $a$, respectivamente, são dadas por:

$$
\begin{aligned}
& E_{b}^{+}=t_{a b} E_{a}^{+} \\
& E_{a}^{-}=r_{a b} E_{a}^{+}
\end{aligned}
$$

Onde $E_{b}^{-}=0$ e sendo $r_{a b}$ e $t_{a b}$ os coeficientes de reflexão e transmissão de Fresnel da interface $a b$. Contudo, de acordo com a equação (14) nós temos:

$$
\left[\begin{array}{c}
E_{a}^{+} \\
E_{a}^{-}
\end{array}\right]=\left[\begin{array}{ll}
I_{11} & I_{12} \\
I_{21} & I_{22}
\end{array}\right]\left[\begin{array}{c}
E_{b}^{+} \\
0
\end{array}\right]
$$

Expandindo temos:

$$
\begin{aligned}
& E_{a}^{+}=I_{11} E_{b}^{+} \\
& E_{a}^{-}=I_{21} E_{b}^{+}
\end{aligned}
$$


Comparações entre as equações (15), (16) e (18), (19) leva às seguintes deduções:

$$
\begin{aligned}
& I_{11}=\frac{1}{t_{a b}} \\
& I_{21}=\frac{r_{a b}}{t_{a b}}
\end{aligned}
$$
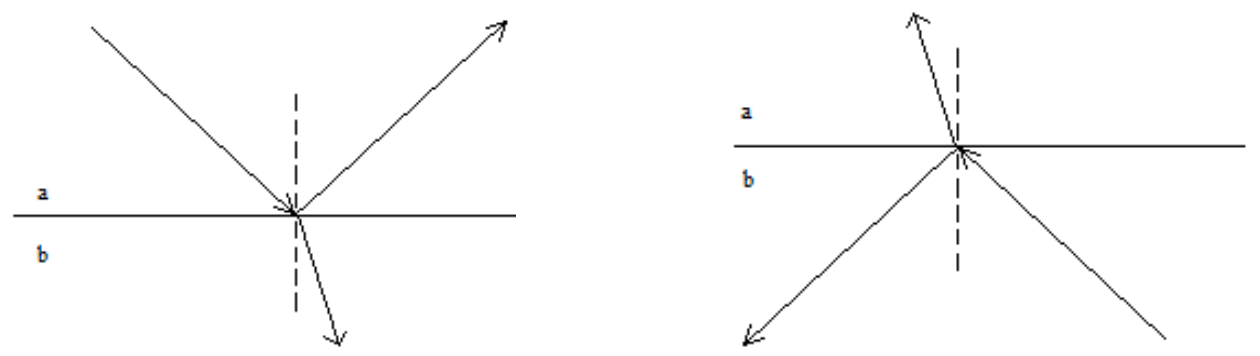

Figura 2.6 - Esquerda: Reflexão e transmissão (ou refração) de uma onda plana na interface entre dois meios $(a b)$. Direita: a direção de propagação da onda transmitida assumindo-se a propagação reversa.

Agora considerando uma onda plana incidente na interface ba vinda do meio $b$ (Figura 2.6 à direita), em um ângulo de incidência igual ao ângulo de refração do meio $b$ no caso descrito pela Figura 2.6 à esquerda. Neste caso os campos imediatamente adjacentes à interface ba são relacionados por:

$$
\begin{aligned}
& E_{b}^{+}=r_{b a} E_{b}^{-} \\
& E_{a}^{-}=t_{b a} E_{b}^{-}
\end{aligned}
$$

E sendo $E_{a}^{+}=0$, onde $r_{\text {ba }}$ e tba são os coeficientes de reflexão e transmissão de Fresnel da interface ba, respectivamente. Por outro lado, a equação (14) aplicada para esse caso mostra que:

$$
\begin{aligned}
& {\left[\begin{array}{c}
0 \\
E_{a}^{-}
\end{array}\right]=\left[\begin{array}{ll}
I_{11} & I_{12} \\
I_{21} & I_{22}
\end{array}\right]\left[\begin{array}{c}
E_{b}^{+} \\
E_{b}^{-}
\end{array}\right]} \\
& 0=I_{11} E_{b}^{+}+I_{12} E_{b}^{-}
\end{aligned}
$$




$$
E_{a}^{-}=I_{21} E_{b}^{+}+I_{22} E_{b}^{-}
$$

Substituindo-se $I_{11}$ e $I_{21}$ das equações (20) e (21) nas equações (25) e (26), temos:

$$
\begin{aligned}
& E_{b}^{+}=-I_{21} t_{a b} E_{b}^{-} \\
& E_{a}^{-}=\left[\frac{r_{a b} r_{b a}}{t_{a b}}+I_{22}\right] E_{b}^{-}
\end{aligned}
$$

Agora, trabalhando as equações (22) e (23) com as equações (27) e (28) temos:

$$
\begin{aligned}
& I_{21}=\frac{-r_{a b}}{t_{a b}} \\
& I_{22}=\frac{\left(t_{a b} t_{b a}-r_{a b} r_{b a}\right)}{t_{a b}}
\end{aligned}
$$

Finalmente, usando as relações de interface dos coeficientes de Fresnel para ambas as direções de propagação (Teorema de Stokes), $r_{a b}=-r_{b a}$ e $t_{a b}=\left(1-r_{b a}^{2}\right) / t_{a b}$, obtemos a matriz de interface final na forma:

$$
I_{a b}=\left[\begin{array}{cc}
1 / t_{a b} & r_{a b} / t_{a b} \\
r_{a b} / t_{a b} & 1 / t_{a b}
\end{array}\right]
$$

Os coeficientes de reflexão e transmissão de Fresnel na interface que aparecem na equação (31) devem ser obtidos usando-se os índices de refração complexos dos dois meios que definem a interface e o ângulo local de incidência. Estes podem ser obtidos pela aplicação repetida da lei de Snell:

$$
N_{0} \sin \phi_{0}=N_{1} \sin \phi_{1}=\ldots=N_{j} \sin \phi_{j}=\ldots=N_{m+1} \sin \phi_{m+1}
$$

Agora, será determinada a matriz de propagação em uma determinada camada (matriz L) [33]. O efeito de propagação através de uma camada homogênea de 
índice de refração $\mathrm{N}$ e espessura d e a relação entre os campos dentro da camada em ambos os lados pode ser determinado pela seguinte matriz:

$$
\left[\begin{array}{c}
E_{0}^{+} \\
E_{0}^{-}
\end{array}\right]=\left[\begin{array}{cc}
e^{j \beta} & 0 \\
0 & e^{-j \beta}
\end{array}\right]\left[\begin{array}{l}
E_{d}^{+} \\
E_{d}^{-}
\end{array}\right]
$$

Os índices zero e d identificam o começo e o fim de uma camada (ao longo da direção de propagação da onda) e a diferença de fase $\beta$ é dada por:

$$
\beta=\frac{2 \pi d N}{\lambda} \cos \phi
$$

Onde $\phi$ representa o ângulo entre a direção de propagação na camada e a perpendicular à sua extremidade (o eixo z). Assim, a matriz da camada $L$ pode então ser escrita como:

$$
L=\left[\begin{array}{cc}
e^{j \beta} & 0 \\
0 & e^{-j \beta}
\end{array}\right]
$$

Das matrizes de interface I e de camada $L$ das equações (31) e (35) se obtém a matriz de dispersão da estrutura estratificada. $S$ pode ser encontrada pela multiplicação sucessiva das equações (31) e (35) como indicado na equação (13). A equação (12) pode ser expandida como:

$$
\left[\begin{array}{c}
E_{0}^{+} \\
E_{0}^{-}
\end{array}\right]=\left[\begin{array}{ll}
S_{11} & S_{12} \\
S_{21} & S_{22}
\end{array}\right]\left[\begin{array}{c}
E_{m+1}^{+} \\
0
\end{array}\right]
$$

Onde os índices 0 e $\mathrm{m}+1$ se referem aos meios em volta da estrutura estratificada de $m$ camadas, e consideraremos $E_{m+1}^{-}=0$ pois assumimos que não há feixes voltando após terem saído da estrutura. A expansão da equação (36) leva aos coeficientes de reflexão e transmissão totais da estrutura estratificada $R$ e $T$ respectivamente: 


$$
\begin{aligned}
& R=\frac{E_{a}^{-}}{E_{a}^{+}}=\frac{S_{21}}{S_{11}} \\
& T=\frac{E_{s}^{+}}{E_{a}^{+}}=\frac{1}{S_{11}}
\end{aligned}
$$

Das equações (37) e (38) nota-se que os elementos da primeira coluna da matriz de dispersão determinam o coeficiente de reflexão e transmissão totais da estrutura estratificada.

A matriz $S$ da estrutura estratificada (ou seus elementos $S_{11}$ e $S_{21}$ ) tem de ser calculados para ambas as polarizações paralela ( $p$ ) e perpendicular (s) ao plano de incidência. Vamos representar $S_{p}$ e $S_{s}$ como as matrizes de dispersão para as polarizações $p$ e $s$ respectivamente. Os coeficientes de reflexão e transmissão se tornam:

$$
\begin{aligned}
& R_{p}=S_{21 p} / S_{11 p} \\
& R_{s}=S_{21 s} / S_{11 \mathrm{~s}} \\
& T_{p}=1 / S_{11 p} \\
& T_{s}=1 / S_{11 \mathrm{~s}}
\end{aligned}
$$

Nota-se que $S_{p}$ e $S_{s}$ são diferentes porque cada uma das matrizes de interface I que aparecem na equação (13) é diferente para cada uma das polarizações p e s. As matrizes $L$ que aparecem na equação (13) são as mesmas para ambas as polarizações [33].

Como um exemplo de aplicação do procedimento acima, tem-se o caso de um único filme entre dois ambientes semi-infinitos. Da equação (13) a matriz de dispersão $S$ neste caso é dada por:

$$
S=I_{01} L_{1} I_{12}
$$

Através de substituição das equações (31) e (35) S se torna:

$$
S=\left(\frac{1}{t_{01} t_{12}}\right)\left[\begin{array}{cc}
1 & r_{01} \\
r_{01} & 1
\end{array}\right]\left[\begin{array}{cc}
e^{j \beta} & 0 \\
0 & e^{j \beta}
\end{array}\right]\left[\begin{array}{cc}
1 & r_{12} \\
r_{12} & 1
\end{array}\right]
$$




$$
S=\left(\frac{e^{j \beta}}{t_{01} t_{12}}\right)\left[\begin{array}{ll}
\left(1+r_{01} r_{12} e^{-j 2 \beta}\right) & \left(r_{12}+r_{01} e^{-j 2 \beta}\right) \\
\left(r_{01}+r_{12} e^{-j 2 \beta}\right) & \left(r_{01} r_{02}+e^{-j 2 \beta}\right)
\end{array}\right]
$$

Substituindo estes valores de $S_{11}$ e $S_{21}$ nas equações (37) e (38) temos:

$$
\begin{aligned}
& R=\frac{r_{01}+r_{12} e^{-j 2 \beta}}{1+r_{01} r_{12} e^{-j 2 \beta}} \\
& T=\frac{t_{01} t_{12} e^{-j \beta}}{1+r_{01} r_{12} e^{-j 2 \beta}}
\end{aligned}
$$

Para muitas camadas teremos o mesmo princípio aplicado através de métodos computacionais. A refletância e transmitância serão dadas, portanto pelas seguintes equações:

$$
\begin{aligned}
& \mathfrak{R}=R^{2} \\
& \mathfrak{I}=1-R^{2}
\end{aligned}
$$

A partir desta teoria foram feitos programas no software Mathematica (Wolfram Research, Inc.) que simulam filtros de diversas camadas com diferentes índices de refração, espessuras, temperaturas e sob a incidência de diferentes comprimentos de onda sob diferentes ângulos em relação à normal dos planos z' e z”.

\subsection{SiMULAÇÕES}

Serão mostradas neste item as simulações realizadas com o programa desenvolvido, os parâmetros utilizados e os resultados obtidos para cada mudança destes parâmetros para uma estrutura estratificada mostrada na Figura 2.7 


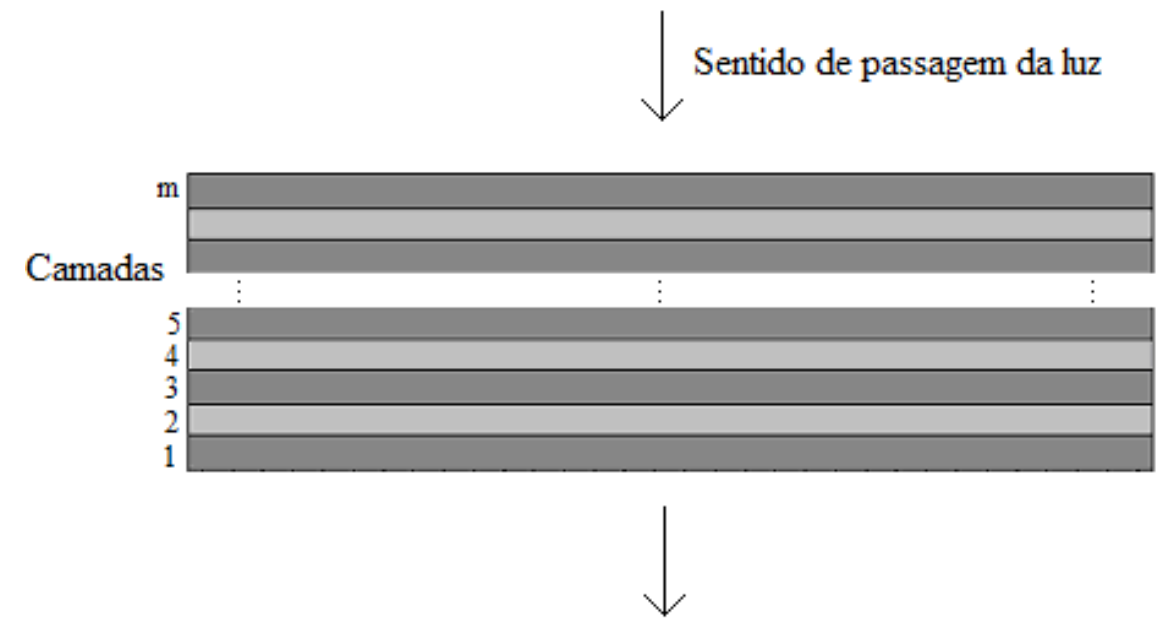

Figura 2.7 - Esquema da estrutura simulada.

Foram realizadas simulações de transmitância em função do comprimento de onda da luz na faixa de estudo de 300nm até $1100 \mathrm{~nm}$.

A primeira simulação mostrada é de um filtro multicamada com sete camadas em um ambiente de índice de refração 1 (ar) e com índices de 1,46 para as camadas pares (CP) e 1,91 para as camadas ímpares (Cl) e com espessuras feitas de forma a serem um múltiplo de uma onda de $\lambda_{v}=633 \mathrm{~nm}$ (no vácuo) viajando em um meio de 1,46 (CP) e 1,91 (Cl). Assim têm-se as seguintes espessuras:

$$
\begin{aligned}
& d_{C P}=\left(\frac{\lambda_{v}}{C P}\right) \cdot 0,25 \cdot m=\lambda_{C P} \cdot 0,25 \cdot m \\
& d_{C l}=\left(\frac{\lambda_{v}}{C I}\right) \cdot 0,25 \cdot m=\lambda_{C l} \cdot 0,25 \cdot m
\end{aligned}
$$

Onde $d_{C P}$ e $d_{C l}$ são as espessuras das camadas pares e ímpares respectivamente, $\mathrm{CP}$ e $\mathrm{Cl}$ os índices de refração destas camadas, e $\lambda_{\mathrm{CP}}$ e $\lambda_{\mathrm{Cl}}$ os comprimentos da onda de $\lambda_{v}=633 \mathrm{~nm}$ quando viajam nos meios das camadas pares e ímpares respectivamente. O múltiplo de onda $\mathrm{m}$ será considerado sempre um número ímpar $(1,3,5,7,9 \ldots)$. Dessa forma o lóbulo principal (neste trabalho a região de comprimentos de onda de maior atenuação de um filtro será chamada de lóbulo principal) de transmitância do filtro (que é o vale de maior atenuação da transmitância dentro do espectro estudado) se posiciona em $633 \mathrm{~nm}$. Pela simulação com $m=1$ tem-se: 


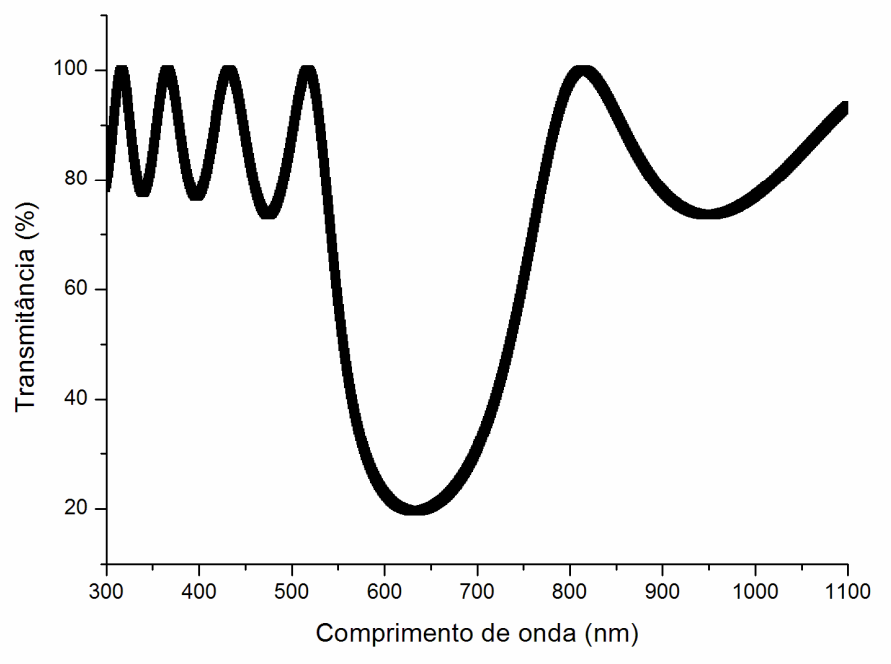

Figura 2.8 - Simulação 1 , filtro de 7 camadas com $\lambda_{v}=633 \mathrm{~nm}, \mathrm{CP}=1,46, \mathrm{Cl}=1,91$ e $\mathrm{m}=1$, para luz incidente de $300 \mathrm{~nm}$ a $1100 \mathrm{~nm}$.

Pode-se observar (Figura 2.8) que o lóbulo principal da transmitância se encontra centralizado em $633 \mathrm{~nm}$ provocando desta forma uma atenuação maior da luz transmitida nos comprimentos de onda em torno de $633 \mathrm{~nm}$.

Outra simulação (Figura 2.9) com um filtro de 15 camadas e com os mesmos parâmetros da simulação anterior mostra que o aumento do número de camadas provoca um estreitamento do lóbulo principal, suas derivadas laterais ficam maiores, ou seja, sua variação fica mais intensa para uma mesma variação de comprimento de onda, há também uma maior atenuação das freqüências próximas a $633 \mathrm{~nm}$ e um aumento no número de lóbulos secundários (vales de menor atenuação da transmitância em torno do lóbulo principal). 


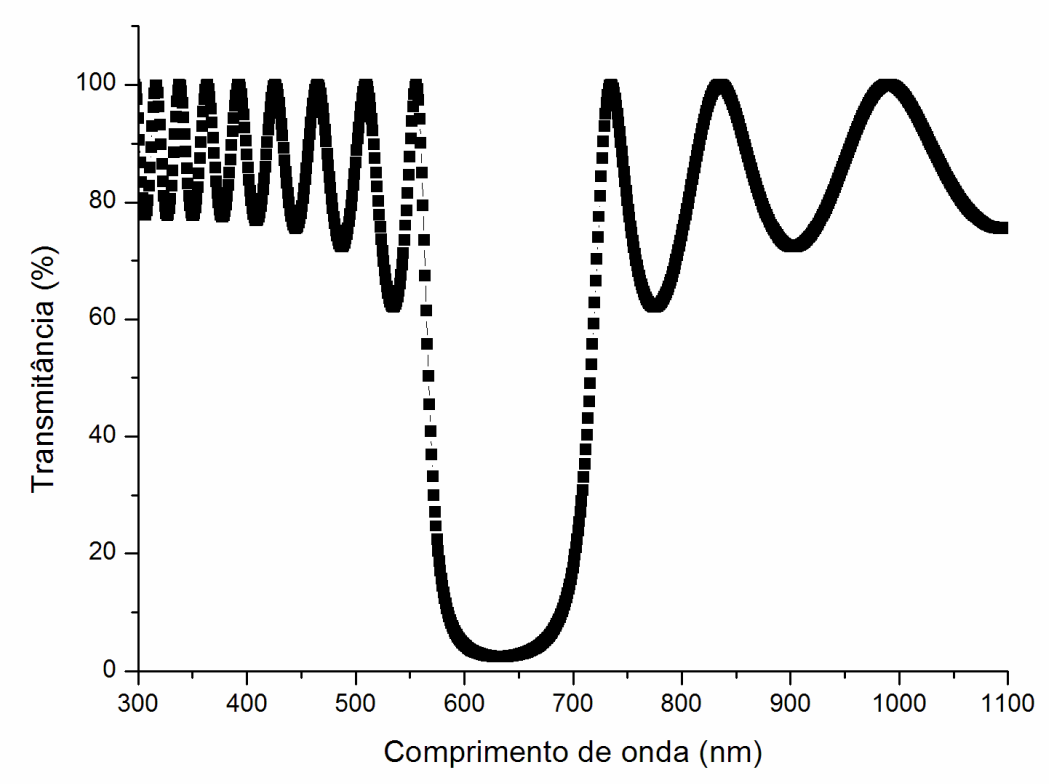

Figura 2.9 - Simulação 2, filtro de 15 camadas com $\lambda_{v}=633 \mathrm{~nm}, \mathrm{CP}=1,46, \mathrm{Cl}=1,91$ e $\mathrm{m}=1$ para luz incidente de $300 \mathrm{~nm}$ a $1100 \mathrm{~nm}$.

Na próxima simulação (Figura 2.10) mantiveram-se os mesmos parâmetros da primeira simulação com exceção da diminuição da diferença entre os índices de refração $\mathrm{CP}$ e $\mathrm{Cl}$. Estes foram simulados como 1,5 e 1,7 e mantiveram-se os mesmos parâmetros da primeira simulação (sete camadas e $m=1$ ).

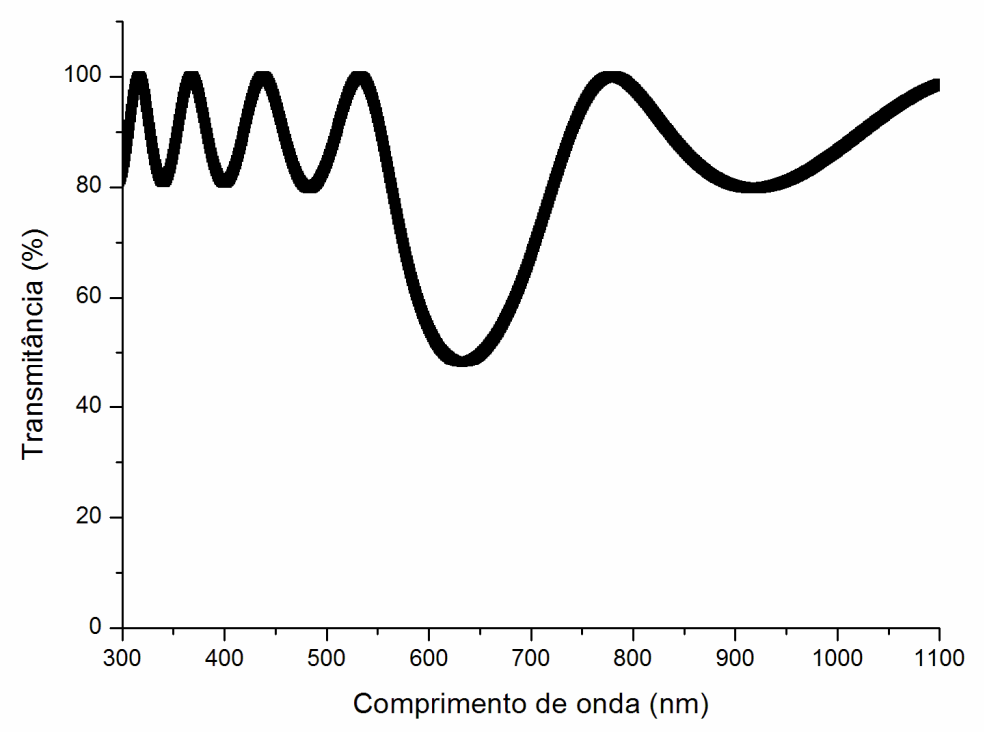

Figura 2.10 -Simulação 3, filtro de 7 camadas com $\lambda_{v}=633 \mathrm{~nm}, \mathrm{CP}=1,5, \mathrm{Cl}=1,7$ e $\mathrm{m}=1$, para luz incidente de $300 \mathrm{~nm}$ a $1100 \mathrm{~nm}$. 
Observa-se na Figura 2.10 que o filtro possui um lóbulo principal que atenua menos nas freqüências em torno de $633 \mathrm{~nm}$ e que a quantidade de lóbulos secundários é a mesma que para a primeira simulação, ou seja ocorre uma perda de seletividade.

A partir da primeira simulação, alterando-se o m para 5, tem-se a aparição, na faixa de freqüência de estudo (300nm até $1100 \mathrm{~nm})$, de outros lóbulos, com a mesma atenuação do lóbulo principal $(633 \mathrm{~nm})$, em freqüências que se distanciam exponencialmente $\left(2^{x}\right)$ (Figura 2.11).

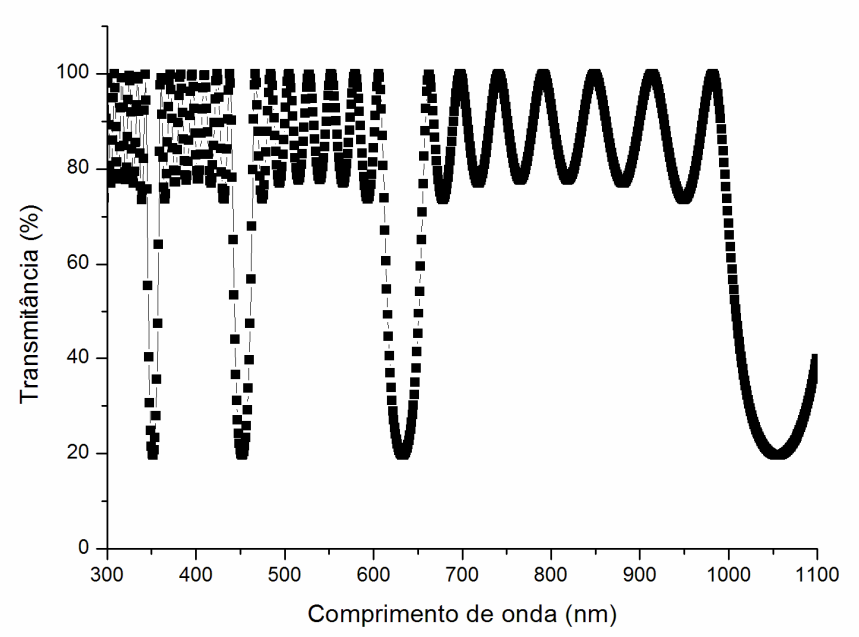

Figura 2.11 -Simulação 4, filtro de 7 camadas com $\lambda_{v}=633 \mathrm{~nm}, \mathrm{CP}=1,46, \mathrm{Cl}=1,91$ e $\mathrm{m}=5$, para luz incidente de $300 \mathrm{~nm}$ a $1100 \mathrm{~nm}$.

Os lóbulos, com a mesma atenuação que o lóbulo principal, aparecem agora dentro da faixa de estudo e as distâncias entre seus pontos mínimos tem uma relação quadrática, $100 \mathrm{~nm}, 200 \mathrm{~nm}$ e $400 \mathrm{~nm}$. A quantidade de lóbulos secundários entre os lóbulos principais (vales com menor atenuação dentro da freqüência de estudo) permaneceu a mesma. Vemos que este filtro (Figura 2.11) possui menor seletividade, pois também atenua freqüências diferentes da desejada.

Foram feitas também simulações com o feixe de luz incidindo sob diferentes ângulos em relação à normal do plano do filtro (Figura 2.12) de 7 camadas $\left(\lambda_{v}=\right.$ $633 \mathrm{~nm}, \mathrm{CP}=1,46, \mathrm{Cl}=1,91$ e $\mathrm{m}=1$ com ângulos de incidência variando de $0^{\circ}$ a $50^{\circ}$, para luz incidente de 350nm a 750nm). 


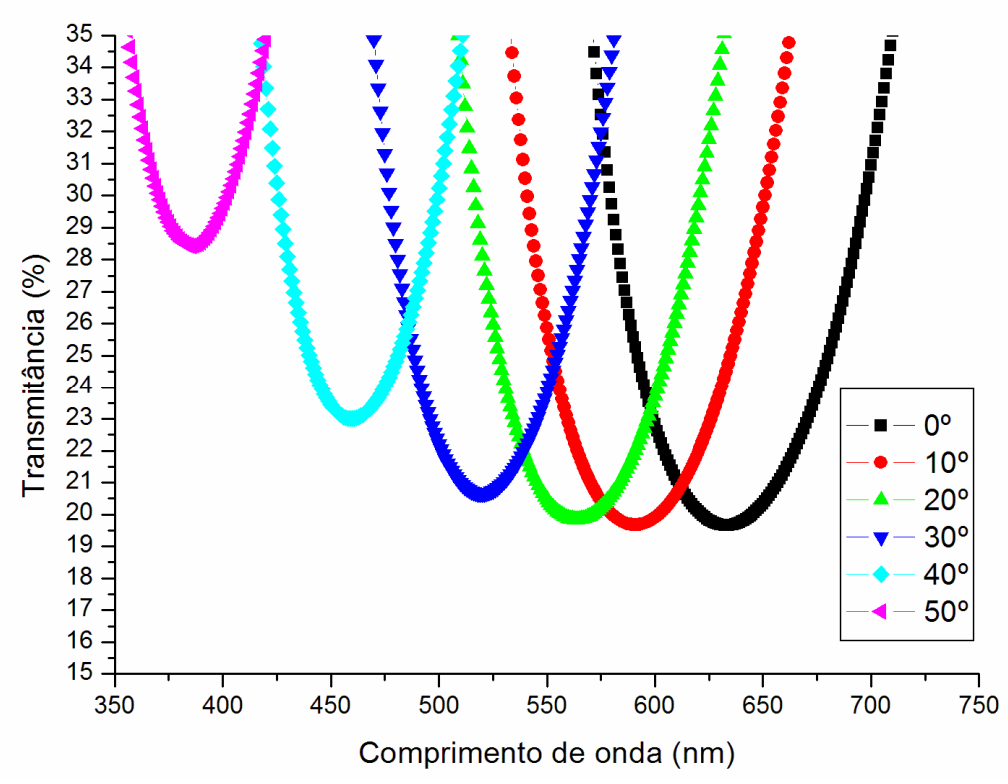

Figura 2.12 -Simulação 5, filtro de 7 camadas com $\lambda_{v}=633 \mathrm{~nm}, \mathrm{CP}=1,46, \mathrm{Cl}=1,91$ e $\mathrm{m}=1$ com ângulos de incidência variando de $0^{\circ}$ a $50^{\circ}$, para luz incidente de $350 \mathrm{~nm}$ a $750 \mathrm{~nm}$.

Na Figura 2.12, percebe-se que o lóbulo principal do filtro se move para regiões de menor comprimento de onda e que a atenuação do lóbulo principal se torna menor e com isso o filtro fica menos seletivo.

Ao se realizar a mesma simulação angular para um filtro com nove camadas $\left(\lambda_{v}\right.$ $=633 \mathrm{~nm}, \mathrm{CP}=1,46, \mathrm{Cl}=1,91$ e $\mathrm{m}=1 \mathrm{com}$ ângulos de incidência variando de 0 a $50^{\circ}$, para luz incidente de 350nm à 750nm) (Figura 2.13) nota-se que a diminuição na atenuação do lóbulo principal ocorre de uma maneira menos intensa e o lóbulo se move um pouco mais devagar em função do ângulo.

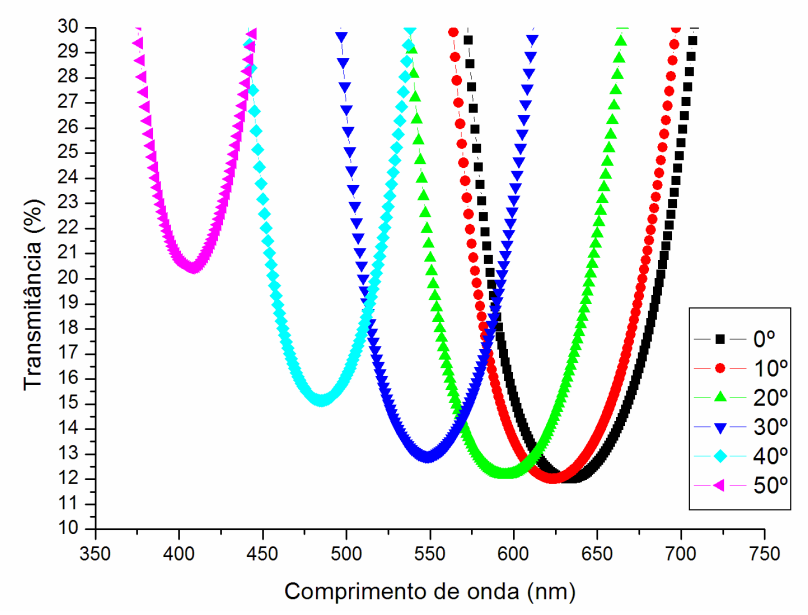

Figura 2.13 -Simulação 6 , filtro de 9 camadas com $\lambda_{v}=633 \mathrm{~nm}, \mathrm{CP}=1,46, \mathrm{Cl}=1,91$ e $\mathrm{m}=1$ com ângulos de incidência variando de $0^{\circ}$ a $50^{\circ}$, para luz incidente de $350 \mathrm{~nm}$ à $750 \mathrm{~nm}$. 
Outra simulação da transmitância em função do ângulo para um feixe de luz monocromático de 633nm também foi realizada (Figura 2.14) pode-se perceber que para um comprimento de onda específico o filtro pode ser usado como sensor angular, devido às variações na transmitância que ocorrem em função do ângulo. $\mathrm{Na}$ Figura 2.14 a simulação foi feita para os mesmos parâmetros utilizados na primeira simulação (Figura 2.8). Para a Figura 2.15 a diferença é que foram usadas nove camadas ao invés de sete. Percebe-se que mais oscilações em função do ângulo apareceram (maior número de lóbulos secundários).

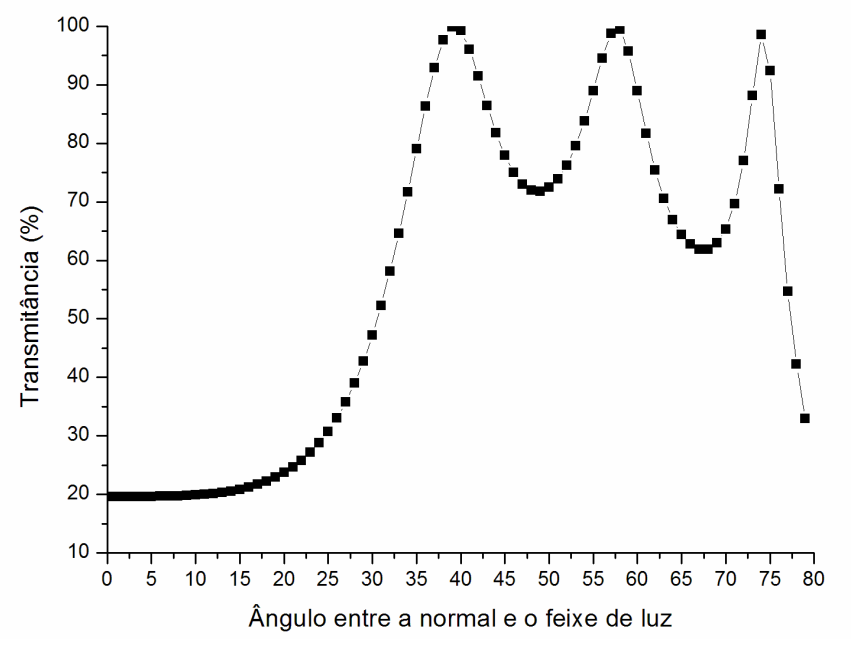

Figura 2.14 -Simulação 7, filtro de 7 camadas com $\lambda_{v}=633 \mathrm{~nm}, \mathrm{CP}=1,46, \mathrm{Cl}=1,91$ e $\mathrm{m}=1$ com ângulos de incidência variando de $0^{\circ}$ a $80^{\circ}$ para luz incidente de $633 \mathrm{~nm}$.

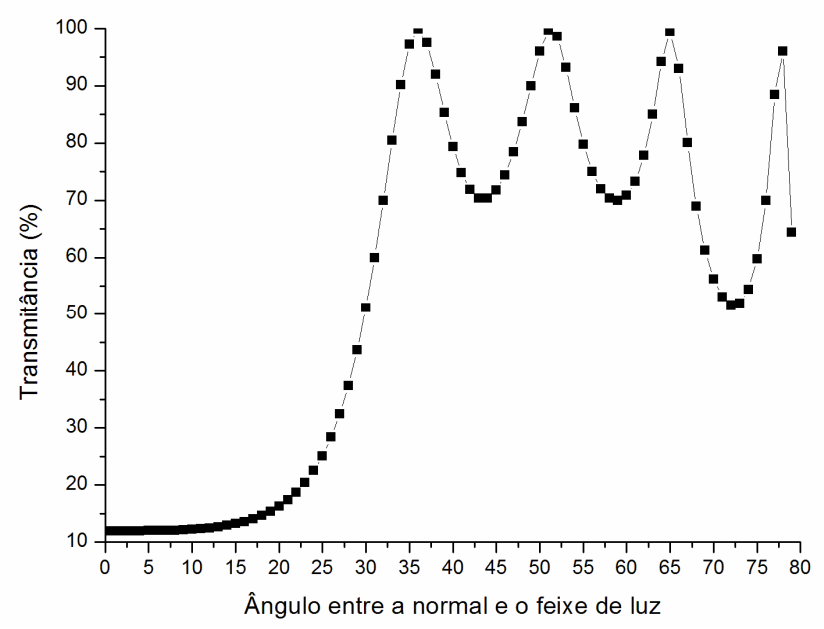

Figura 2.15 -Simulação 8, filtro de 9 camadas com $\lambda_{v}=633 \mathrm{~nm}, \mathrm{CP}=1,46, \mathrm{Cl}=1,91$ e $\mathrm{m}=1$ com ângulos de incidência variando de $0^{\circ}$ a $80^{\circ}$ para luz incidente de $633 \mathrm{~nm}$. 
Foram realizadas também simulações em função da temperatura (Figura 2.16), onde o índice de refração das camadas variava de acordo com o coeficiente termo óptico dos materiais utilizados $\left(10^{-5} /{ }^{\circ} \mathrm{C}\right.$ para o óxido de silício e o nitreto de silício), ou seja, eram variados os índices de refração como uma função linear da temperatura (ex: $\mathrm{Cl}=1,91+10^{-5}$ t e $\mathrm{CP}=1,46+10^{-5} \mathrm{t}$ ) para um comprimento de onda específico $(633 \mathrm{~nm})$ e ângulo de incidência entre a normal do filtro e o laser iqual a $0^{\circ}$.

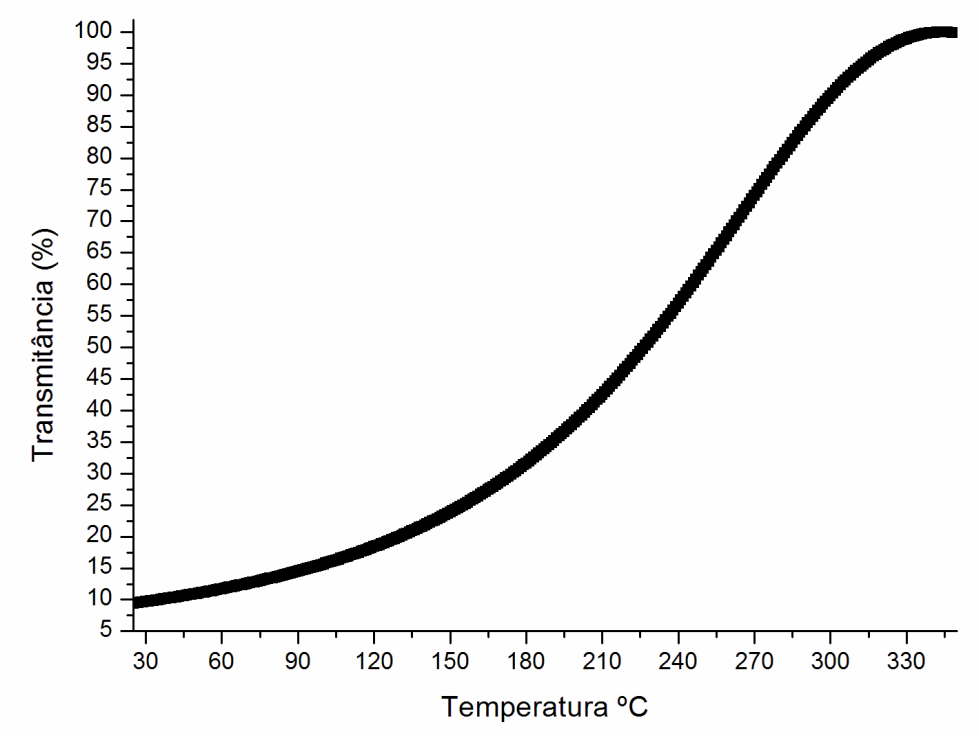

Figura 2.16 -Simulação 9, filtro de 13 camadas com $\lambda_{v}=634 \mathrm{~nm} \quad \mathrm{CP}=1,46, \mathrm{Cl}=1,91 \mathrm{e}$ $m=10.25$, variação com a temperatura para luz de 633nm incidente com ângulo de 0 ․

Para a Figura 2.16 nota-se que o m utilizado é grande, isso gera um lóbulo "fino" (sharp) em volta comprimento de onda do laser utilizado (633nm) mesmo assim é necessário que a espessura seja modificada fazendo-se $\circ \lambda_{v}=634 \mathrm{~nm}$ das fórmulas da espessura (50) e (51) um pouco maior de forma que a parte de maior derivada do lóbulo fique posicionada em $633 \mathrm{~nm}$ e dessa forma variação da temperatura resulte em uma grande variação da potência transmitida (Figura 2.16). Vemos abaixo o mesmo filtro da Figura 2.16 numa simulação para a luz incidente indo de $630 \mathrm{~nm}$ à $640 \mathrm{~nm}$ e em duas temperaturas diferentes $25^{\circ} \mathrm{C}$ e $375^{\circ} \mathrm{C}$. 


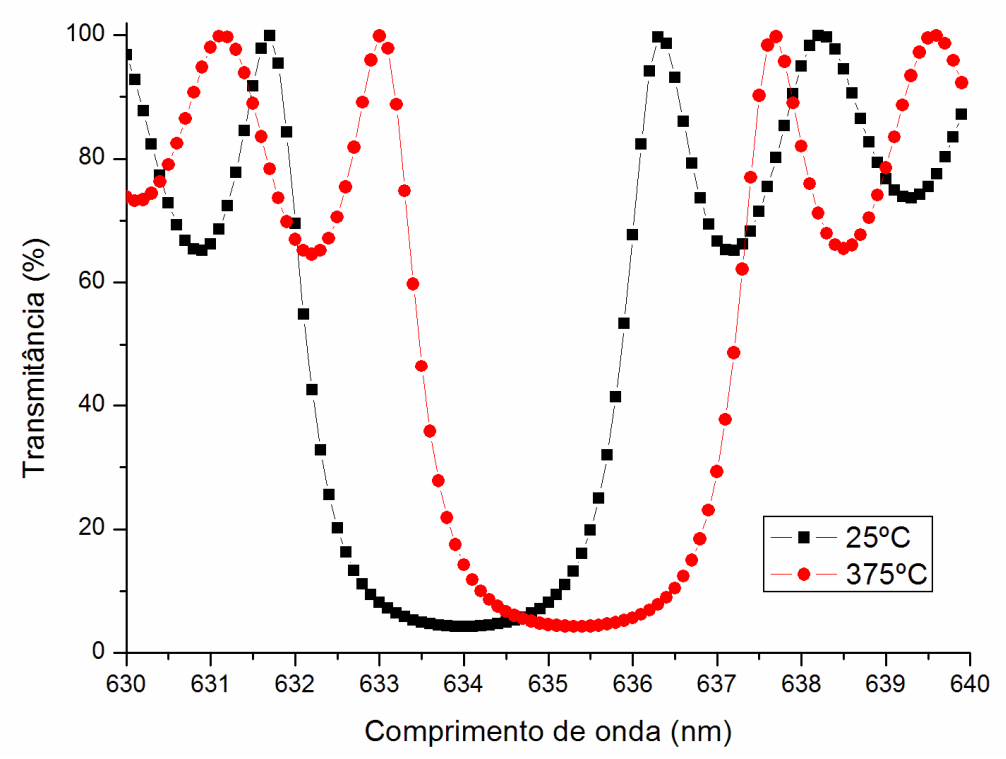

Figura 2.17 -Simulação 10, filtro de 13 camadas com $\lambda_{v}=634 \mathrm{~nm} \quad \mathrm{CP}=1,46, \mathrm{Cl}=1,91 \mathrm{e}$ $\mathrm{m}=10.25$, variação com a temperatura para luz incidente de $630 \mathrm{~nm}$ até $640 \mathrm{~nm}$. Pela legenda: gráfico vermelho o filtro se encontra a $375^{\circ} \mathrm{C}$ e gráfico em preto o filtro está à $25^{\circ} \mathrm{C}$ e centrado em $634 \mathrm{~nm}$.

O efeito obtido na mudança de espessura, mudando-se o $\lambda_{v}$ para $634 \mathrm{~nm}$, e desta forma deslocando-se o lóbulo principal, pode ser obtido também com uma mudança angular na luz incidente sobre o filtro (Figura 2.17).

Conclui-se desta forma que filtros mais seletivos devem possuir: uma maior diferença de índice de refração entre as camadas, um maior número de camadas e valores de $\mathrm{m}$ menores para se ter uma seletividade maior dentro da faixa de estudo. Contudo, um filtro para uso como sensor térmico tem que possuir um $\mathrm{m}$ de alto valor de forma que a variação de temperatura cause uma grande variação na potência transmitida. Desta forma ele possuirá menos seletividade abrangendo uma banda maior no espectro. 


\section{Capítulo 3 - ETAPAS DE FABRICAÇÃO}

\subsection{INTRODUÇÃO}

Neste capítulo é mostrada a fabricação dos dispositivos como também um detalhamento dos processos utilizados para a construção de filtros multicamadas depositados por PECVD.

\subsection{FABRICAÇÃO}

Para a fabricação dos dispositivos ópticos foram utilizados materiais dielétricos com diferentes índices de refração e transparentes na região de operação do laser (633nm), todos eles depositados por PECVD sobre substratos de silício <100> e Corning Glass (7059) (vidro com a banda de passagem relativamente plana que introduz pouco ruído, como pode ser visto pela Figura 3.1). As lâminas de silício

utilizadas têm $540 \mu \mathrm{m}$ de espessura, dopagem tipo $P$, orientação $<100>$ e resistividade 1-10 $\Omega . c m$, estas lâminas são circulares e foram cortadas em quadrados de 1"x1".

As características das lâminas de Corning Glass utilizadas estão descritas na Tabela 3.1, seu ponto de liquefação é alto e por isso ele pode ser usado na técnica de PECVD que utiliza baixas temperaturas $\left(320^{\circ} \mathrm{C}\right)$. Também sua expansão térmica é pequena $\left(46,0 \times 10^{-7} / 0 \mathrm{C}\right)$ e com isso pode ser usado para testes térmicos sem afetar a qualidade do filtro depositado sobre ele, pois sua espessura vária pouco. Sua transmitância (\%) em função do comprimento de onda $(\mathrm{nm})$ é relativamente estável apresentando baixa variação de $400 \mathrm{~nm}$ à $1100 \mathrm{~nm}$ como pode ser visto na Figura 3.1 e desta forma introduzindo poucas alterações no filtro depositado sobre este tipo de substrato. Na Figura 3.1 está mostrada a transmitância (\%) em função do comprimento de onda $(\mathrm{nm})$. Esta curva foi obtida por um espectrofotômetro Shimadzu, UV-Visible-1650 PC model que tem uma capacidade de varredura no 
espectro que vai de 190nm à 1100nm. As lâminas de Corning Glass possuíam aproximadamente 1"x1/2", e foram cortadas a partir de lâminas de 1"x1" essa clivagem foi necessário para que as lâminas pudessem ser analisadas no espectrofotômetro que possui compartimentos de entrada com essas medidas.

Tabela 3.1 - Características das lâminas de Corning Glass (7059) utilizadas (retirado do datasheet no site http://www.vinkarola.com/Technical\%20Information.htm).

\begin{tabular}{|l|l||}
\hline Densidade & $2,76 \mathrm{~g} / \mathrm{cm} 3$ \\
\hline Ponto de liquefação & $844^{\circ} \mathrm{C}$ \\
\hline Ponto de Recozimento & $639^{\circ} \mathrm{C}$ \\
\hline Expansão Térmica $\left(0-300^{\circ} \mathrm{C}\right)$ & $46,0 \times 10^{-1} /{ }^{\circ} \mathrm{C}$ \\
\hline Índice de Refração & $1,53 \mathrm{em} 633 \mathrm{~nm}$ \\
\hline Espessura & $0,000813 \mathrm{~m}$ \\
\hline
\end{tabular}

Pode-se perceber, pela Figura 3.1, que o Corning Glass (7059) possui uma atenuação aproximadamente constante em torno de $5 \%$ que vai de $400 \mathrm{~nm}$ à 1100 $\mathrm{nm}$.

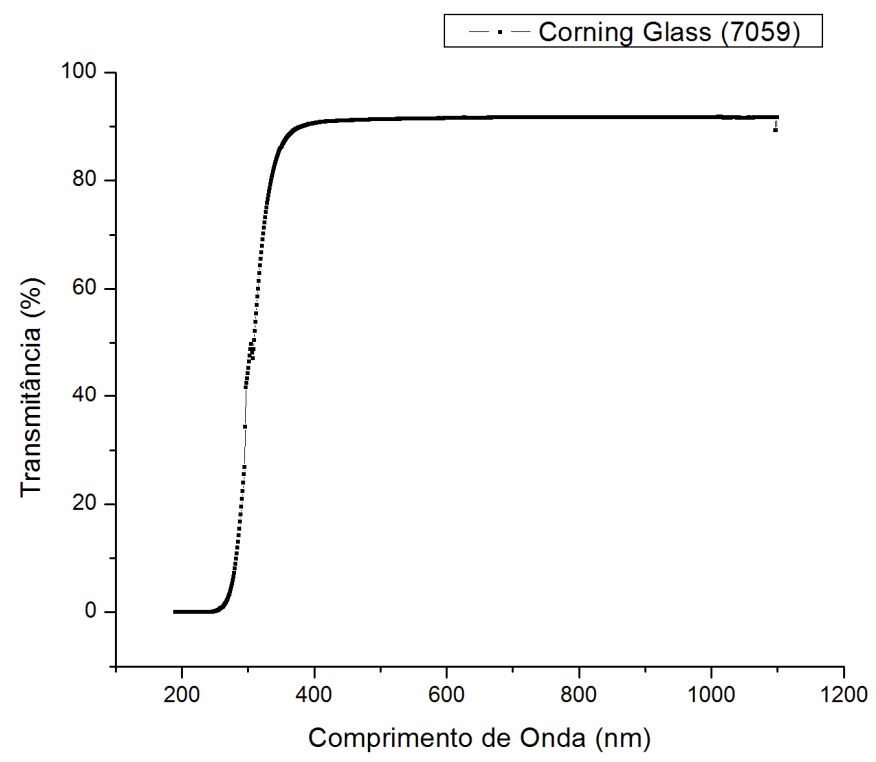

Figura 3.1 - Transmitância (\%) em função do comprimento de onda para o Corning Glass (7059).

Todas as lâminas após serem cortadas passaram por uma limpeza inicial na sala limpa, descrita na Tabela 3.2 (silício todas as etapas e vidro todas com exceção das etapas 3 e 4), e após algumas partes de processamento que serão descritas, as lâminas passaram também pela limpeza mostrada na Tabela 3.3 para que fossem 
desengorduradas. Estas limpezas são padrões em microfabricação e são utilizadas no Laboratório de Microeletrônica da Universidade de São Paulo.

Tabela 3.2 - Descrição da limpeza inicial realizada após a clivagem nas lâminas.

1) Lâminas colocadas por 15 minutos em solução de $\mathrm{H}_{2} \mathrm{SO}_{4} \mathrm{e} \mathrm{H}_{2} \mathrm{O}_{2}$ a $105^{\circ} \mathrm{C}$ na proporção 3 partes de $\mathrm{H}_{2} \mathrm{SO}_{4}$ para 1 parte de $\mathrm{H}_{2} \mathrm{O}_{2}$.

2) Em seguida as lâminas são lavadas por 25 minutos em água corrente deionizada.

3) Mergulha-se as lâminas por 15 segundos em solução de DLV (apenas para lâminas de Silício).

4) Depois, as lâminas que passaram pela etapa 5 são lavadas em água corrente deionizada por 15 minutos.

5) São então colocadas em uma solução de $\mathrm{H}_{2} \mathrm{O}, \mathrm{H}_{2} \mathrm{O}_{2}$ e $\mathrm{HCl}$ a $80^{\circ} \mathrm{C}$ numa proporção de 6 partes de $\mathrm{H}_{2} \mathrm{O}$ para 1 parte de $\mathrm{H}_{2} \mathrm{O}_{2}$ e 1 parte de $\mathrm{HCl}$.

6) Ao final as lâminas são lavadas por 10 minutos em água corrente deionizada e secas com jato de $\mathrm{N}_{2}$.

Tabela 3.3 - Descrição da limpeza intermediária que foi realizada após algumas etapas de processamento que serão descritas.

1) a) As lâminas de silício são colocadas por 15 minutos em tricloroetileno.

b) As lâminas de vidro são colocadas em uma solução de $\mathrm{H}_{2} \mathrm{O}, \mathrm{H}_{2} \mathrm{O}_{2}$ e $\mathrm{NH}_{4}$ a $75^{\circ} \mathrm{C}$ por 15 minutos na proporção de 7 partes de $\mathrm{H}_{2} \mathrm{O}, 2$ partes de $\mathrm{H}_{2} \mathrm{O}_{2}$ e 1 parte de $\mathrm{NH}_{4}$.

2) a) Em seguida as lâminas de silício passam por mais 15 minutos imersas em acetona.

3) E finalmente as lâminas de silício e de vidro são colocadas por mais 15 minutos em isopropanol e então são secas com jato de $\mathrm{N}_{2}$.

Para a construção dos filtros foram utilizados filmes dielétricos depositados por PECVD com diferentes índices de refração e diferentes espessuras. Para isso foi necessário um estudo destes filmes durante o mestrado de forma a aperfeiçoar a construção dos filtros.

Dentre os diversos processos de síntese de filmes finos, a deposição através de precursores na fase gasosa ativados por descarga luminescente, PECVD, (Plasma Enhanced Chemical Vapor Deposition) destaca-se devido a algumas de suas particularidades: O processo é seco, limpo, rápido, relativamente barato e de 
fácil execução. Proporcionam materiais uniformes, homogêneos, com baixa densidade de defeitos e com propriedades fortemente dependentes dos parâmetros de deposição.

O plasma gerado para a fabricação dos dispositivos utiliza a aplicação de campos elétricos alternados a um gás a baixa pressão $\left(10^{-1}\right.$ a $\left.10^{-3} \mathrm{~Pa}\right)$. Elétrons livres do gás adquirem energia do campo elétrico e são acelerados. Colisões inelásticas entre elétrons energéticos e moléculas, dão origem a uma série de espécies tais como, outros elétrons, íons, radicais livres, átomos e moléculas em estados excitados. De uma forma geral, espécies ativadas pela descarga são muito reativas e tendem a interagir com as superfícies (adsorção), formando um filme.

O reator que utilizamos para este trabalho apresenta um sistema de acoplamento capacitivo com os eletrodos na configuração tipo triódo cuja freqüência de RF é fixa em 13.56MHz [34]. Há a possibilidade de atuar em vários parâmetros do processo de deposição como: temperatura, fluxo de gases, pressão de processo e potência de RF. Cabe destacar que o porta-substrato encontra-se invertido no intuito de evitar a deposição de particulados na superfície da amostra. Um diagrama esquemático do sistema utilizado é apresentado na Figura 3.2.

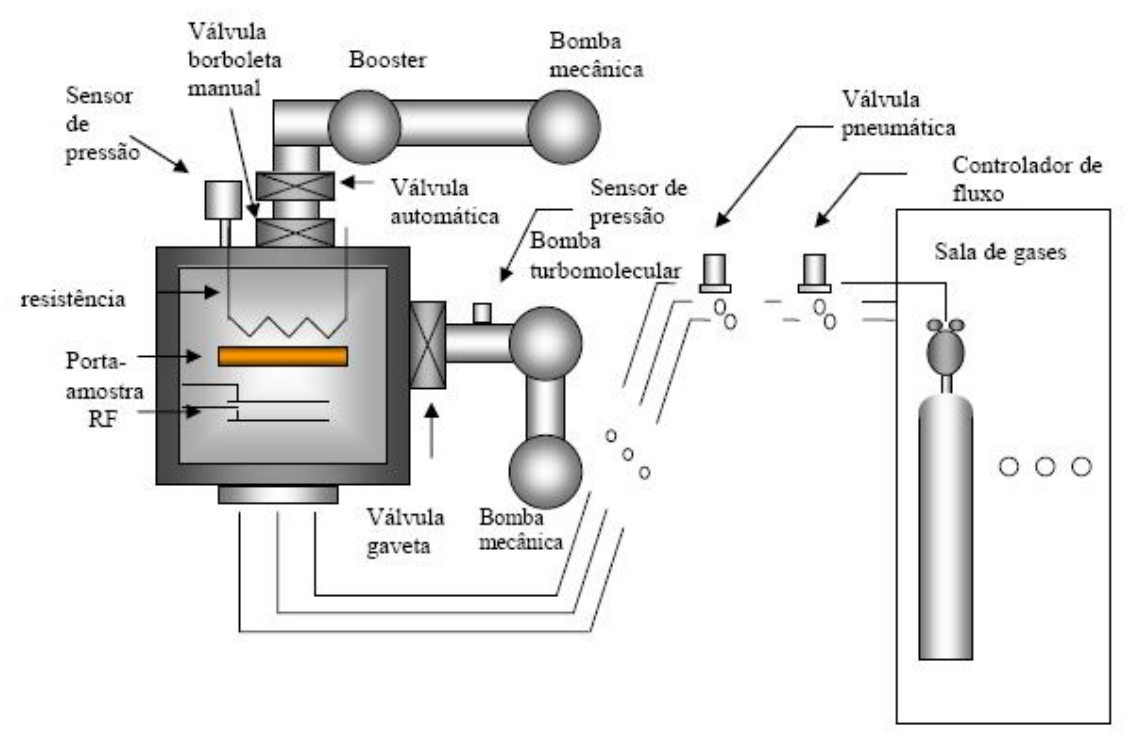

Figura 3.2 - Diagrama esquemático do reator de PECVD. 
O sistema de aquecimento é do tipo resistivo, podendo chegar a temperaturas de até $400^{\circ} \mathrm{C}$. O monitoramento da temperatura é feito através de um termopar tipo K colocado diretamente no porta-substrato.

O bombeamento é provido de dois sistemas de vácuo, um composto de uma bomba difusora assistido por uma bomba rotatória (sistema de alto vácuo), e outro composto de uma bomba Roots em série com uma bomba rotatória (sistema de processo). O sistema de alto vácuo é necessário para que sejam removidos do reator possíveis contaminantes provindos do ar atmosférico, ou seja, é um vácuo de limpeza. Já o sistema de processo é utilizado na deposição permitindo baixas pressões.

Materiais depositados por PECVD podem ser orgânicos ou inorgânicos, dependendo da composição química do plasma. Pode-se obter, por exemplo, filmes poliméricos, carbono-amorfo hidrogenados [35], carbono tipo diamante (diamond like carbon) [36], oxinitreto de silício $\left(\mathrm{SiO}_{x} \mathrm{~N}_{y}\right)$, entre outros.

A variedade de filmes obtidos com esta técnica é devido ao diferente grau de interação entre o plasma e a superfície, e pode ser controlado pelos parâmetros experimentais (como potência, pressão e fluxo de gases, freqüência de excitação e temperatura do substrato durante o processo). Variações nestes parâmetros afetam diretamente as características "intrínsecas" do plasma, isto é, a densidade eletrônica e iônica, a função distribuição de energia dos elétrons e o potencial de plasma, entre outros. Portanto, a técnica de PECVD permite a obtenção de filmes com uma ampla gama de propriedades através do controle dos parâmetros do processo. Exemplos são camadas isolantes/condutoras com espessuras controladas utilizadas na fabricação de dispositivos eletrônicos, filmes transparentes apropriados para aplicações ópticas como janelas ópticas, camadas anti-refletivas, revestimentos de lentes e óculos esportivos, filmes biocompatíveis, materiais hidrofóbicos convenientes para aplicações em embalagens alimentícias e para a confecção de sensores.

Particularmente no que se refere aos filmes dielétricos, muitos autores $[37,38,39]$ observaram que o índice de refração é fortemente dependente da composição atômica dos filmes de oxinitreto de silício $\left(\mathrm{SiO}_{\mathrm{x}} \mathrm{N}_{\mathrm{y}}\right)$ obtidos por PECVD. Ainda mais, foi também observado que a composição atômica dos filmes PECVD$\mathrm{SiO}_{\mathrm{x}} \mathrm{N}_{\mathrm{y}}$ pode ser variada desde óxido de silício até nitreto de silício dependendo das condições de deposição usadas [40,41]. Na Figura 3.3 podemos observar os índices 
de refração para diferentes relações de fluxo de gases usando uma temperatura de $320^{\circ} \mathrm{C}$ e uma densidade de potencia de RF de $500 \mathrm{~mW} . \mathrm{cm}^{-1}$.

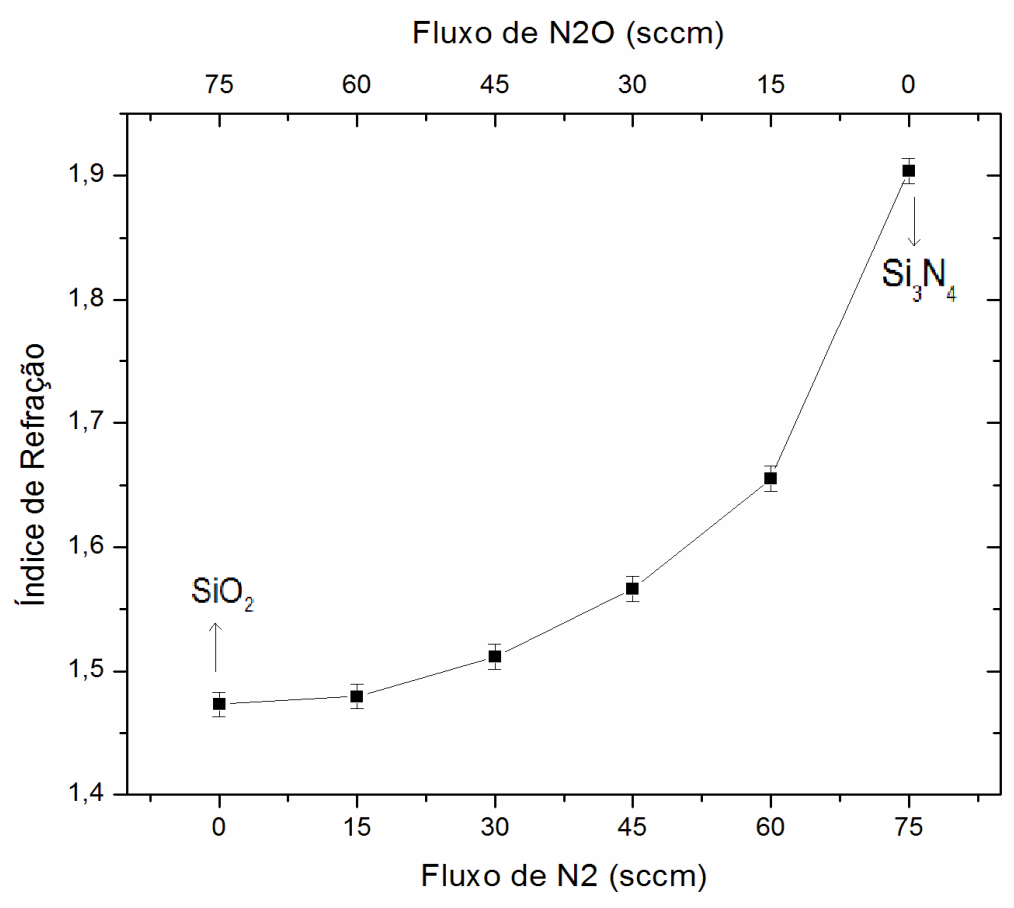

Figura 3.3 - Índice de refração em função do fluxo dos gases nitrogênio $\left(\mathrm{N}_{2}\right)$ e óxido nitroso $\left(\mathrm{N}_{2} \mathrm{O}\right)$ em sccm que entram no reator de PECVD.

Os gases usados foram óxido nitroso $\left(\mathrm{N}_{2} \mathrm{O}\right)$, nitrogênio $\left(\mathrm{N}_{2}\right)$ e silana $\left(\mathrm{SiH}_{4}\right)$, com a soma de óxido nitroso e nitrogênio sempre em $75 \mathrm{sccm}$ e variando suas quantidades de $15 \mathrm{em} 15 \mathrm{sccm}$ desde 0 à $75 \mathrm{sccm}$ como mostrado na Figura 3.3. A silana era sempre mantida em $30 \mathrm{sccm}$ e as deposições foram realizadas no reator de PECVD do Laboratório de Microeletrônica da Universidade de São Paulo (Figura 3.4). $O$ índice de refração mostrado na Figura 3.3 tem precisão de duas casas decimais (1,91 para $\mathrm{Si}_{3} \mathrm{~N}_{4}$ e 1,46 para $\mathrm{SiO}_{2}$ ). 


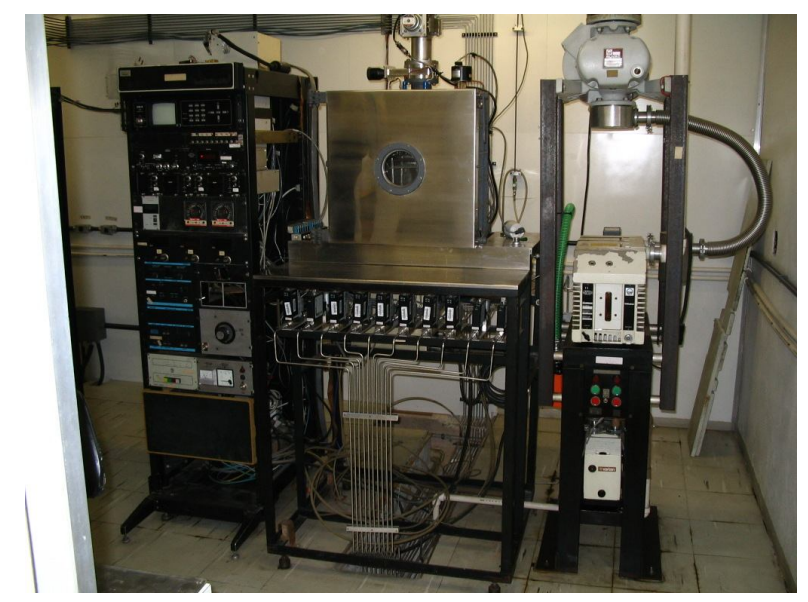

Figura 3.4 - Reator de PECVD do Laboratório de Microeletrônica da Escola Politécnica da Universidade de São Paulo.

O índice de refração das películas depositadas neste trabalho foram medidas usando a técnica de elipsometria.

A Elipsometria é uma técnica óptica de investigação das propriedades dielétricas (índice de refração) de filmes finos. Sendo uma técnica óptica ela é não destrutiva e não é feita através de contato. Através da análise da mudança da polarização da luz, que é refletida de uma amostra, pode-se obter informações sobre as camadas de filme fino que são mais finas que o comprimento de onda da luz utilizada no processo.

A elipsometria mede a mudança da polarização que ocorre através da reflexão ou da transmissão. Tipicamente a elipsometria é feita somente pela reflexão como foi o caso deste trabalho. A exata natureza da mudança da polarização da luz é determinada pelas propriedades da amostra (espessura, índice de refração). Através de técnicas ópticas ligadas à difração, a elipsometria explora a informação contida na fase e no estado de polarização da luz. A amostras devem ser compostas por até duas camadas bem definidas e discretas que são opticamente homogêneas, isotrópicas e não absorventes [33]. 


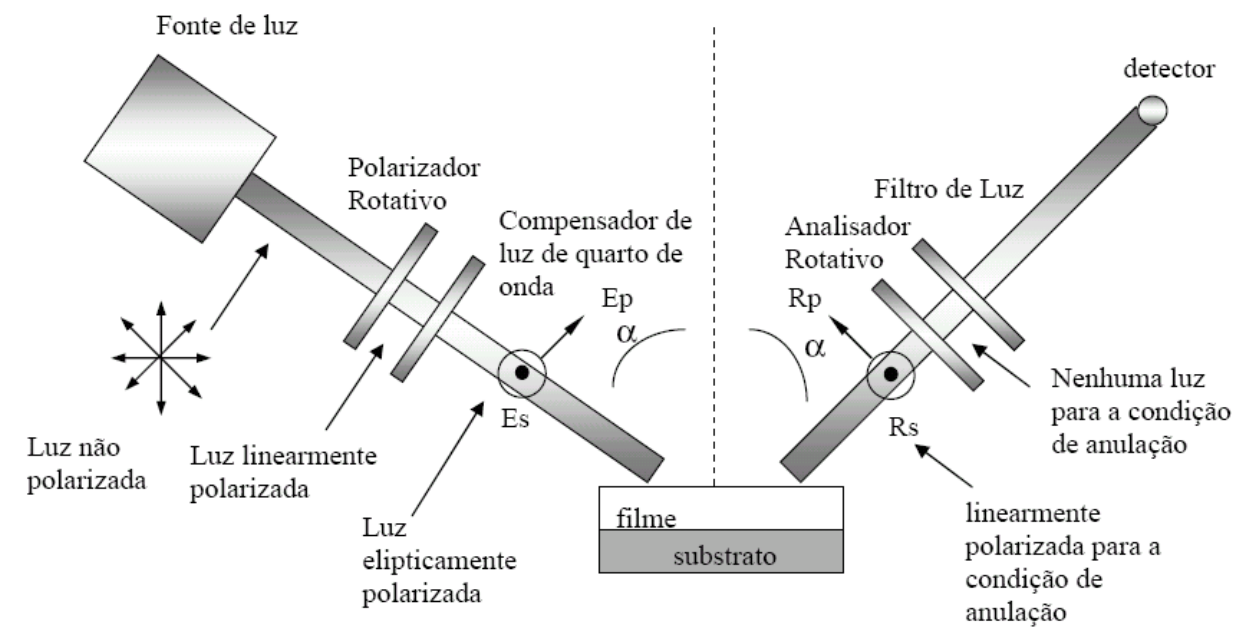

Figura 3.5 - Arranjo experimental da medida de índice de refração por elipsometria.

Pela Figura 3.5 vemos o arranjo experimental onde a radiação eletromagnética é emitida por uma fonte de luz linearmente polarizada que passa por um polarizador, por um compensador e atinge a amostra. Após a reflexão, a radiação passa por um analisador rotativo e um filtro de luz, e finalmente atinge o detector.

A Elipsometria mede 2 parâmetros de Stokes, que são denotados por $\Psi$ e $\Delta$ [33]. O estado da polarização da luz incidente através da amostra pode ser decomposto nas componentes s e p. As amplitudes das componentes s e p após a reflexão e a normalização e a relação ao valor inicial são denotadas pelos coeficientes de Fresnel $r_{p}$ e $r_{s}$ [33]. A elipsometria mede a relação entre $r_{p}$ e $r_{s}$, que pode ser descrita pela equação fundamental da elipsometria:

$$
\rho=\frac{r_{p}}{r_{s}}=\tan (\psi) e^{i \Delta}
$$

Assim tem-se que a $\tan (\Psi)$ é a taxa da amplitude após a reflexão e $\Delta$ é a diferença de fase. Usando um processo iterativo (o método dos mínimos quadrados), as equações de Fresnel e as variáveis obtidas do elipsômetro ( $\Psi$ e $\Delta$ ) é possível calcular as constantes ópticas desconhecidas (os índices de refração) [33].

O equipamento utilizado para a medida de elipsometria e obtenção dos índices de refração das amostras foi um Rudo/ph Research-Auto EL NIR-3/4D/SS1 existente no Laboratório de Sistemas Integráveis da Escola Politécnica da Universidade de São Paulo. Este equipamento já realiza o cálculo dos índices de refração 
automaticamente fornecendo inclusive o erro da medida. O erro de medida é de aproximadamente 0,01 .

Como podemos observar na Figura 3.3 o índice de refração aumenta desde a composição do óxido de silício onde é usado $75 \mathrm{sccm}$ de óxido nitroso e $30 \mathrm{sccm}$ de silana (índice de refração de 1,46 ) até a composição do nitreto de silício onde é usado $75 \mathrm{sccm}$ de nitrogênio e $30 \mathrm{sccm}$ de silana (índice de refração de 1,91). O índice de refração aumenta isso ocorre devido ao aumento da concentração de nitrogênio como pode-se observar pela concentração atômica do filme fino formado em função do fluxo de $\mathrm{N}_{2}$ durante a deposição do mesmo como pode ser observado pela Figura 3.6.

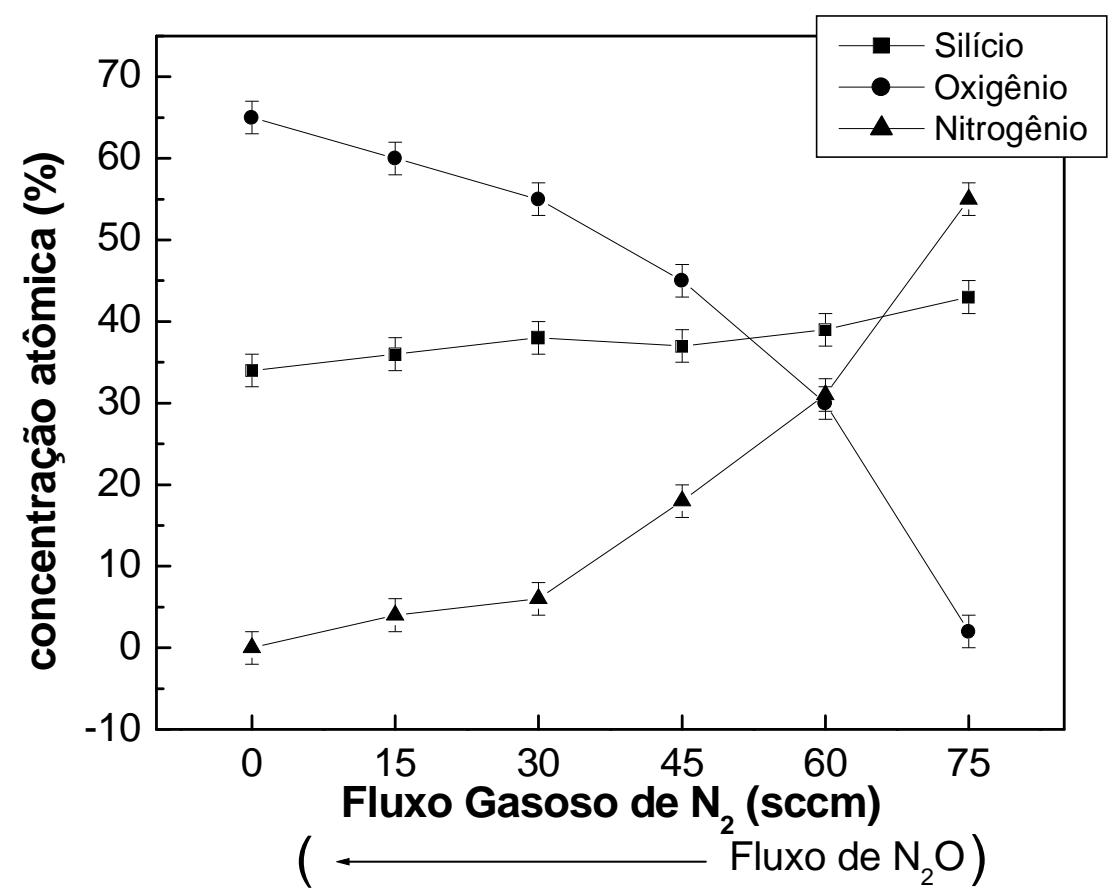

Figura 3.6 - Concentração de silício, nitrogênio e oxigênio no filme depositado em função do fluxo gasoso que entra no reator durante a deposição.

As taxas de deposição em PECVD sobre as amostras foram calculadas através da técnica de perfilometria (a elipsometria também poderia ser utilizada para se obter as espessuras dos filmes) utilizando-se uma máscara mecânica de modo a se formar um degrau de filme fino que pode ser medido com o perfilômetro. O princípio básico da técnica perfilométrica para a realização de uma medida é o seguinte: uma agulha se move na horizontal sobre a superfície de um substrato, ocorrendo um deslocamento da ponteira na vertical, em resposta às características da superfície. Esse deslocamento na vertical é monitorado pelo LVDT (Linear Variable Differential 
Transformer) e o sinal elétrico na sua saída é amplificado, digitalizado, processado e mostrado em um monitor de vídeo. Por se tratar de uma técnica de contato mecânico de alta precisão, este equipamento deve ser operado numa área que apresente um mínimo de vibrações mecânicas, já que estas podem causar erros apreciáveis na medida [42]. Esta medida tem como objetivo a determinação da espessura dos filmes depositados. Com os dados obtidos e o tempo de deposição do filme calculam-se as taxas de deposição mostradas na Figura 3.7.

As taxas de deposição foram calculadas a partir da medida em 3 diferentes pontos da amostra e a partir das diferenças de espessura em uma mesma amostra foram calculados os erros que mostram também a diferença de espessura entre os diferentes pontos da amostra, a uniformidade de espessura é necessária para que a luz do laser inserido no filtro sofra as mesmas variações quando atravessa a estrutura e gere uma resposta de saída mais uniforme. O aparelho utilizado foi um perfilômetro Tencor, modelo Alpha Step 500, localizado no Laboratório de Microeletrônica da Escola Politécnica da Universidade de São Paulo. Esse aparelho apresenta uma margem de erro de $\pm 10 \mathrm{~nm}$ e a ponta do equipamento é de diamante com um diâmetro na ponta de $12,5 \mu \mathrm{m}$.

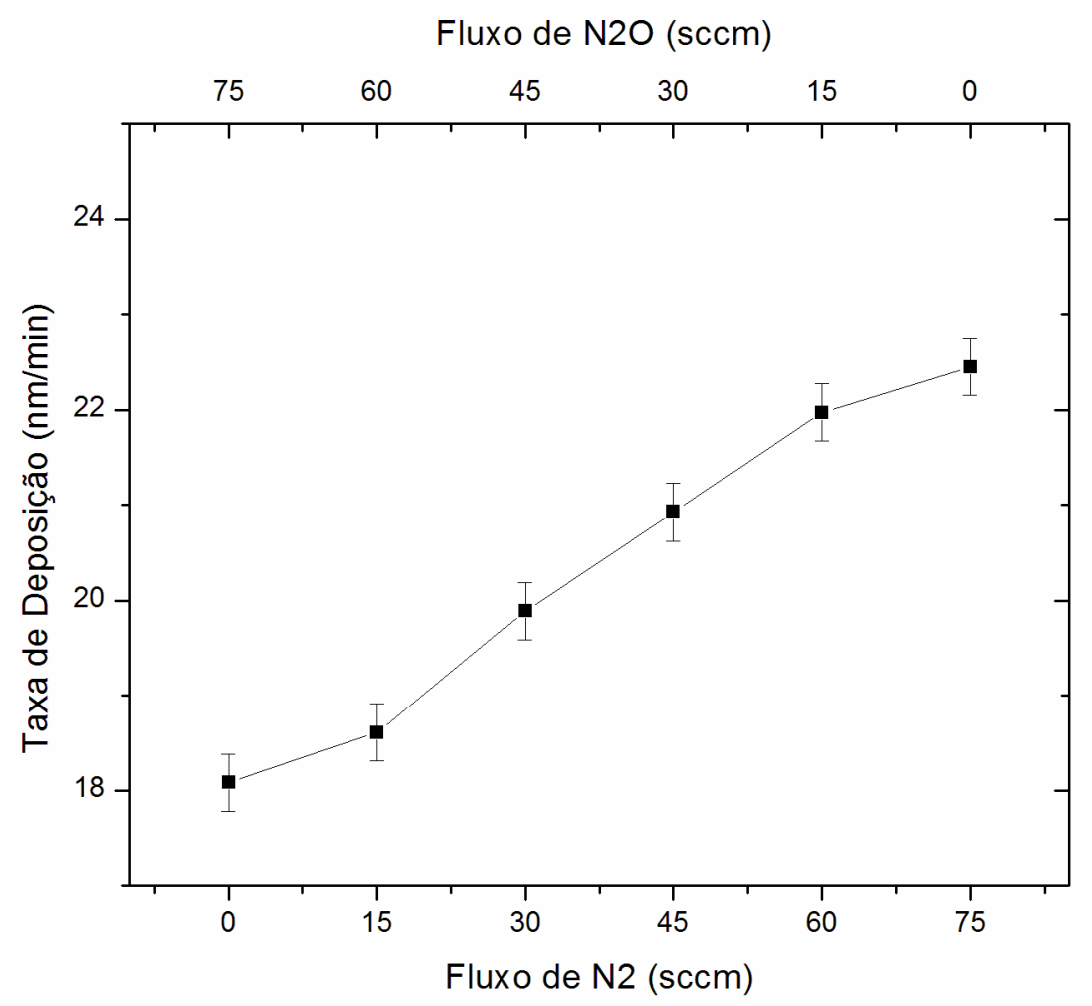

Figura 3.7 - Taxa de deposição em função da composição dos gases que entram no reator. 
Com a obtenção das taxas de deposição e dos índices de refração das amostras depositadas por PECVD foi possível a construção de filtros ópticos sobre Corning Glass (7059) com índices e espessuras determinadas. Estes filtros serão chamados neste trabalho de filtros verticais.

A construção dos filtros ópticos passa pela etapa de clivagem e de limpeza inicial (Tabela 3.2) e a deposição de filmes sucessivos de óxido de silício e nitreto de silício, que possuem índices de refração com maiores diferenças entre si, de forma a obter um filtro mais seletivo, tal como foi concluído no capítulo 2 .

A deposição é iniciada com a colocação das lâminas no interior do reator de PECVD através da utilização de garras de ferro que prendem as lâminas na placa de cobre que será aquecida (porta-substrato invertido). Essas garras têm o inconveniente de gerar sombra na hora da deposição afetando a taxa de deposição nas regiões próximas. Por esse motivo foram feitos também filtros em que graxa de vácuo (Dow Corning high vacuum grease), que é inerte e resistente ao aquecimento, foi utilizada para prender as amostras na placa, da mesma forma que uma cola. Isto permitiu que a deposição ficasse mais uniforme em toda a lâmina com diferenças menores que $50 \mathrm{~nm}$. Após o aquecimento do reator eram liberados os gases na composição estipulada e o plasma era ligado, com a deposição de uma camada desligava-se o plasma e se introduzia a nova composição ligando-se o plasma em seguida e assim sucessivamente construindo dessa forma o filtro óptico da Figura 3.8. Após a deposição foi feita a limpeza descrita na Tabela 3.3.

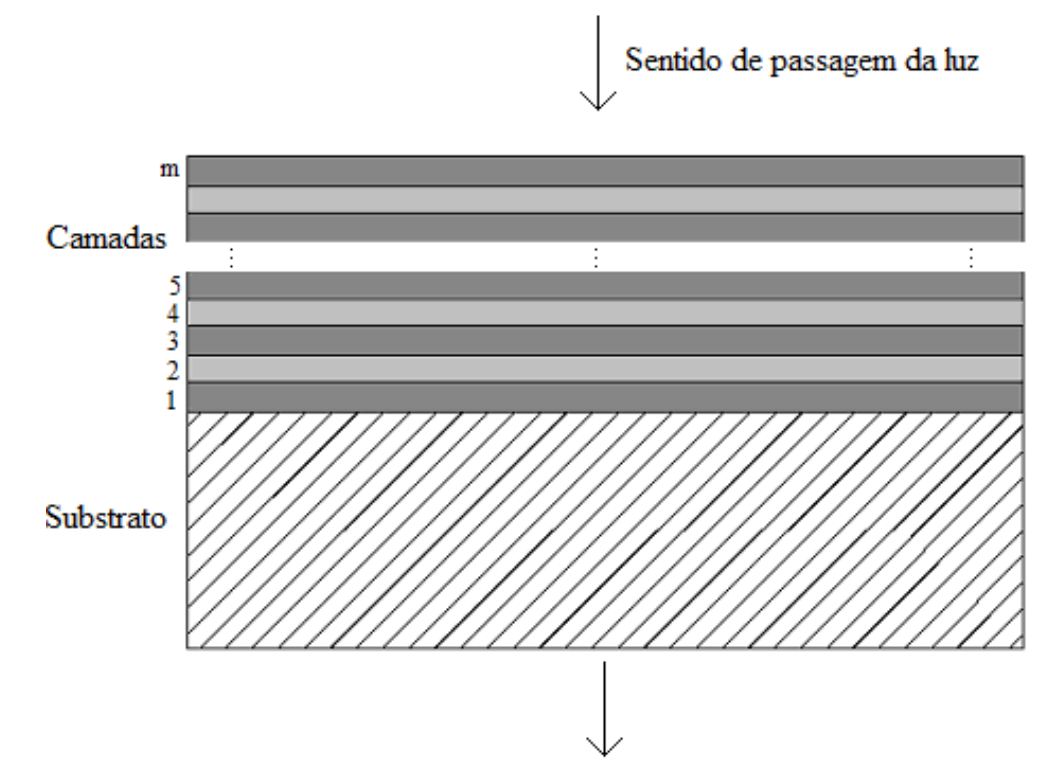

Figura 3.8 - Filtro sobre vidro Corning Glass (7059) com a luz passando no sentido vertical. 
Foram criados também filtros sobre silício através de outros processos que chamaremos neste trabalho de filtros horizontais (este tipo de filtro multicamada horizontal também é tratado na literatura como filtro Bragg). Nestes filtros a luz passava em um sentido diferente sobre as camadas e com o auxilio de fibra óptica, como mostrado na Figura 3.9.

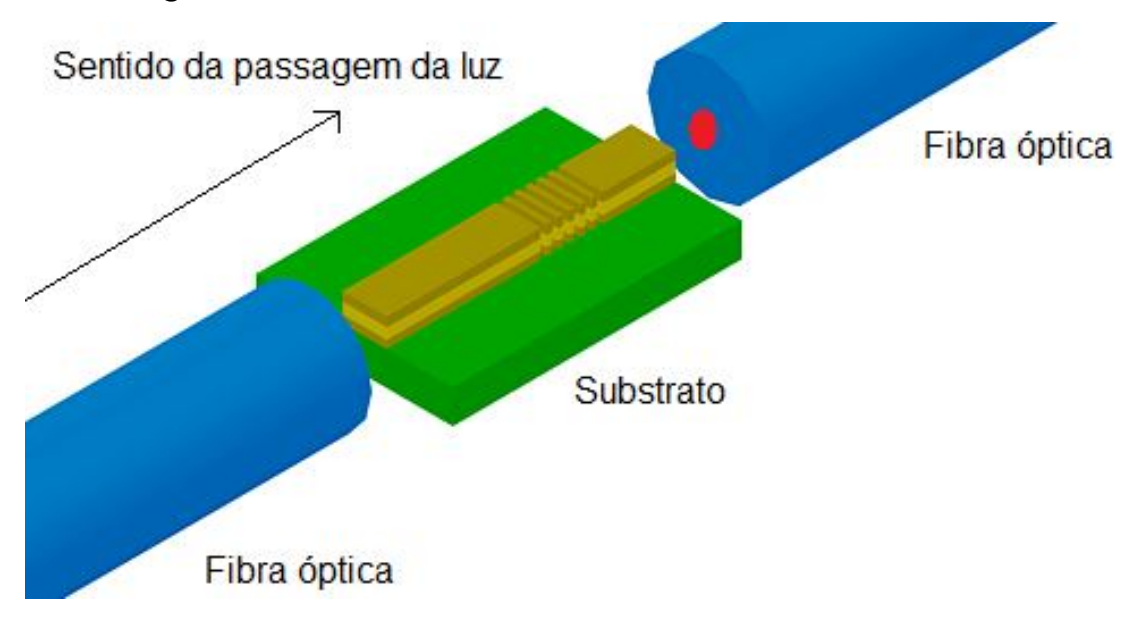

Figura 3.9 - Filtro sobre silício com a luz passando no sentido horizontal.

Estes filtros (Figura 3.9) foram construídos sobre substratos de silício e são baseados em guias ópticos compostos por camadas de cladding, núcleo e cobertura. Assim, foram feitas deposições em PECVD para as camadas com óxido de silício como cladding, nitreto de silício como núcleo e novamente, óxido de silício como cobertura de forma a confinar a luz no núcleo pela técnica de Reflexão Interna Total.

A primeira etapa da fabricação foi a clivagem das lâminas de silício em quadrados de 1"x1". Após a clivagem foi feita a limpeza inicial mostrada na Tabela 3.2, e em seguida as lâminas foram levadas para o reator de PECVD e foram depositadas camadas de óxido de silício como cladding (Figura 3.11-b); nitreto de silício como núcleo (Figura 3.11-c); e óxido de silício como cobertura (Figura 3.11-d).

Após a deposição em PECVD, foi realizada a limpeza descrita pela Tabela 3.3. A seguir foi depositada uma camada de cromo de 0,1 $\mu \mathrm{m}$ através de um reator que utiliza a técnica de deposição física a vapor chamada sputtering (pulverização catódica) (Figura 3.10) para servir de máscara na corrosão das camadas dielétricas. 


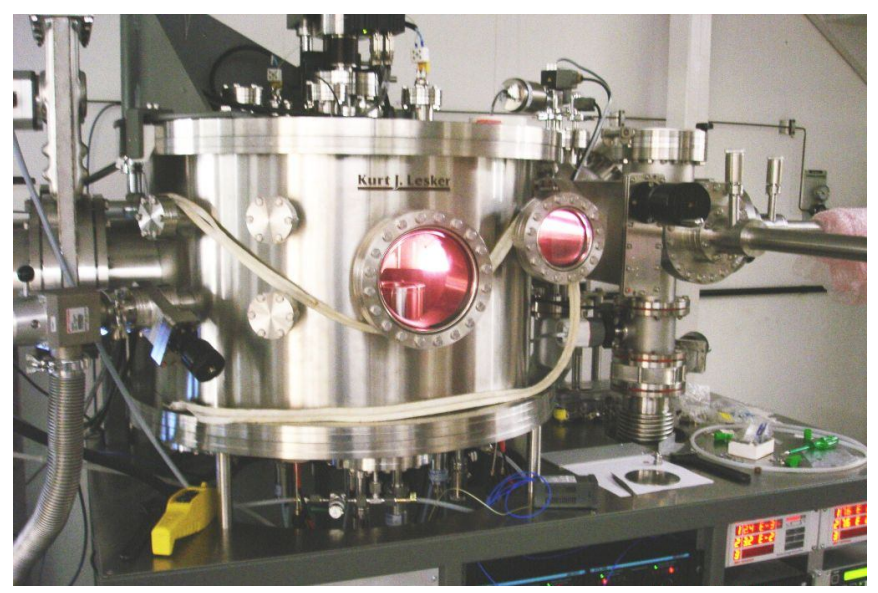

Figura 3.10 -Reator de sputtering (pulverização catódica) da sala do reator do Laboratório de Microeletrônica da Escola Politécnica da Universidade de São Paulo.

O Sputtering (pulverização catódica) é um processo de evaporação à vácuo que remove fisicamente porções de um material chamado alvo e deposita um filme fino e fortemente ligado em uma superfície adjacente (o substrato). O processo ocorre através do bombardeio da superfície do alvo com íons gasosos (no caso íons de argônio) acelerados através de uma alta voltagem. Com a colisão destes íons com o alvo, átomos ou ocasionalmente moléculas inteiras do material do alvo são ejetadas e propelidas contra o substrato, onde elas formam uma ligação muito forte. A cobertura resultante se liga firmemente à superfície por forças mecânicas, formando desta forma até mesmo uma liga ou uma ligação química. Por ser um processo físico, virtualmente qualquer material pode ser depositado através desta técnica.

Neste trabalho a técnica de sputtering (pulverização catódica) foi utilizada apenas para a deposição de máscaras de cromo (Figura 3.11-e) que iriam ser utilizadas para definição de estruturas através da corrosão por plasma pela técnica de RIE (reactive ion etching) estas máscaras eram definidas através de fotogravação onde o fotorresiste servia de máscara na corrosão do cromo e desta forma o cromo protegia as camadas depositadas por PECVD da corrosão por RIE nas regiões prédefinidas. Estas etapas estão descritas e ilustradas na Figura 3.11.

As máscaras de cromo depositadas pela técnica de deposição física a vapor chamada sputtering (pulverização catódica) foram feitas sob pressão de $10 \mathrm{mTorr}$, potência de $70 \mathrm{~W}$ e fluxo de argônio de $10 \mathrm{sccm}$. O reator de sputtering 
(pulverização catódica) utilizado encontra-se no Laboratório de Microeletrônica da Escola Politécnica da Universidade de São Paulo (Figura 3.10).

Após a deposição do cromo era realizada uma nova limpeza conforme a Tabela 3.3. A etapa seguinte foi a colocação de fotoressiste (Figura 3.11-f) e a definição de uma máscara por fotogravação (Figura 3.11-g). Em seguida foi feito um corrosão no cromo (Figura 3.11-h). Posteriormente, com a geometria da máscara definida sobre cromo, foi feita a corrosão por plasma através da técnica de RIE (reactive ion etching).

O RIE é uma técnica de corrosão usada na microfabricação ${ }^{43}$. Esta técnica usa plasma quimicamente reativo para remover materiais depositados em lâminas. $\mathrm{O}$ plasma é gerado em baixa pressão por um campo eletromagnético. Íons de alta energia do plasma atacam os materiais depositados na lâmina e reagem com eles.

O plasma (que é um gás ionizado) é iniciado em um sistema pela aplicação de RF, a oscilação do campo elétrico ioniza as moléculas de gás tirando delas os elétrons e criando desta forma o plasma.

Com o acúmulo de carga negativa na região do substrato, pela da aplicação de tensão negativa pelo próprio sistema do reator e devido à carga positiva desenvolvida no plasma pela retirada de elétrons os íons de plasma tendem a colidir cineticamente com a amostra e reagir com ela de forma a realizar uma corrosão anisotrópica (com um sentido de corrosão específico) que forma superfícies planas necessárias para a realização do acoplamento com a fibra e passagem da luz sem que ocorra a dispersão por superfícies arredondadas que se formariam em uma corrosão isotrópica (igual em todas as direções).

Para a definição das estruturas foi usado RIE (reactive ion etching) com 50 sccm de $\mathrm{O}_{2}$ e $35 \mathrm{sccm}$ de $\mathrm{SF}_{6}$ à 100 mTorr de pressão e $150 \mathrm{~W}$ de potência. A taxa de corrosão em função da relação de fluxo dos gases é dado na Figura 3.11. O reator usado na corrosão utiliza a técnica de RIE (reactive ion etching) para a corrosão dos filmes de oxinitreto e se encontra na sala limpa do Laboratório de Microeletrônica da Escola Politécnica da Universidade de São Paulo (Figura 3.12). 


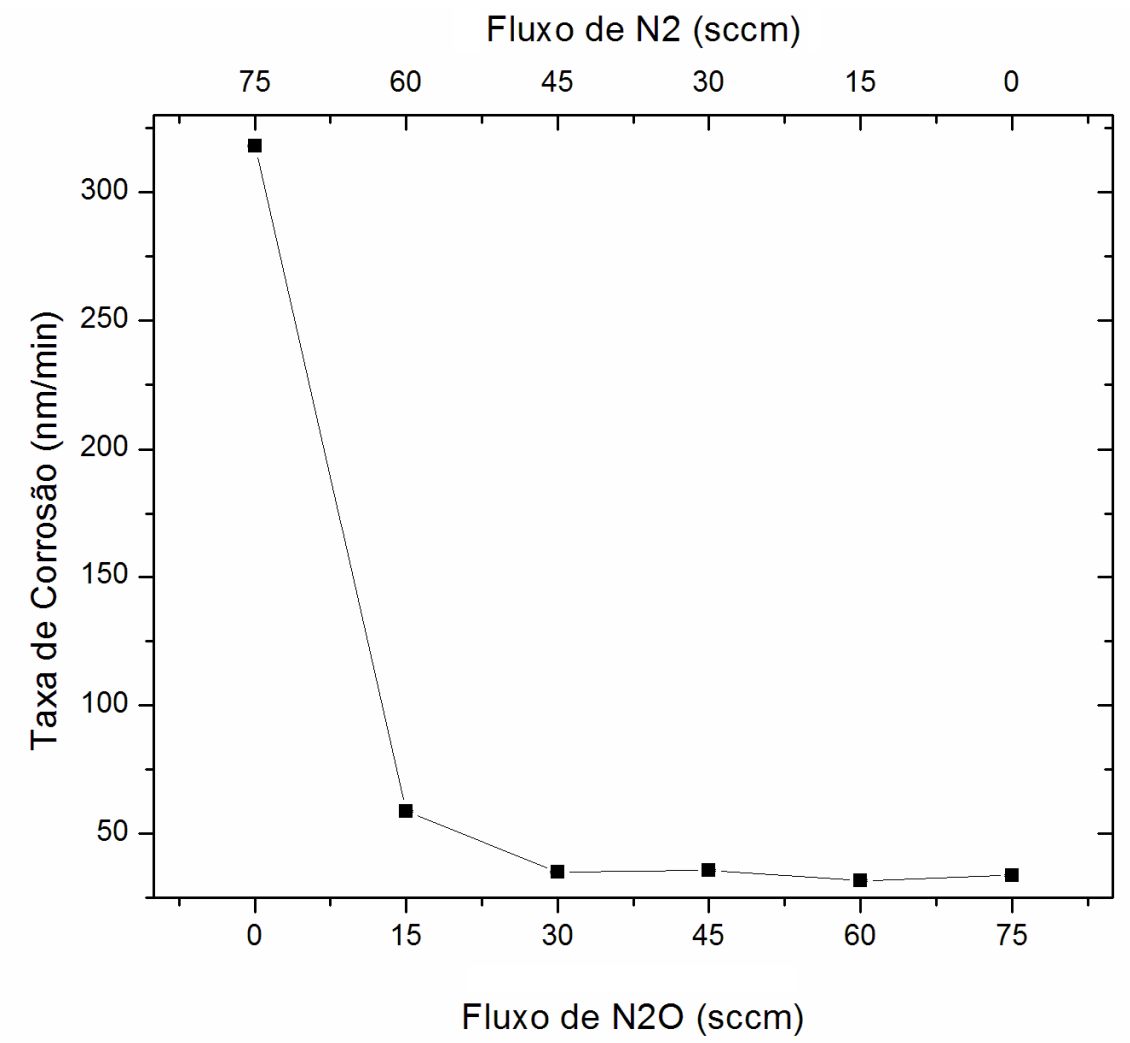

Figura 3.11 -Taxa de corrosão dos filmes de Oxinitreto de silício em função da composição usada de gases no reator de PECVD.

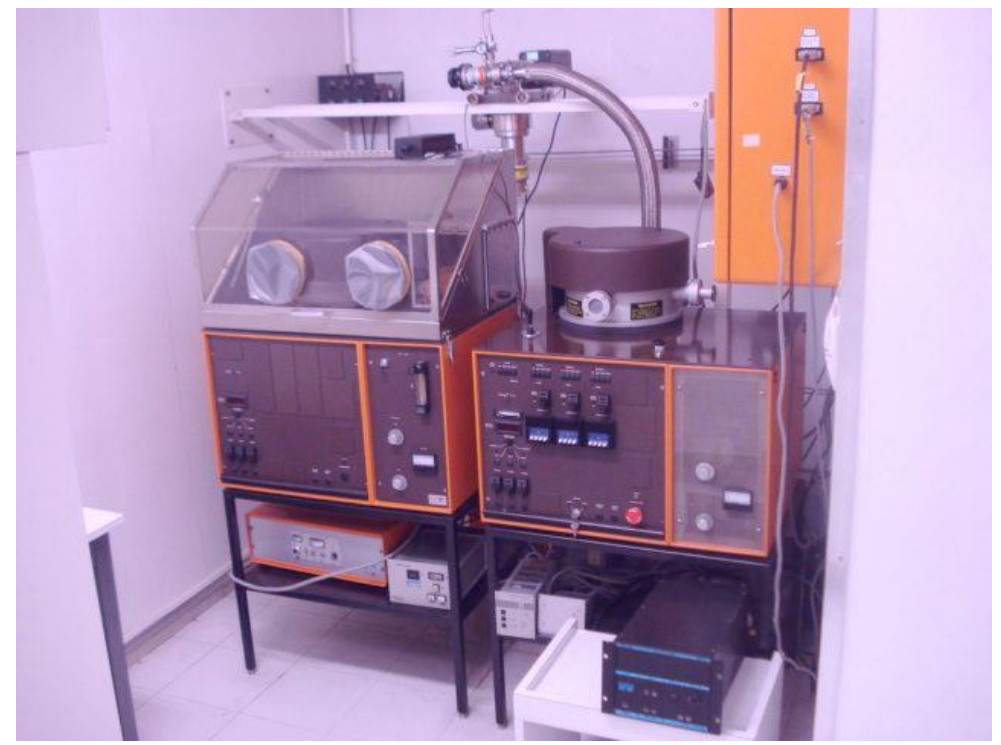

Figura 3.12 -Reator de RIE (reactive ion etching) para a corrosão dos filmes de oxinitreto e se encontra na sala limpa do Laboratório de Microeletrônica da Escola Politécnica da Universidade de São Paulo. 
A corrosão em RIE definiu a geometria de cavidades de ar (Figura 3.11-i). Após este processo foi realizada a remoção do cromo (Figura 3.11-j) e a limpeza descrita pela Tabela 3.3.

A máscara usada para a definição das geometrias dos guias está mostrada na Figura 3.14-a. Por outro lado, a máscara usada para definir a geometria dos filtros é mostrada na Figura 3.14-b. 

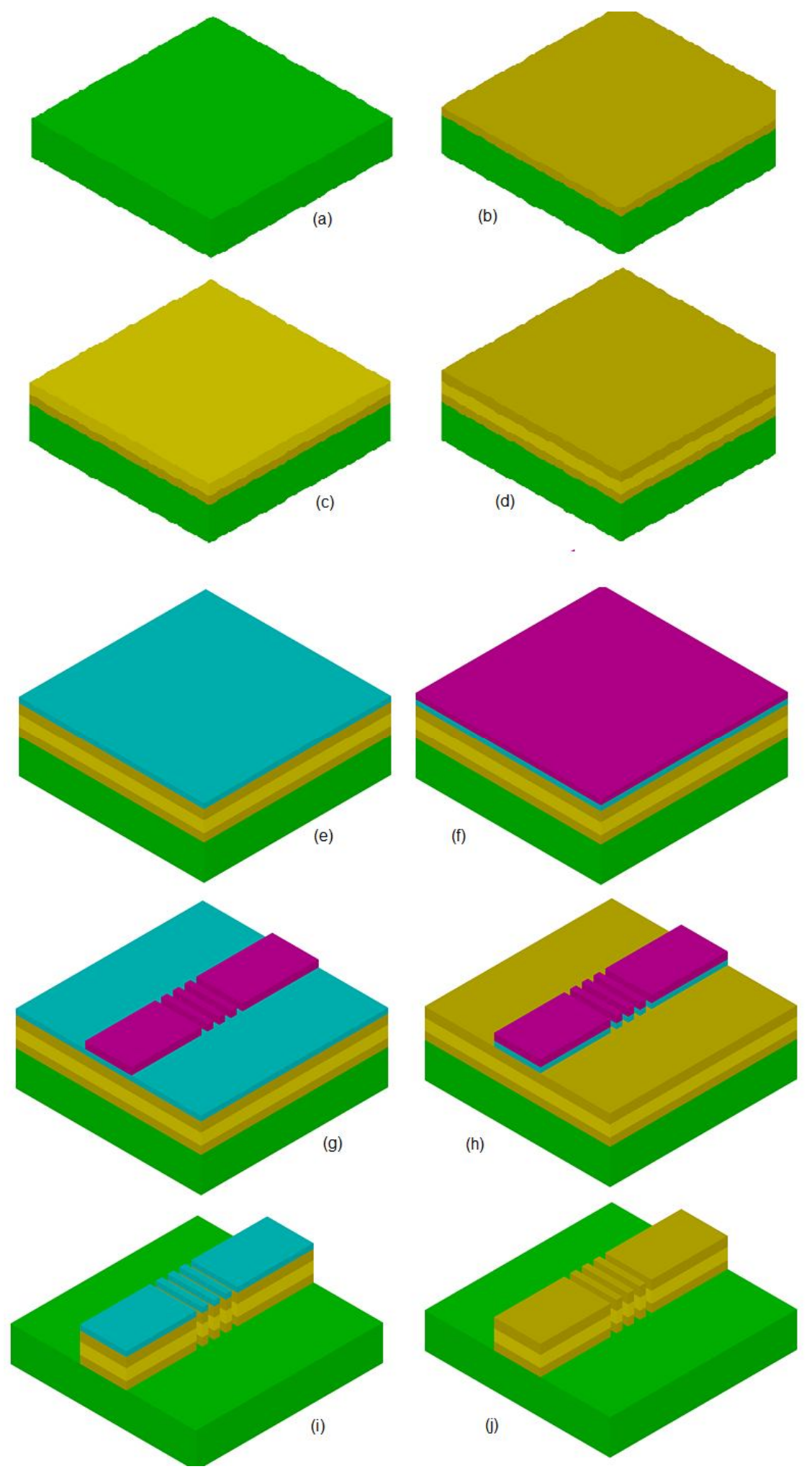

Figura 3.13 - (a) llustração da lâmina de 1"x1"; (b) Deposição em PECVD de 1,5 $\mu$ m de óxido de silício (cladding); (c) Deposição em PECVD de $3 \mu \mathrm{m}$ de nitreto de silício (núcleo); (d) Deposição de 1,5 $\mu \mathrm{m}$ de óxido de silício (cobertura); (e) Deposição da camada de cromo; (f) deposição de fotoresiste; (g) Fotogravação; (h) corrosão do cromo; (i) Corrosão por RIE dos dielétricos; (j) Corrosão do cromo. 
Para a fabricação dos dispositivos estas máscaras foram usadas em conjunto no momento da fotogravação. Primeiramente a máscara (a) foi exposta e o filme revelado, e em seguida a máscara (b) da Figura 3.14. A ordem deve ser essa, pois as marcas de alinhamento da máscara (a) são $10 \mu \mathrm{m}$ menores que as marcas de alinhamento da máscara (b) e isso possibilita o alinhamento preciso da máscara (b) na foto gravadora após ter sido revelada a máscara (a).

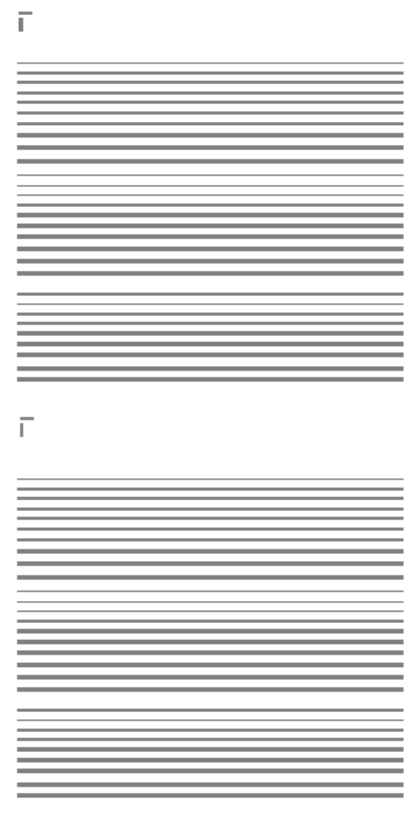

(a)

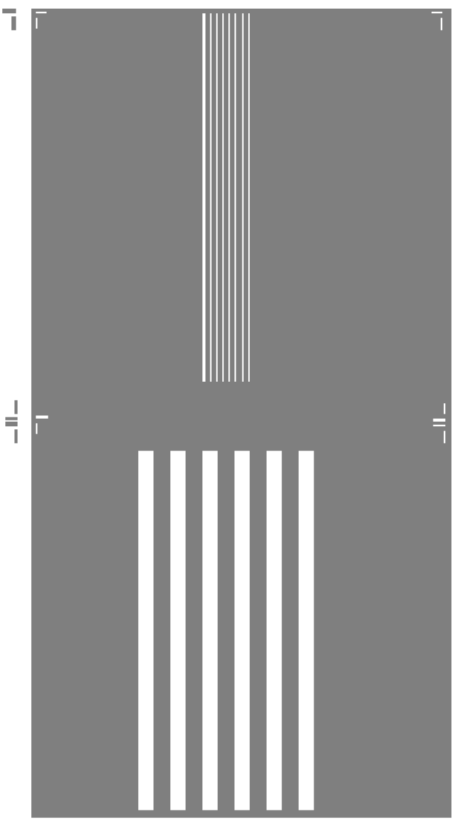

(b)

Figura 3.14 -(a)Máscaras utilizadas para definição de filtros horizontais; (b) máscara utilizada na definição dos filtros.

As linhas mostradas na máscara (a) possuem larguras que variam de $10 \mu \mathrm{m}$ à $100 \mu \mathrm{m}$ e correspondem à dimensão "L" (largura da guia) indicada na Figura 3.15. Por outro lado, as linhas da máscara (b) na parte superior possuem larguras de 100 $\mu \mathrm{m}$ e as mostradas na parte inferior possuem larguras de $1000 \mu \mathrm{m}$. Ambas correspondem às dimensões "d" (espessura das camadas do filtro) mostrada na Figura 3.15. (fora de escala para a melhor visualização). 


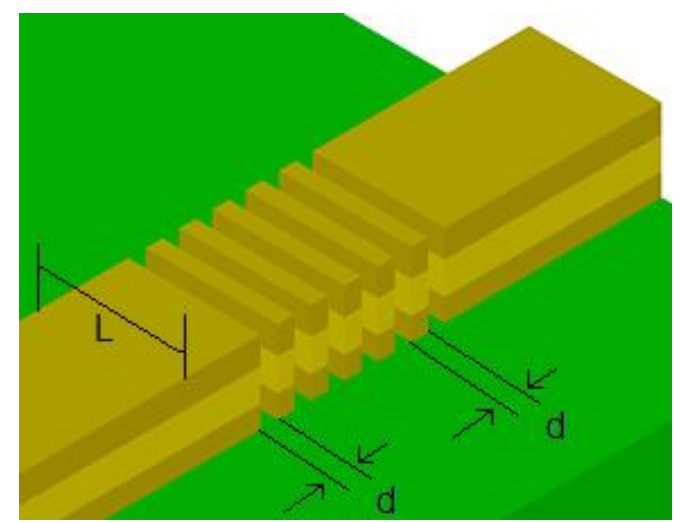

Figura 3.15 -Dimensões dos filtros horizontais.

Após a obtenção dos filtros horizontais sobre silício era necessário realizar processos para polimento das entradas e saídas de luz para que houvesse acoplamento máximo com a fibra óptica. Para isso foram realizados os seguintes procedimentos na ordem mostrada.

Primeiramente foi realizado o embutimento dos dispositivos ópticos, no intuito de evitar danos às estruturas ópticas durante o processo de lixamento e polimento.

A resina acrílica da EXTEC foi usada para fazer o embutimento por apresentar rápido enrijecimento, fácil manuseio do embutimento no lixamento e polimento, e fácil remoção da amostra de seu interior, além de visibilidade parcial da amostra em seu interior, dado que é feita de material translúcido. Na Figura 3.16 vemos a lâmina de silício na vertical. O suporte plástico mantém a lâmina nesta posição até a secagem da resina acrílica.

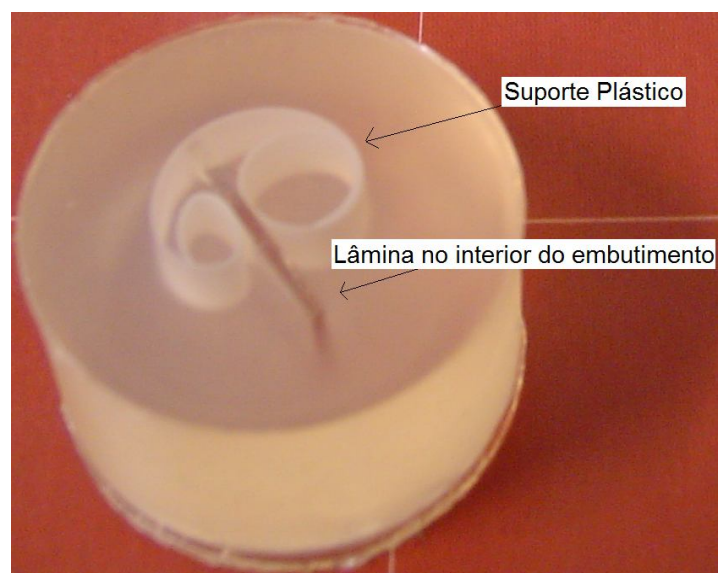

Figura 3.16 -Lâmina embutida. 
Uma vez embutidas, as amostras são levadas ao Departamento de Engenharia Metalúrgica e de Materiais, onde se localizam as lixadeiras utilizadas.

Neste local as amostras passaram por etapas de lixamento (Figura 3.17) de diversas granulações, partindo das lixas "mais grossas" (A400 e A600), com grãos de várias centenas de micrômetros até as mais finas (A1200), com apenas alguns micrômetros. Esta etapa é necessária, pois em média retira-se $0,75 \mathrm{~mm}$ de material, o que é inviável somente com o polimento. Após esta etapa é possível ver através de um microscópio óptico o material depositado sobre o substrato, contudo o acoplamento óptico com a fibra não é o suficiente para haver guiamento de luz, por isso é necessária a próxima etapa onde é feito o polimento da lâmina.

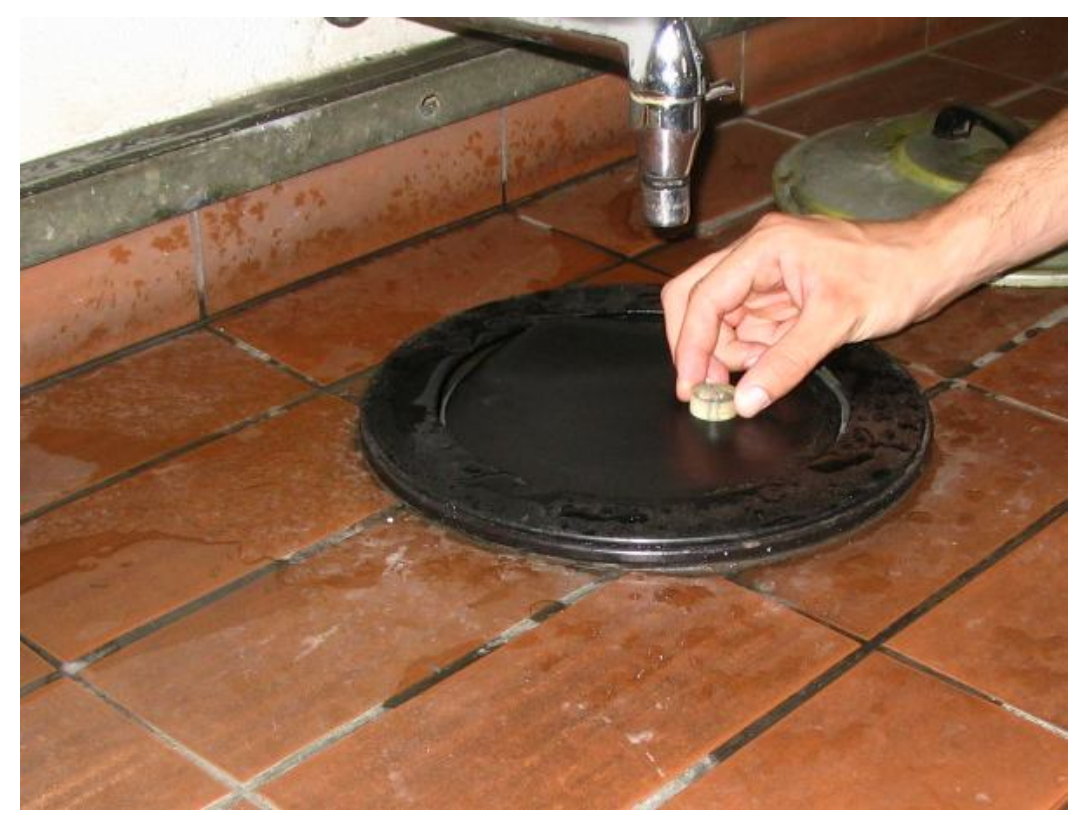

Figura 3.17 -Lâmina embutida sendo lixada.

Após o lixamento foram realizados polimentos utilizando-se a politriz MINIMET 1000 (Figura 3.18), da BUEHLER, e foi feito com granulações muito finas, 1 micrometro e 0,1 micrometros, em feltros especialmente projetados para este fim proporcionando assim devida homogeneidade que a caracterização óptica impõe. 


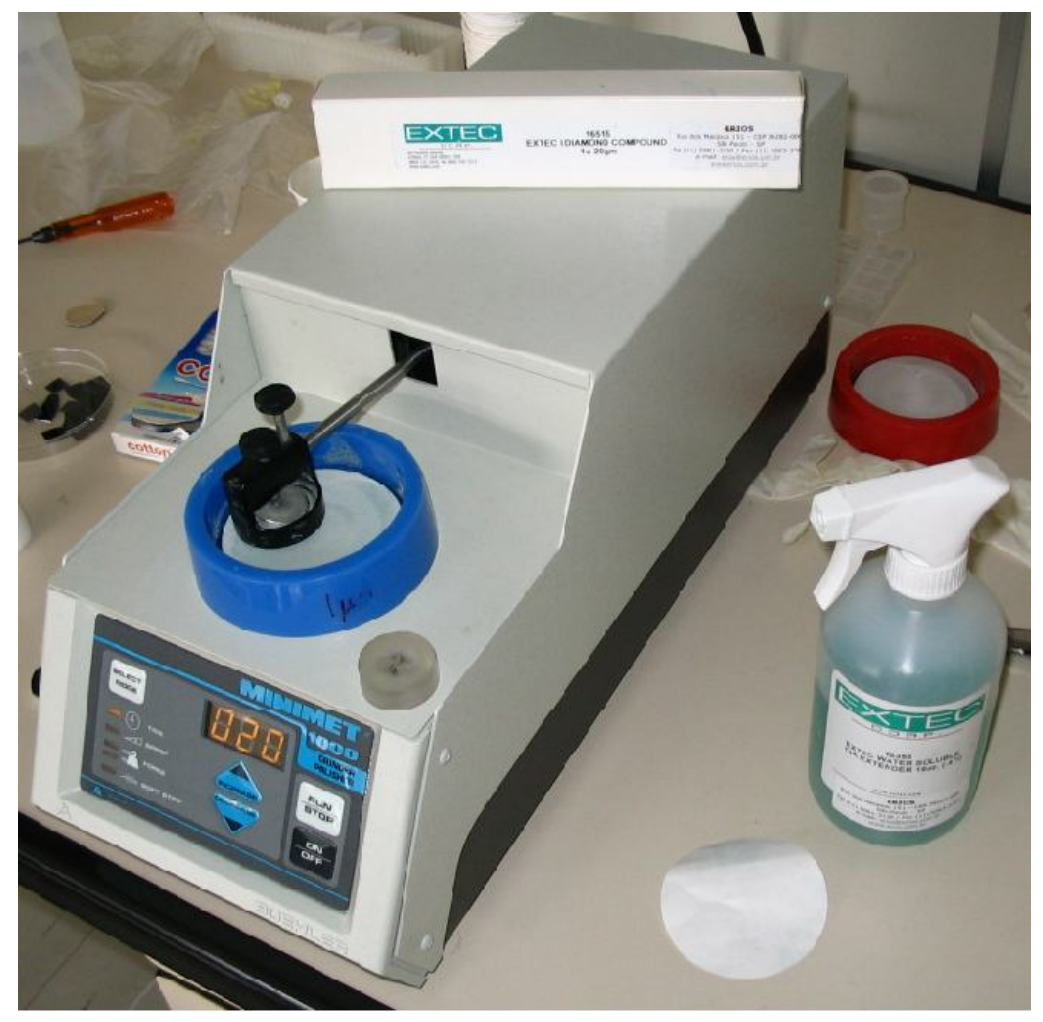

Figura 3.18 -Acima na caixa branca: Pasta de diamante de 1 micrometro. No centro: Polimetriz MINIMET 1000. À direita: solução de sílica de 0,1 micrometros.

As condições de polimento usadas foram:

- Intervalo de uso em cada lado da lâmina: 20 minutos.

- Velocidade: $20 \mathrm{rpm}$.

- Força: 15 Newton.

Após o polimento com a pasta de diamante foi realizada uma verificação no microscópio da sala limpa aonde foram observadas as entradas e saídas de luz das guias de onda das amostras, em seguida a resina foi removida com o uso de banho em acetona e após isso foi feita outra limpeza de tri-cloro, acetona e álcool (Tabela 3.3).

Um terceiro tipo de filtro feito sobre lâminas de silício fino $(300 \mu m)$ foi construído de forma a se obter o mesmo efeito de um filtro suspenso (Figura 3.19). 


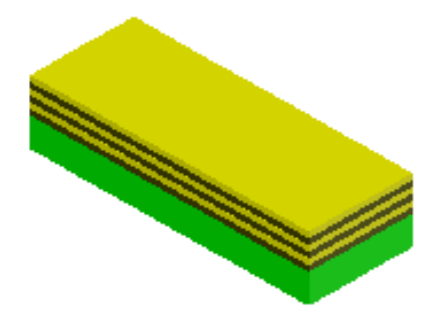

(a)

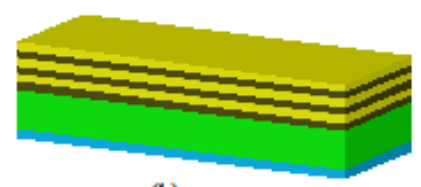

(b)

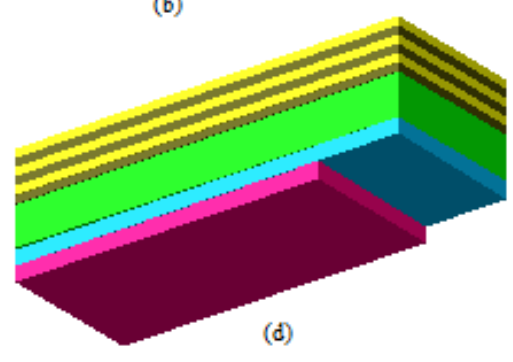

(c)

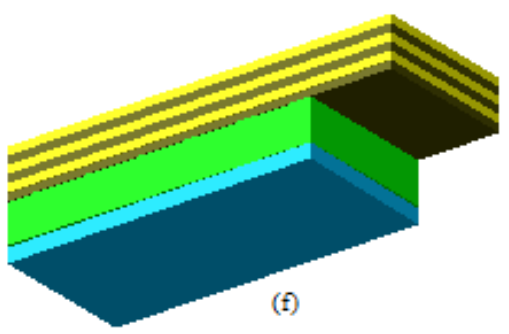

Figura 3.19 -(a) Deposição de filtro multicamada; (b) Deposição da camada de cromo; (c) Deposição de fotoressiste; (d) Fotogravação; (e) Corrosão do cromo; (f) Corrosão do substrato de silício por $\mathrm{KOH}$.

Este filtro foi construído de forma a se obter as mesmas características do filtro sobre Corning Glass, através da corrosão do substrato de silício, construindo-se desta forma um filtro que seja adaptado às técnicas de fabricação da microeletrônica. Primeiramente multicamadas de nitreto e óxido de silício foram depositadas sobre uma das faces, posteriormente uma fina camada de cromo foi depositada na face oposta da lâmina, em seguida foi depositada uma fina camada de cromo 0,1 $\mu \mathrm{m}$ com o uso de um reator de sputtering (pulverização catódica). Uma deposição de fotoressiste e uma fotogravação foram realizados com o intuito de definir a região onde foi realizada a corrosão do cromo que serviu de máscara para a corrosão da lâmina de silício por $\mathrm{KOH}$ definindo desta forma um filtro suspenso. Após a corrosão não foi realizada a remoção do cromo, pois ele serviria para transmitir melhor o calor pela lâmina e o filtro durante o aquecimento e um processo de corrosão seria prejudicial ao filtro, pois poderia ocasionar quebras ou rachaduras na fina camada suspensa. Não ocorrem problemas com estresse nesta estrutura pois o óxido de silício e o nitreto de silício tem características opostas de contração e distensão e os efeitos se equilibram em um sistema multicamada. 


\section{Capítulo 4 - RESULTADOS EXPERIMENTAIS E DISCUSSÕES}

\subsection{INTRODUÇÃO}

Neste capítulo serão mostrados os testes realizados e os resultados obtidos para os filtros que foram construídos. Primeiramente serão mostrados os filtros fabricados sobre vidro Corning Glass (7059), e os testes como sensor de temperatura e sensor angular. Depois serão mostrados os testes para sensor térmico do filtro depositado sobre silício. E finalmente os testes como sensor angular para o filtro suspenso.

\subsection{FILTROS DEPOSITADOS SOBRE CORNING GLASS (7059)}

Como explicado no capítulo anterior, esses dispositivos foram depositados em PECVD alternando-se os gases da deposição de forma a depositar camadas com diferentes índices de refração e com espessuras específicas (Filtros verticais).

\subsubsection{FILTRO 1}

O primeiro filtro fabricado sobre Corning Glass chamaremos de filtro 1. Os parâmetros utilizados na deposição em PECVD do filtro 1 estão mostrados na Tabela 4.1. Basicamente, o filtro 1 é composto de 9 camadas, sendo as camadas ímpares formadas de nitreto de silício e as camadas pares de óxido de silício numeradas desde o substrato para o meio ambiente. 
Tabela 4.1 - Características da deposição em PECVD do filtro 1.

\begin{tabular}{|c|c|}
\hline Filtro 1 & \\
\hline Substrato: & Corning Glass (7059) \\
\hline Número de Camadas: & 9 \\
\hline Temperatura de Deposição: & $320^{\circ} \mathrm{C}$ \\
\hline Pressão de Alto Vácuo (Torr): & $3,7 \times 10-5$ \\
\hline Potência Aplicada (W): & 200 \\
\hline Potência Refletida (W): & 23 \\
\hline Espessura total do filtro programada $(\mathrm{nm})$ : & 2800 \\
\hline Espessura das camadas de nitreto de silício $(\mathrm{nm})$ : & 291 \\
\hline Espessura das camadas de óxido de silício (nm): & 340 \\
\hline Comprimento de onda central do lóbulo principal (nm) & 680 \\
\hline Largura do lóbulo principal $(\mathrm{nm})$ & 80 \\
\hline Transmitância mínima (\%) & 31 \\
\hline Gases (camadas pares) & Fluxo (sccm) \\
\hline $\mathrm{SiH}_{4}$ & 30 \\
\hline $\mathrm{N}_{2} \mathrm{O}$ & 75 \\
\hline Gases (camadas ímpares) & Fluxo (sccm) \\
\hline $\mathrm{SiH}_{4}$ & 30 \\
\hline $\mathrm{N}_{2}$ & 75 \\
\hline
\end{tabular}

O resultado da transmitância (\%) em função do comprimento de onda, obtidos através do espectrofotômetro Shimadzu, é mostrado na Figura 4.1 (curva em vermelho). Estas medidas foram feitas para uma incidência de luz à $0^{\circ}$ graus de inclinação, ou seja, perpendicular ao filtro. Também nesta mesma figura é colocada a transmitância simulada em função do comprimento de onda baseada no programa desenvolvido neste trabalho (curva em preto). 


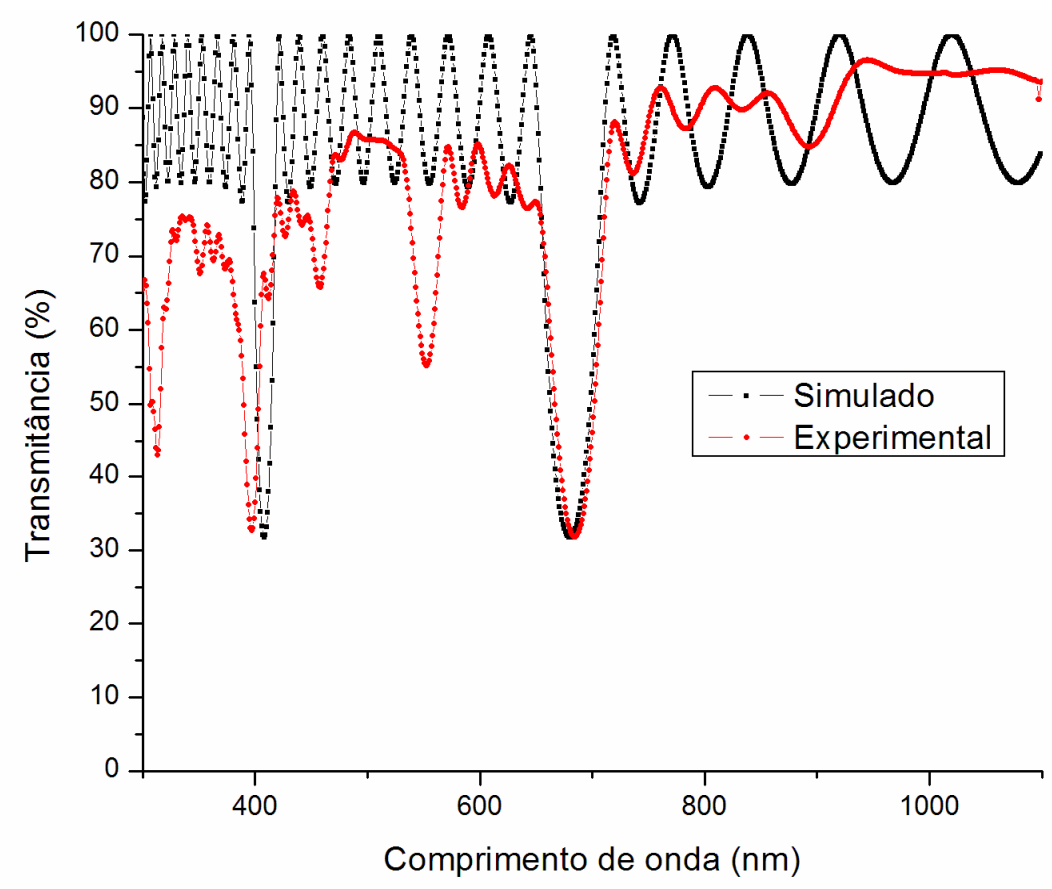

Figura 4.1 - Transmitância (\%) em função do comprimento de onda para o filtro 1.

As camadas foram projetadas com uma espessura específica de forma a atenuar mais fortemente em torno de um determinado comprimento de onda. No caso do filtro 1 este comprimento é 680nm e é dependente das espessuras das camadas de óxido de silício e nitreto de silício que também estão mostradas na Tabela 4.1. Existe outro lóbulo com a mesma atenuação de transmitância que o lóbulo principal no projeto deste filtro, e ele se localiza à $410 \mathrm{~nm}$ isso se deve ao m (variável descrita no capítulo 2 parte 3), causando desta forma aparecimento de outros lóbulos. Outros dados da deposição em PECVD como a potência aplicada pelo $R F(200 \mathrm{~W})$, a potência refletida ( $23 \mathrm{~W})$, pressão de alto vácuo $\left(3,7 \times 10^{-5} \mathrm{Torr}\right)$ e a temperatura $\left(320^{\circ} \mathrm{C}\right)$ também são mostrados e são parâmetros importantes pois sua variação deve ser pequena durante a deposição para que haja uniformidade na espessura das camadas depositadas e dessa forma se obtenha um filtro de boa qualidade. Outro dado mostrado na tabela é a largura do lóbulo principal $(80 \mathrm{~nm})$ que também depende da espessura das camadas depositadas como foi mostrado no capítulo 2. A transmitância mínima mostrada na Tabela 4.1 trata do valor da transmitância em 680nm (lóbulo principal).

Como pode-se perceber o filtro simulado não condiz perfeitamente com 0 experimental, isso se deve principalmente neste caso ao uso de pequenas garras para que ele fosse preso na placa de cobre do reator de PECVD durante a 
deposição. Estas garras interferem na deposição em regiões próximas a ela, deixando os filmes desuniformes a diferença entre as espessuras nas varias regiões do filtro é de aproximadamente $200 \mathrm{~nm}$. Isso pode ser percebido pelo colorido característico (Figura 4.2) deste filtro que mostra a reflexão de vários comprimentos de onda diferentes em torno do visível. A medida foi realizada de forma que a incidência de luz se desse na região mais próxima ao centro do filtro e desta forma se concentrasse a luz incidente em um a região mais homogênea de material depositado.

Os lóbulos secundários do filtro também não acompanham o projetado isso se deve às imperfeições causadas pelas garras durante a deposição e impurezas que podem ter se depositado no filtro durante os processos.

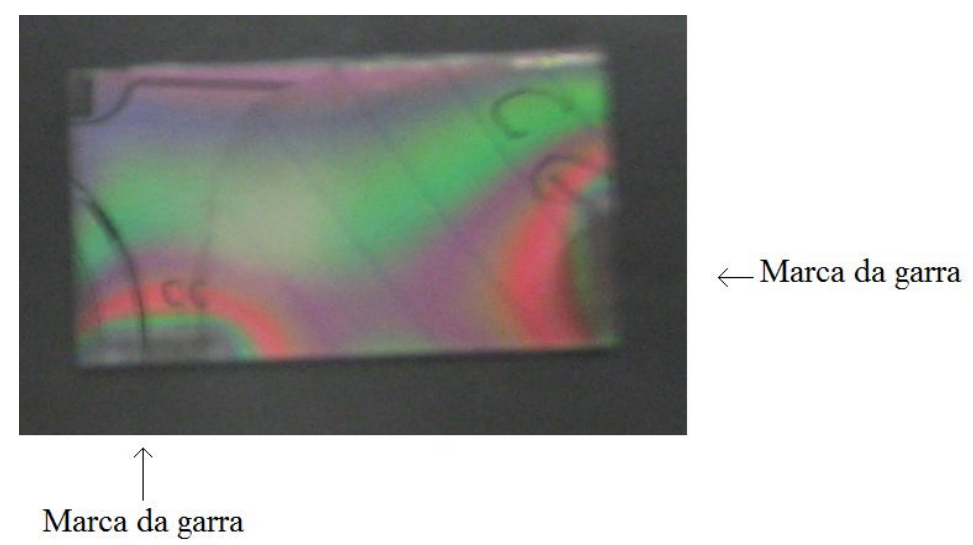

Figura 4.2 - Foto do filtro 1 onde se pode perceber a reflexão da luz branca sobre sua superfície e seu colorido característico e as regiões onde foram colocadas as garras para que o substrato fosse preso ao reator.

\subsubsection{FILTRO 2}

Na Tabela 4.2 abaixo estão mostrados os parâmetros de deposição do filtro 2, que também possui 9 camadas como o filtro 1. Contudo este filtro foi projetado para possuir apenas um lóbulo de maior atenuação na região de estudo (300nm $1100 \mathrm{~nm})$. Pode ser observado também na Tabela 4.2 que existe uma pequena diferença em relação ao filtro 1 na pressão de alto-vácuo e na potência refletida, o que não afeta a deposição de maneira significativa. 
Tabela 4.2 - Características da deposição em PECVD do filtro 2.

\begin{tabular}{|c|c|}
\hline Filtro 2 & \\
\hline Substrato: & Corning Glass (7059) \\
\hline Número de Camadas: & 9 \\
\hline Temperatura de Deposição: & $320^{\circ} \mathrm{C}$ \\
\hline Pressão de Alto Vácuo (Torr): & $4,2 \times 10-6$ \\
\hline Potência Aplicada (W): & 200 \\
\hline Potência Refletida (W): & 24 \\
\hline Espessura total do filtro programada $(\mathrm{nm})$ : & 592 \\
\hline Espessura das camadas de nitreto de silício $(\mathrm{nm})$ : & 58 \\
\hline Espessura das camadas de óxido de silício (nm): & 75 \\
\hline Comprimento de onda central do lóbulo principal (nm) & 450 \\
\hline Largura do lóbulo principal (nm) & 175 \\
\hline Transmitância minima (\%) & 25 \\
\hline Gases (camadas pares) & Fluxo (sccm) \\
\hline $\mathrm{SiH}_{4}$ & 30 \\
\hline $\mathrm{N}_{2} \mathrm{O}$ & 75 \\
\hline Gases (camadas ímpares) & Fluxo (sccm) \\
\hline $\mathrm{SiH}_{4}$ & 30 \\
\hline $\mathrm{N}_{2}$ & 75 \\
\hline
\end{tabular}

Durante a sua deposição não foram usadas garras para prender a amostra no porta-substrato. Em vez disso, esse dispositivo foi preso à placa de cobre do reator utilizando graxa de vácuo (Dow Corning high vacuum grease, que é inerte e resistente ao aquecimento). Dessa forma ele não possui o colorido característico do filtro 1, como pode-se perceber pela Figura 4.3, (apenas sujeira provocada pelo aquecimento da graxa de vácuo) a uniformidade em sua cor ocorre pois o fluxo de gases fica uniforme sobre o Corning Glass durante a deposição. 


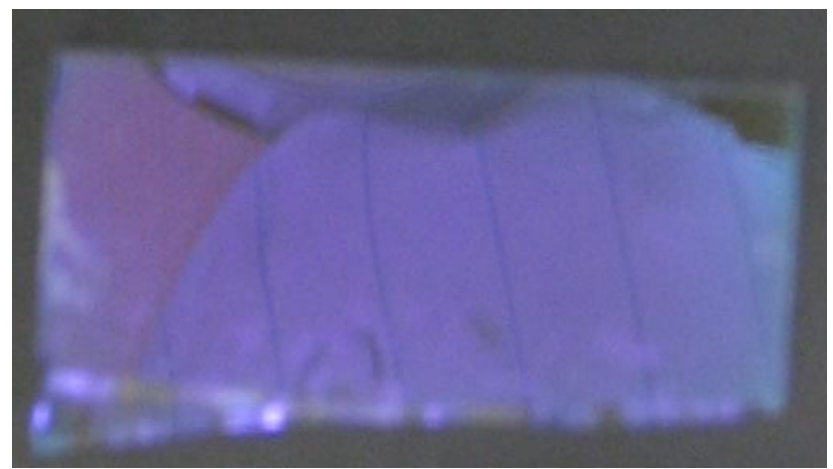

Figura 4.3 - Foto do filtro 2 onde se pode perceber a reflexão da luz branca sobre sua superfície.

$\mathrm{Na}$ Figura 4.4 é mostrada a transmitância experimental em função do comprimento de onda (curva em vermelho). Também nesta mesma figura é colocada a transmitância simulada em função do comprimento de onda baseada no programa desenvolvido neste trabalho (curva em preto).

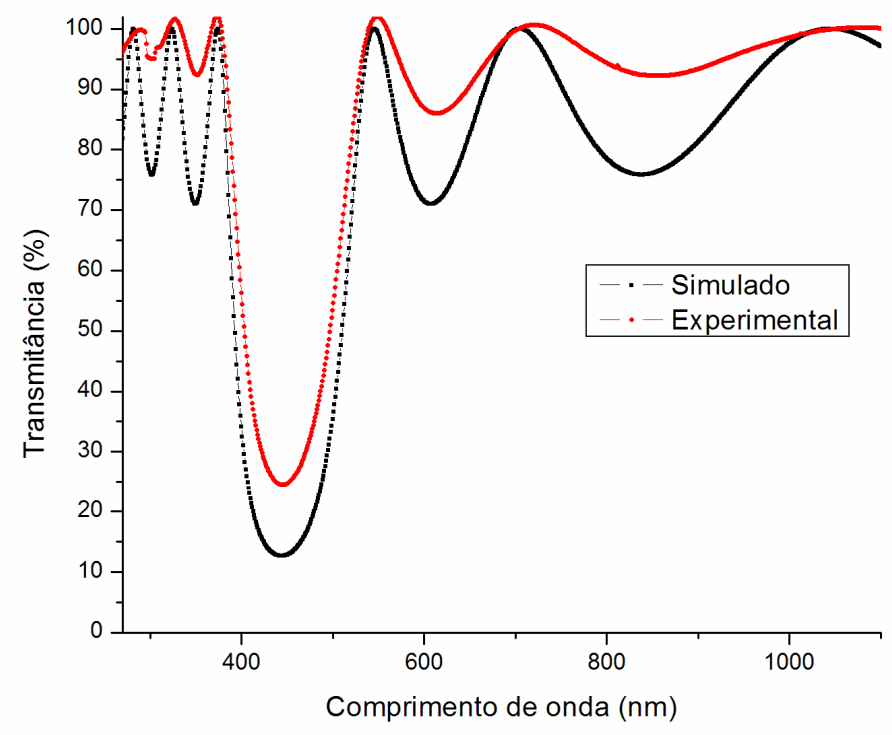

Figura 4.4 - Transmitância (\%) em função do comprimento de onda para o filtro 2.

Vemos pela Figura 4.4 que a curva experimental está mais similar que a curva simulada quando comparada com a Figura 4.1 (do filtro 1), e isso se deve ao uso da graxa de vácuo ao invés da garra. Com isso, imperfeições maiores como as que ocorreram no filtro 1 não são encontradas. Contudo, esse filtro também apresenta lóbulos (tanto o principal como os secundários) com menor atenuação do que o projetado, existe uma diferença de aproximadamente $13 \%$ entre os lóbulos principais 
simulado e experimental, isso se deve a influencia do substrato de vidro na transmitância total do filtro que não foi considerada nas simulações. Um problema na deposição do filtro 2 é que a contaminação gerada no uso de graxa de vácuo inviabiliza que qualquer outro processo de microeletrônica possa ser realizado dentro de uma sala limpa com este dispositivo pois ela engordura materiais utilizados na limpeza. A limpeza do filtro 2 feita após a deposição foi realizado em separado e o recipiente utilizado foi descontaminado novamente para que pudesse ser re-utilizado. Mesmo após a limpeza não é possível que se realizem outros processos com esse dispositivo dentro da sala limpa.

\subsubsection{FILTRO 3}

O filtro 3, mostrado neste tópico, foi projetado com 19 camadas. Neste caso, ele possui camadas mais finas de modo a atenuar comprimentos de onda que estão na faixa de $360 \mathrm{~nm}$, como pode ser visto pela Figura 4.5 , onde não há reflexão de nenhum comprimento de onda visível.

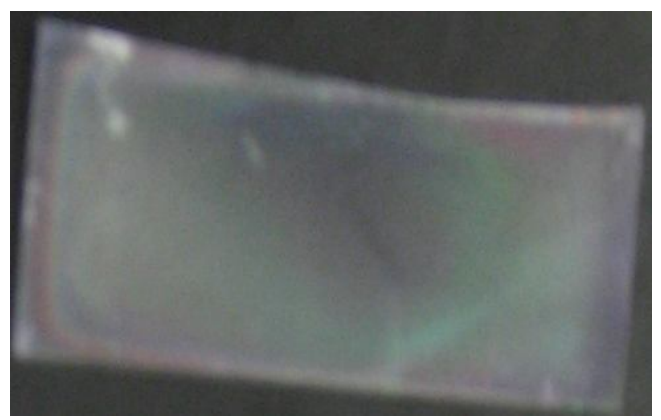

Figura 4.5 - Foto do filtro 3 onde se pode perceber a reflexão da luz branca sobre sua superfície.

Com este grande número de camadas se obtiveram resultados melhores para o lóbulo principal (Figura 4.6), com maior atenuação (transmitância mínima de 3\%) e melhor similaridade com as simulações. Os lóbulos secundários continuam com uma atenuação menor o qual, como foi dito anteriormente, pode ser devido a impurezas e imperfeições do filtro. 


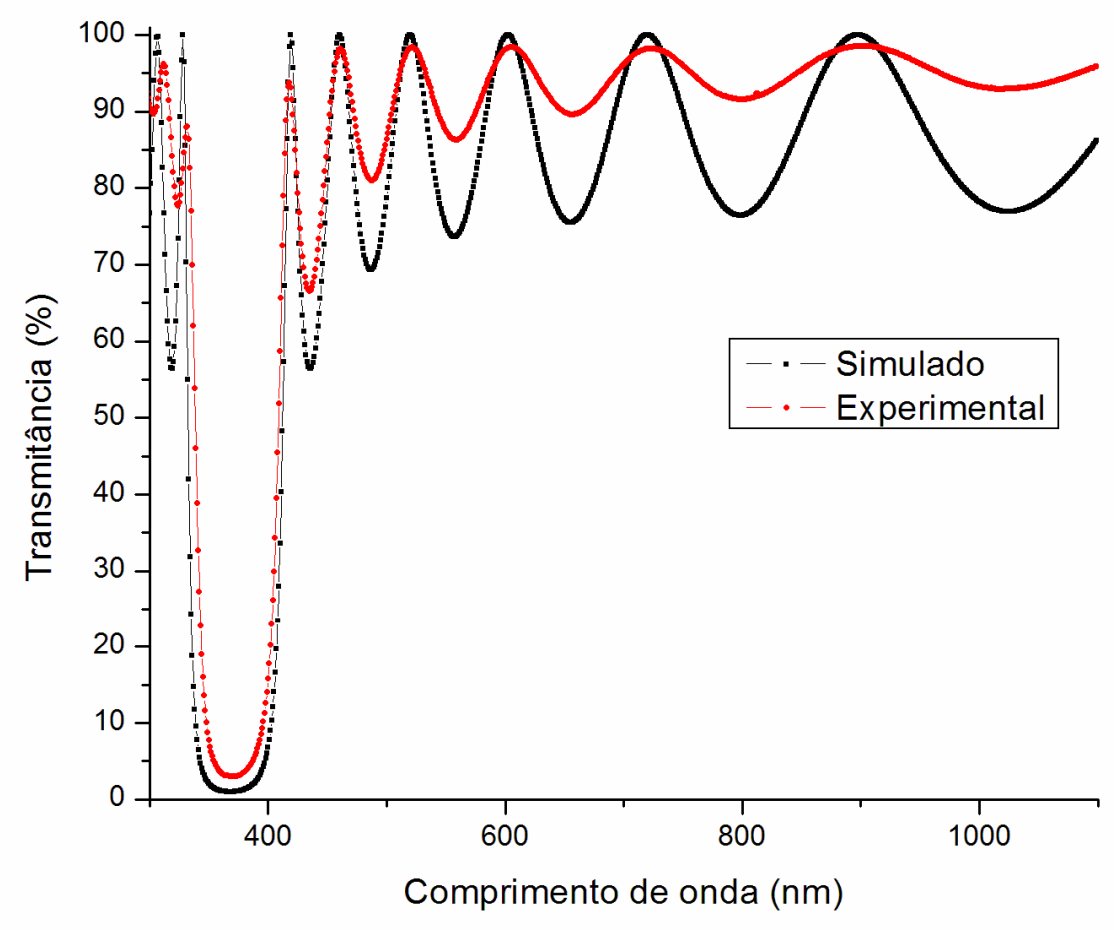

Figura 4.6 - Transmitância (\%) em função do comprimento de onda para o filtro 3.

Suas características de deposição (temperatura, potência refletida, pressão de alto-vácuo) também não variam muito em relação aos dois filtros anteriores e estão mostradas na Tabela 4.3. 
Tabela 4.3 - Características da deposição em PECVD do filtro 3.

\begin{tabular}{||l|r||}
\hline Filtro 3 & \multicolumn{1}{|c||}{ Corning Glass (7059) } \\
\hline Substrato: & $320^{\circ} \mathrm{C}$ \\
\hline Número de Camadas: & $3,9 \times 10-5$ \\
\hline Temperatura de Deposição: & 200 \\
\hline Pressão de Alto Vácuo (Torr): & 24 \\
\hline Potência Aplicada (W): & 1093 \\
\hline Potência Refletida (W): & 48 \\
\hline Espessura total do filtro programada (nm): & 62 \\
\hline Espessura das camadas de nitreto de silício (nm): & 360 \\
\hline Espessura das camadas de óxido de silício (nm): & 175 \\
\hline Comprimento de onda central do lóbulo principal (nm) & 3 \\
\hline Largura do lóbulo principal (nm) & \\
\hline Transmitância mínima (\%) & Fluxo (sccm) \\
\hline Gases (camadas pares) & \\
\hline SiH & \\
\hline $\mathrm{N}_{2} \mathrm{O}$ & \multicolumn{2}{|c||}{ Fluxo (sccm) } \\
\hline Gases (camadas ímpares) & \\
\hline SiH & \\
\hline $\mathrm{N}_{2}$ & \\
\hline \hline
\end{tabular}

No filtro 3 também foi usada graxa de vácuo gerando o problema de contaminação já citado para o filtro 2. Por possuir um número superior de camadas (19) em comparação com o filtro 2 e 1 (9), o filtro 3 tem uma seletividade maior, a diferença de atenuação entre o lóbulo principal e o maior lóbulo secundário é de aproximadamente $70 \%$, o filtro 3 possui também e uma boa similaridade com a simulação pois a diferença de transmitância, entre o lóbulo principal simulado e o experimental é de aproximadamente $1,5 \%$ isso ocorre pois o efeito do vidro não foi considerado nas simulações. O filtro 3 possui camadas finas e desta forma não realiza uma variação notável com a temperatura através do efeito termo-óptico, como foi mostrado no capítulo 2 na Figura 2.16 é necessário um "m grande", ou seja, uma espessura de camadas maior para se obter um efeito termo-óptico apreciável, no caso do filtro 3 a variação transmitância (\%) por grau ${ }^{\circ} \mathrm{C}$ não chega a $0,1 \% /{ }^{\circ} \mathrm{C}$ pelas simulações. Desta forma é necessário que se crie um filtro que possua o maior número de camadas possível se o interesse for obter mais seletividade na banda filtrada, e com camadas mais grossas possíveis para que se 
possa obter mais variação através do efeito termo-óptico, mas não tão grossas, pois o filme perde qualidade quando chega próximo ao limite de espessura da técnica de PECVD $(10 \mu \mathrm{m})$ e aparecem outros lóbulos com mesma atenuação que o lóbulo principal na faixa de comprimentos de onda de estudo (300 nm - $1100 \mathrm{~nm}$ ) (para camadas que tenham "m's" maiores como foi visto no capitulo 2 surgem mais ou menos destes lóbulos de mesma atenuação que o principal na faixa de estudo isso depende também dos outro parâmetros do filtro) e desta forma perde-se seletividade de banda. Também é necessário que não use graxa de vácuo para não apresentar problemas de contaminação e que ao mesmo tempo não apresente os defeitos e imperfeições das garras de cobre. Essas são as variáveis do processo, ao otimizálas pode-se obter um filtro o mais seletivo possível, com apenas um lóbulo de mesma atenuação que o lóbulo principal na faixa de estudo, e desta forma obter-se um bom filtro ou pode-se construí-lo com camadas mais grossas para realizar-se variação através do efeito termo-óptico obter-se um bom sensor. No filtro 4 abaixo temos ambos dispositivo que funciona como um filtro e como um sensor.

\subsubsection{FILTRO 4}

Tendo observado os filtros anteriores e sabendo dos defeitos e imperfeições gerados pelas garras, como também da contaminação gerada pela graxa de vácuo (essa contaminação foi percebida pois a graxa não se dispersava completamente das amostras com as limpezas padrões realizadas), assim como da necessidade de se aproveitar o efeito termo-óptico utilizando-se camadas grossas (como foi mostrado no capítulo 2), e considerando-se os limites de espessura dos filmes depositados por PECVD, foi realizada a deposição do filtro 4, que possui 13 camadas com uma espessura maior em cada camada e atingindo uma espessura total de $1,4 \mu \mathrm{m}$.

Na Figura 4.7 temos um filtro projetado em que uma das pontas do lóbulo principal se situa numa freqüência próxima a $633 \mathrm{~nm}$, este filtro foi usado como sensor angular e como sensor térmico na bancada óptica sob atuação de um laser de He-Ne de $633 \mathrm{~nm}$. 


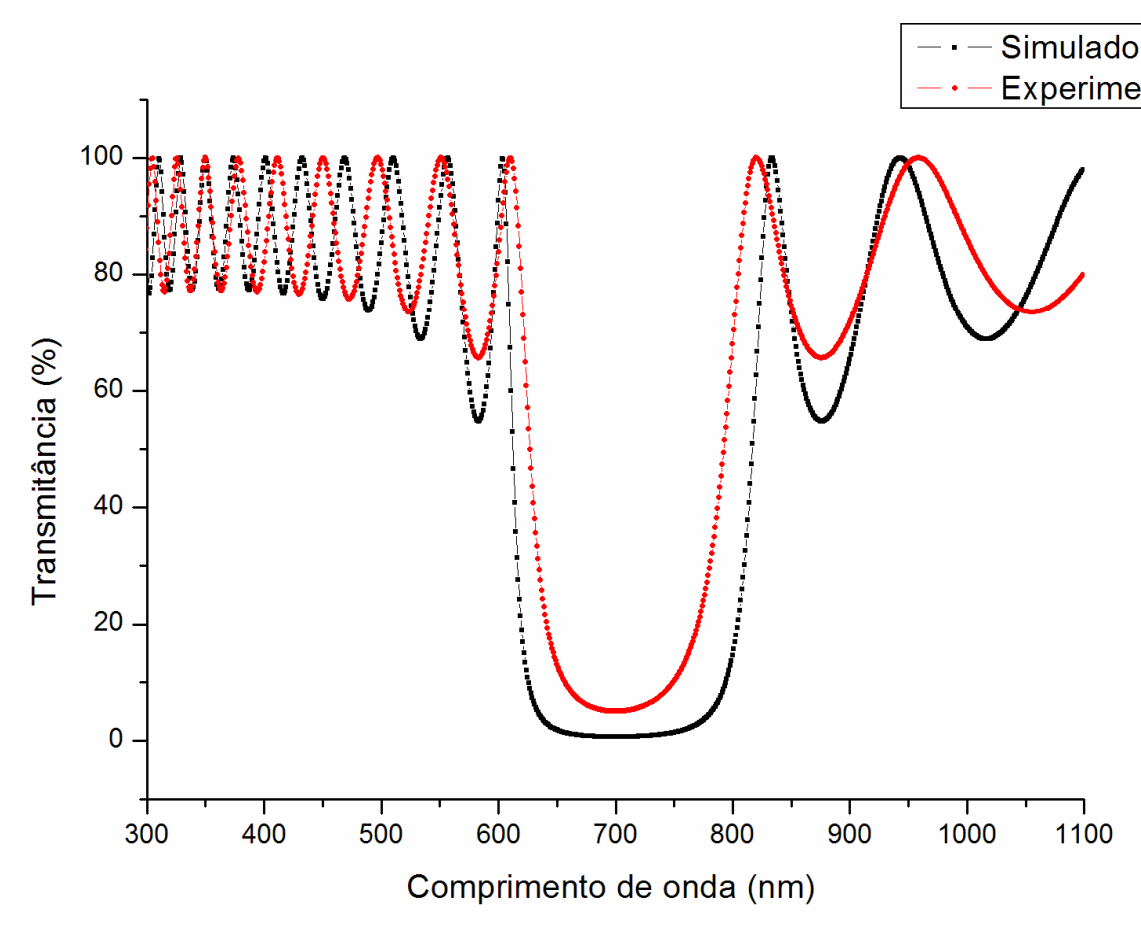

Figura 4.7 - Transmitância (\%) em função do comprimento de onda para o filtro 4.

Também foram usadas garras para prender o filtro 4 no reator, contudo estas novas garras possuem pontas mais finas e são mais alongadas fazendo com que 0 filtro tenha uma área útil maior (Figura 4.8), isso pode ser observado pelo fato de o colorido se estabilizar em um vermelho contínuo na parte do filtro mais distante da posição onde foi colocada a garra e desta forma tem-se um filtro com uma boa parte útil e livre de contaminação.

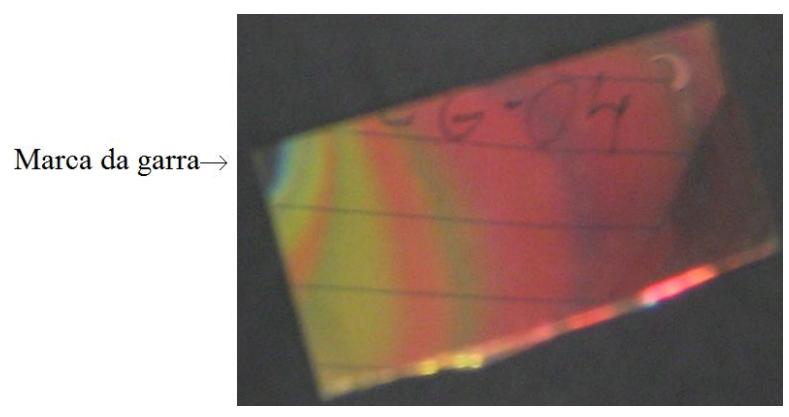

Figura 4.8 - Foto do filtro 4 onde se pode perceber a reflexão da luz branca sobre sua superfície, o colorido se limita ao laranja e ao vermelho e se estabiliza ao se distanciar da marca da garra, tendo-se uma área útil muito maior para a realização de testes.

Na Tabela 4.4 estão mostradas as características da deposição, os parâmetros (pressão, temperatura, potência) são muito parecidos com os dos outros filtros, a 
diferença entre simulado e experimental no pico do lóbulo principal é iqual a $5 \%$ e o comprimento de onda central do lóbulo principal é de 700nm.

Tabela 4.4 - Características da deposição em PECVD do filtro 4.

\begin{tabular}{||l|l||}
\hline Filtro 4 & Corning Glass (7059) \\
\hline Substrato: & 13 \\
\hline Número de Camadas: & $320^{\circ} \mathrm{C}$ \\
\hline Temperatura de Deposição: & $3,2 \times 10-5$ \\
\hline Pressão de Alto Vácuo (Torr): & 200 \\
\hline Potência Aplicada (W): & 23 \\
\hline Potência Refletida (W): & 1400 \\
\hline Espessura total do filtro programada(nm): & 87,5 \\
\hline Espessura das camadas de nitreto de silício (nm): & 125 \\
\hline Espessura das camadas de óxido de silício (nm): & 700 \\
\hline Comprimento de onda central do lóbulo principal (nm) & 200 \\
\hline Largura do lóbulo principal (nm) & 5 \\
\hline Transmitância mínima (\%) & Fluxo (sccm) \\
\hline Gases (camadas pares) & 30 \\
\hline SiH $_{4}$ & 75 \\
\hline $\mathrm{N}_{2} \mathrm{O}$ & Fluxo (sccm) \\
\hline Gases (camadas ímpares) & 30 \\
\hline $\mathrm{SiH}_{4}$ & 75 \\
\hline $\mathrm{N}_{2}$ & \\
\hline
\end{tabular}

Os lóbulos obtidos experimentalmente apresentam atenuações menores do que o projetado o qual se deve à interferência do vidro que não foi considerado na simulação. Há também para este filtro uma pequena diferença de fase entre o experimental e o simulado isso se deve à garra utilizada que apesar de melhorada ainda deixou esta pequena imperfeição. 


\subsection{FILTRO DEPOSITADO SOBRE SILÍCIO (FILTRO HORIZONTAL)}

Esses dispositivos foram depositados em PECVD alternando-se os gases da deposição de forma a depositar 3 camadas com diferentes índices de refração sendo a primeira e a terceira camadas de óxido de silício $(1,5 \mu \mathrm{m})$ e a segunda camada de nitreto de silício $(3 \mu \mathrm{m})$ sobre silício cristalino $<100>$. As etapas de fabricação desta estrutura já foram explicadas no capítulo 3 deste trabalho e uma foto desta estrutura é mostrada na Figura 4.9.

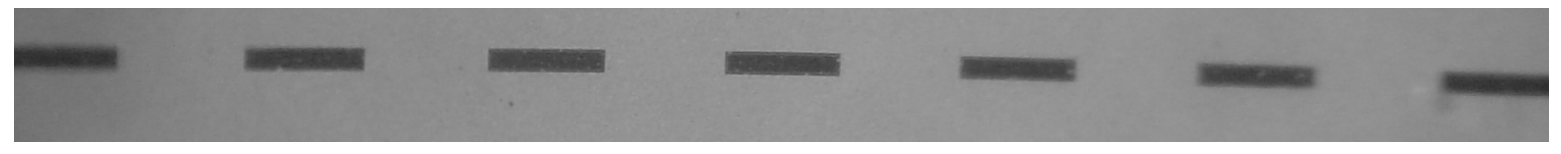

Figura 4.9 - Foto do filtro sobre silício.

O filtro horizontal construído sobre silício foi submetido a testes térmicos que são mostrados no item 4.4.5. Os parâmetros de deposição (pressão, temperatura, potência) deste filtro são semelhantes aos dos filtros sobre Corning Glass (Tabela 4.5). Neste tipo de dispositivo, a luz irá passar no sentido horizontal neste filtro e os testes serão realizados com o auxílio de fibra óptica tanto na injeção como na coleção da luz. 
Tabela 4.5 - Características da deposição do filtro sobre silício com a luz passando no sentido horizontal.

\begin{tabular}{||l|r||}
\hline \hline Filtro Horizontal & Silício $<100>$ \\
\hline Substrato: & 3 \\
\hline Número de Camadas: & $320^{\circ} \mathrm{C}$ \\
\hline Temperatura de Deposição: & $3,1 \times 10-5$ \\
\hline Pressão de Alto Vácuo (Torr): & 200 \\
\hline Potência Aplicada (W): & 6 \\
\hline Potência Refletida (W): & Fluxo (sccm) \\
\hline Expessura total das camadas $(\mu \mathrm{m}):$ & 75 \\
\hline Gases (cladding e cobertura) & Fluxo (sccm) \\
\hline SiH & 30 \\
\hline $\mathrm{N}_{2} \mathrm{O}$ & 75 \\
\hline Gases (núcleo) & 30 \\
\hline $\mathrm{SiH}_{4}$ & $\mathrm{~N}_{2}$ \\
\hline
\end{tabular}

\subsection{Filtro Depositado sobre SilícIo Fino (FILTRO SUSPENSO)}

Este filtro multicamada foi depositado sobre um substrato de silício com menor espessura $(\sim 300 \mu \mathrm{m})$ no intuito de diminuir o tempo de corrosão em $\mathrm{KOH}$ de algumas regiões desta lâmina. Na parte oposta do substrato foi depositada uma camada de cromo que serviu como máscara para a corrosão em $\mathrm{KOH}$. Este filtro foi submetido a testes térmicos e angulares. Os parâmetros de deposição são semelhantes aos dos filtros sobre vidro, contudo este filtro está adaptado às técnicas de microfabricação como fotogravação e corrosão por $\mathrm{KOH}$.

Na Tabela 4.6 estão mostradas as características da deposição, os parâmetros (pressão, temperatura, potência) são muito parecidos com os dos filtros sobre vidro, a transmitância mínima experimental obtida chega a $5 \%$ nos dois lóbulos sendo o principal localizado à $700 \mathrm{~nm}$ e os secundário à $410 \mathrm{~nm}$. 
Tabela 4.6 - Características da deposição do filtro suspenso.

\begin{tabular}{|c|c|}
\hline Filtro Suspenso & \\
\hline Substrato: & $\begin{array}{c}\text { Silicio }<100>, 300 \mu \mathrm{m} \text { de } \\
\text { espessura }\end{array}$ \\
\hline Número de Camadas: & 15 \\
\hline Temperatura de Deposição: & $320^{\circ} \mathrm{C}$ \\
\hline Pressão de Alto Vácuo (Torr): & $3,1 \times 10-5$ \\
\hline Potência Aplicada (W): & 200 \\
\hline Potência Refletida (W): & 23 \\
\hline Espessura total do filtro programada(nm): & 4700 \\
\hline Espessura das camadas de nitreto de silício $(\mathrm{nm})$ : & 275 \\
\hline Espessura das camadas de óxido de silício (nm): & 360 \\
\hline Comprimento de onda central do lóbulo principal (nm) & 700 \\
\hline Largura do lóbulo principal (nm) & 50 \\
\hline Transmitância mínima (\%) & 5 \\
\hline Gases (camadas pares) & Fluxo (sccm) \\
\hline $\mathrm{SiH}_{4}$ & 30 \\
\hline $\mathrm{N}_{2} \mathrm{O}$ & 75 \\
\hline Gases (camadas ímpares) & Fluxo (sccm) \\
\hline $\mathrm{SiH}_{4}$ & 30 \\
\hline $\mathrm{N}_{2}$ & 75 \\
\hline
\end{tabular}

Na Figura 4.10 é mostrada a foto desta estrutura onde é apontada a região suspensa.

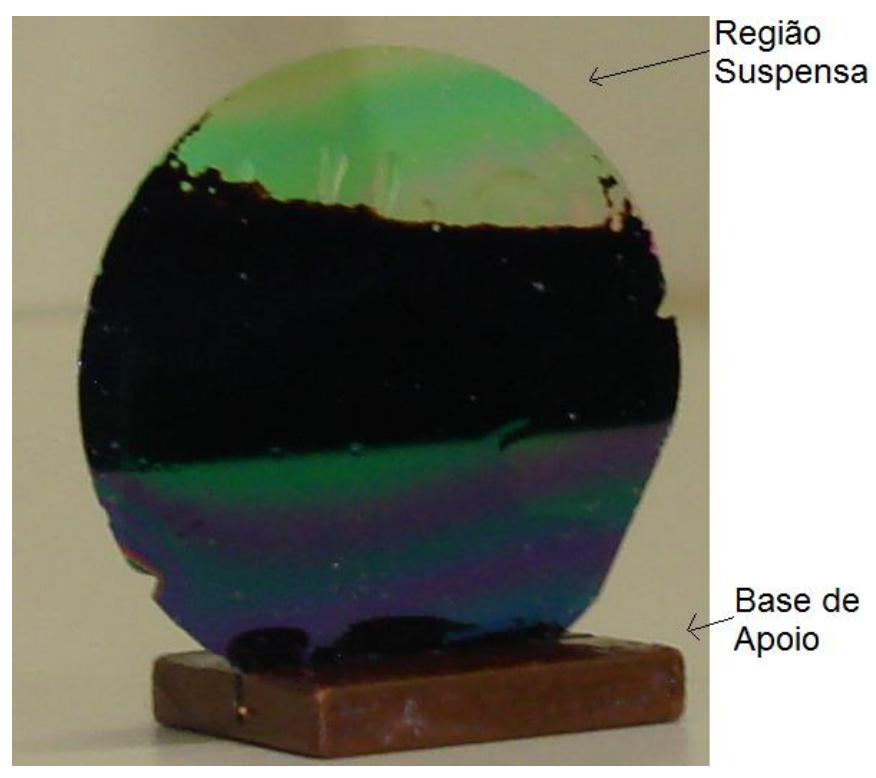

Figura 4.10 -Filtro suspenso sobre base de apoio. 
$\mathrm{Na}$ Figura 4.11 podemos apreciar a curva experimental e simulada da transmitância do Filtro suspenso em função do comprimento de onda. Como pode ser observado na figura, o filtro apresenta dois lóbulos principais, em 425 e 700 nm. O experimental e o simulado se aproximam muito (diferença do lóbulo principal simulado e experimental de menos que 0,1\%) nesta configuração, pois a luz atravessa apenas a fina multicamada depositada, e não mais o corning glass.

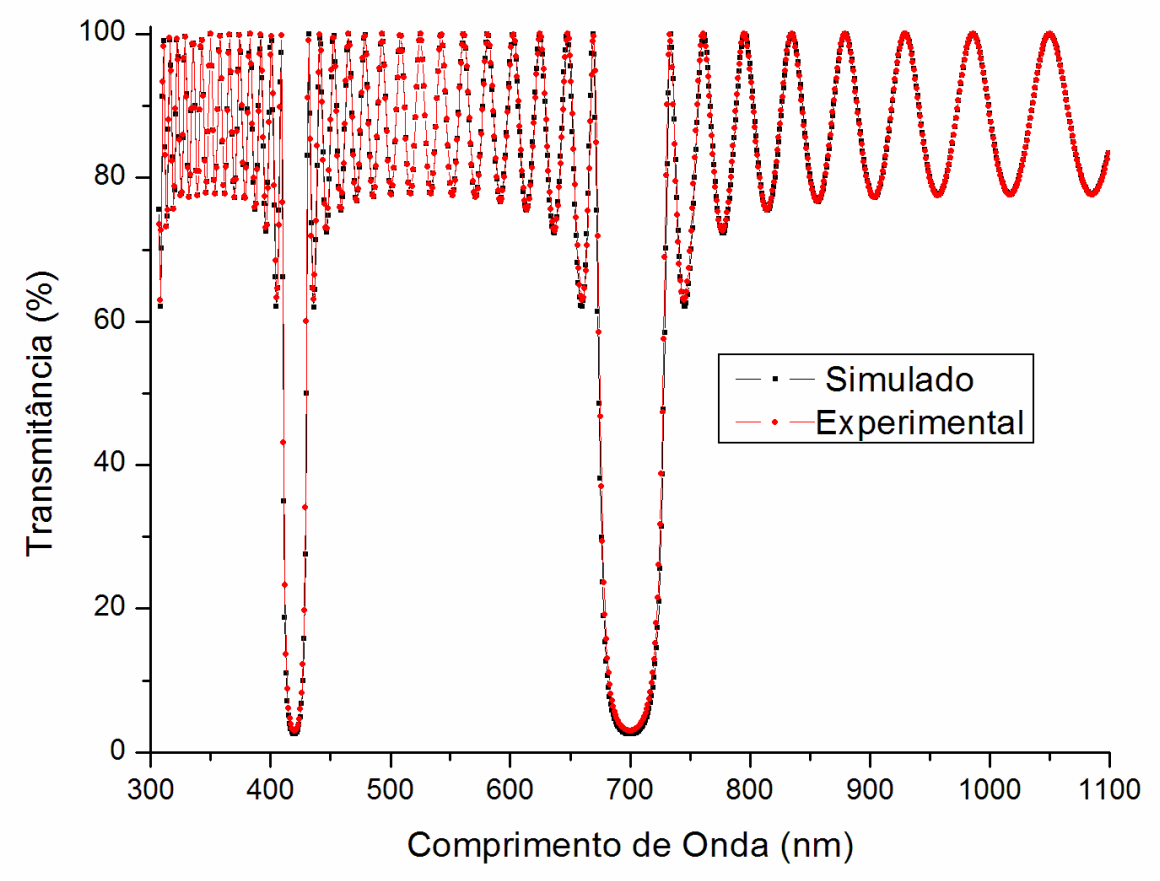

Figura 4.11 -Filtro suspenso, devidos às menores perdas deste filtro, as curvas experimental e simulada são praticamente idênticas, pois a luz passa apenas pela fina camada de filme fino PECVD.

\subsection{MoNTAGENS EXPERIMENTAIS E RESULtADOS}

Nesta etapa foram realizados testes tanto com os filtros feitos sobre Corning Glass (filtros verticais) como com os filtros feitos sobre silício (filtros horizontais). Primeiramente serão mostrados os testes angulares em seguida os testes térmicos 
dos filtros em Corning Glass e em seguida os testes térmicos do filtro depositado sobre silício.

\subsubsection{Filtro VERTICAL COMO SENSOR ANGULAR}

Para o teste angular, o filtro 4 foi submetido à incidência de luz sob diferentes ângulos dentro do espectrofotômetro, para isso foi realizada a montagem mostrada na Figura 4.12 onde pode-se perceber que é possível posicionar a lâmina como se queira através de um dispositivo simples sob uma pequena placa de cobre que possui um sulco onde o filtro é colocado, e desta forma pode-se analisar o comportamento do filtro para diversos ângulos de incidência de luz, dentro do espectrofotômetro (Figura 4.13).

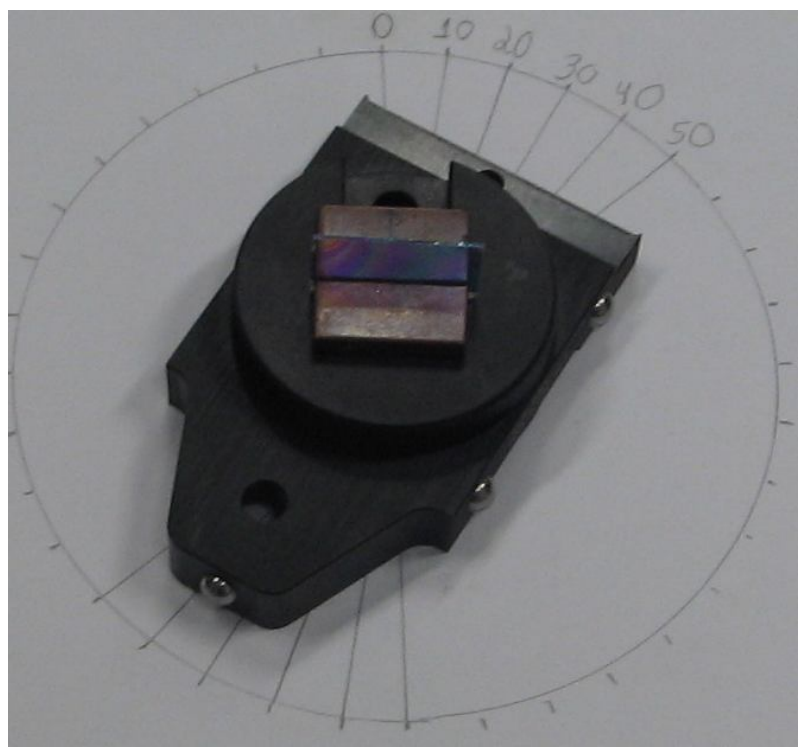

Figura 4.12 -Estrutura que permite realizar a mudança angular do filtro, em cima de esboço do circulo trigonométrico. 


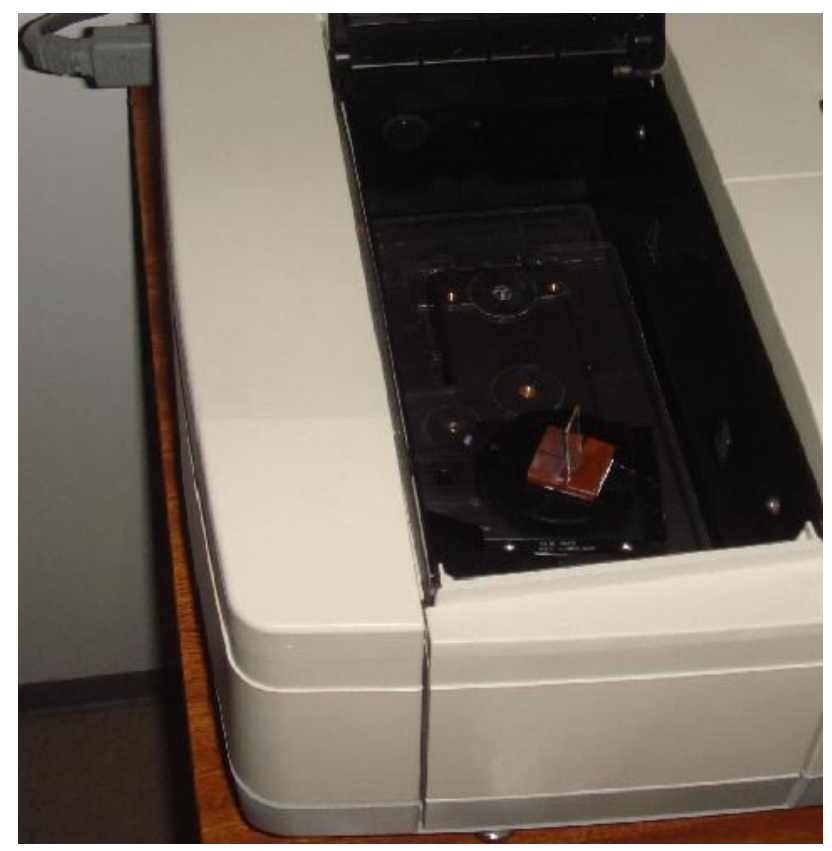

Figura 4.13 -Estrutura que permite realizar a mudança angular do filtro, dentro do espectrofotômetro.

Pelos testes realizados em diferentes ângulos, podemos ver que o lóbulo principal caminha de forma a atenuar a transmissão de comprimentos de onda menores (Figura 4.14) como foi previsto pelas simulações no capítulo 2. Percebe-se que este filtro pode ser usado como sensor angular para comprimentos de onda específicos, pois ele varia a atenuação com a mudança angular para um mesmo comprimento de onda. 


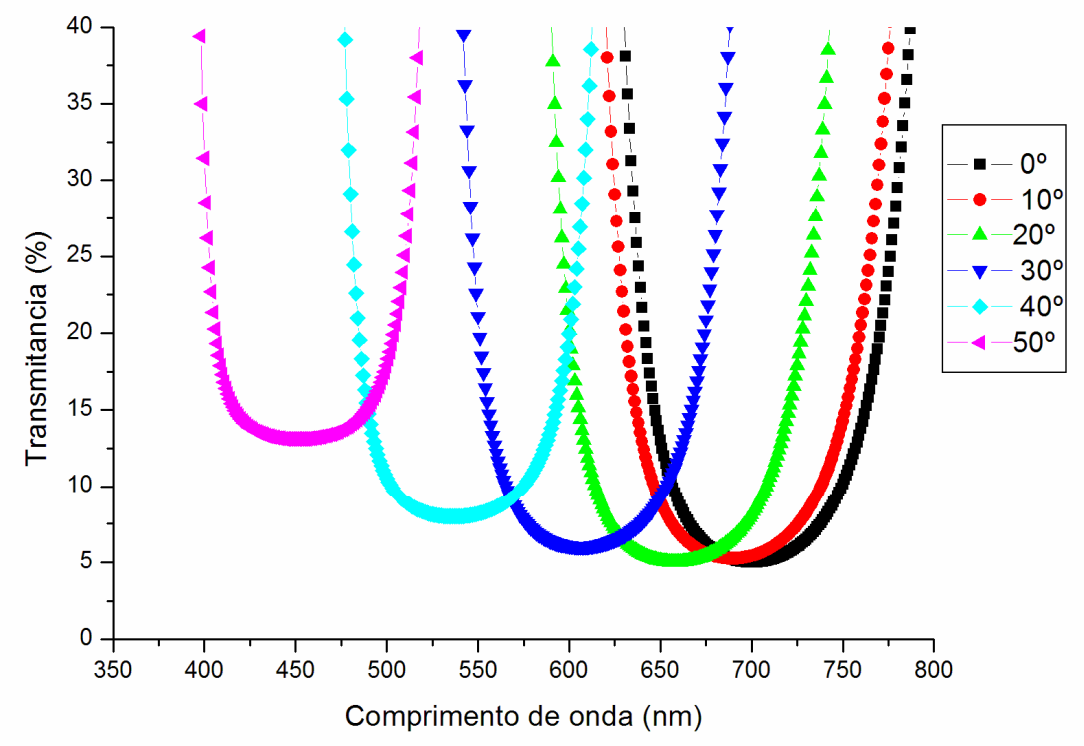

Figura 4.14 -Dados experimentais da transmitância do filtro 4 sob diferentes ângulos de incidência da luz.

Em vista disso foi feita uma nova simulação do filtro 4 tomando-se a transmitância em função do ângulo de entrada para um único comprimento de onda (633nm) obtendo-se o gráfico mostrado na Figura 4.15.

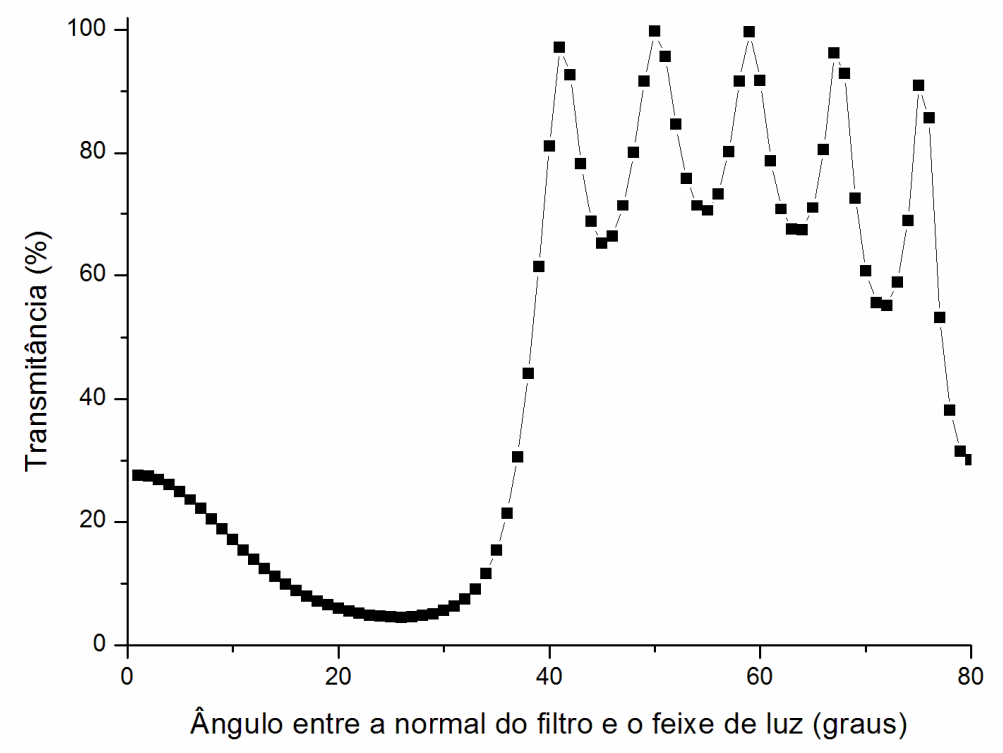

Figura 4.15 -Simulação da transmitância do filtro 4 em função do ângulo entre a normal para um feixe de luz monocromático de $633 \mathrm{~nm}$. 
Tendo este resultado simulado, decidimos testar experimentalmente o funcionamento do filtro nessa configuração no intuito de compará-lo com o resultado simulado. Para isso, uma nova montagem (Figura 4.16) foi realizada na bancada óptica do LME, onde o filtro foi posicionado em frente a um laser de He-Ne de 633 nm e movido em diferentes ângulos.

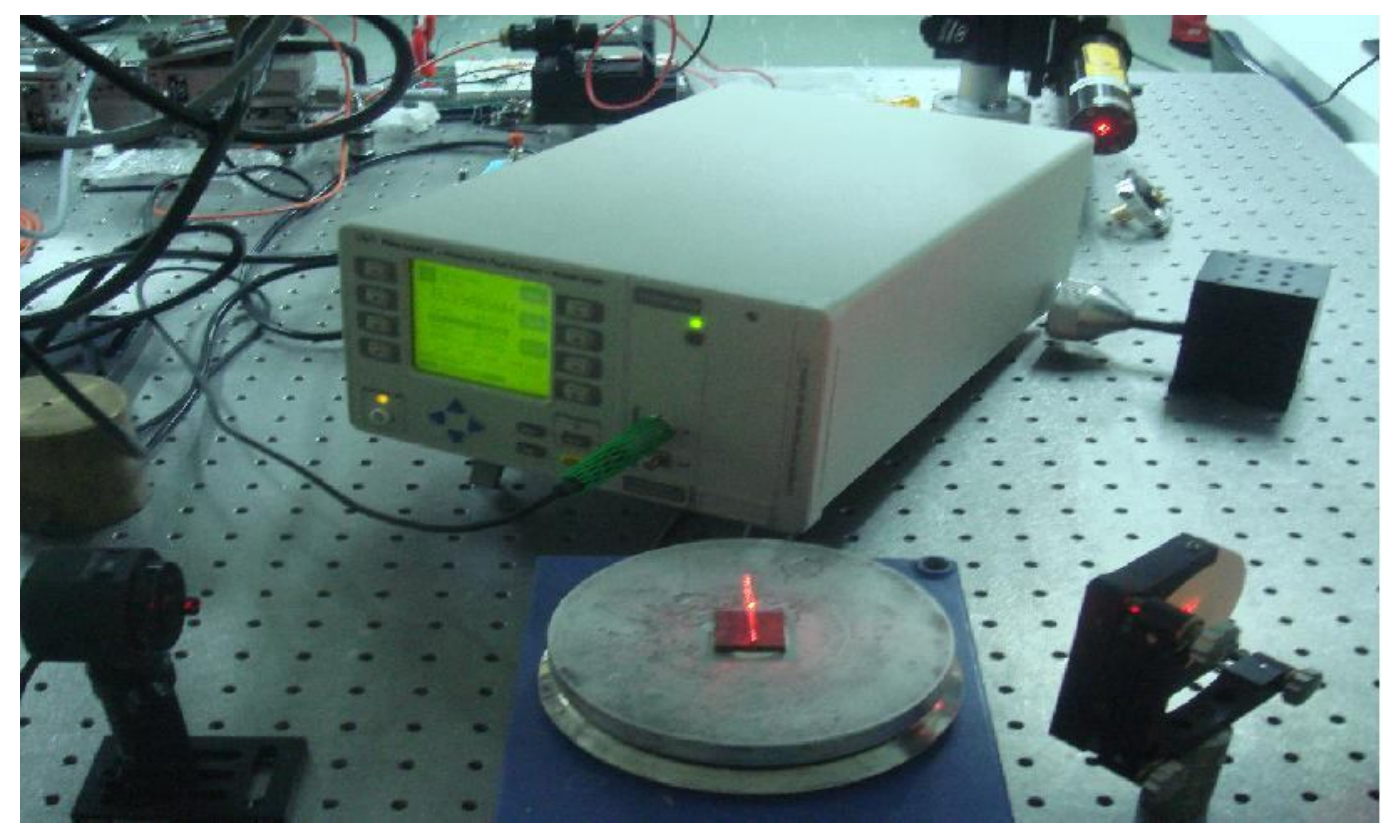

Figura 4.16 -Montagem para teste angular; à esquerda fotodetector; no centro, o filtro depositado sobre Corning Glass sobre o hot plate; à direita, o espelho; acima no centro, display óptico PTS-OPM-1 e acima à direita, o canhão do laser de 633nm.

O resultado desta caracterização é apresentado na Figura 4.17 onde aparece a potência óptica detectada $(\mathrm{mW})$ em função dos ângulos de incidência da luz em relação à normal do plano do filtro 4. 


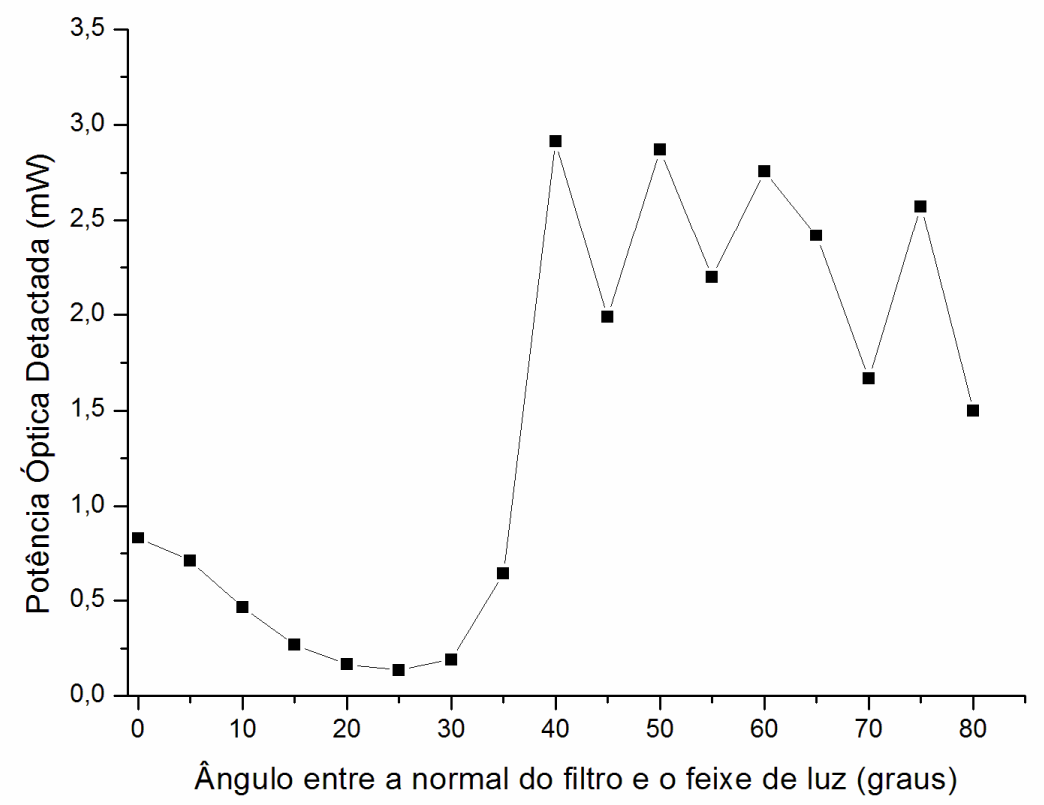

Figura 4.17 -Dados experimentais obtidos pelo teste angular, para o comprimento de onda de $633 \mathrm{~nm}$ no filtro 4 .

Comparando-se os gráficos das figuras Figura 4.17 e Figura 4.15 percebemos que eles são compatíveis, embora não tenham a mesma quantidade de picos, o qual se deve à impossibilidade de variação angular de alta precisão do experimento. Este dispositivo se mostrou eficiente como sensor angular desde que a variação da potência detectada é notável em função do ângulo.

\subsubsection{FiltRo VERTICAL COMO SENSOR DE TEMPERATURA}

Simulações no capítulo 2 mostram que para uma variação de temperatura, ocorre um deslocamento no gráfico da transmitância, com diferenças notáveis de variação no valor da transmitância para uma variação de temperatura em regiões de derivada máxima do gráfico.

Visto que os filtros possuem a capacidade de deslocamento da transmitância em função do ângulo entre a normal e o feixe de luz, esta propriedade foi utilizada para ajustar o filtro 4 (através de variação angular como foi mostrado no tópico 
anterior). Desta forma o filtro foi alinhado em um ângulo que permitisse deixar o pico de atenuação em posições próximas a 633 nm (regiões de maior derivada da transmitância), fazendo desta forma com que qualquer variação de índice de refração devido a uma variação de temperatura (efeito termo-óptico) provocasse uma variação na potência transmitida pelo filtro. Cabe destacar que isso ocorreria sempre, pois existem também os lóbulos secundários, mas para certos ângulos essa variação da transmitância em função da temperatura é mais intensa (lóbulo principal). A montagem foi a mesma que a utilizada para o teste angular (Figura 4.16), só que para este teste a amostra foi aquecida por um sistema resistivo e a variação da potência transmitida foi medida em função da temperatura para o ângulo de 38으 (ângulo onde a transmitância tem derivada alta, Figura 4.14) entre o feixe de luz e a normal do filtro, os resultados estão mostrados na Figura 4.18.

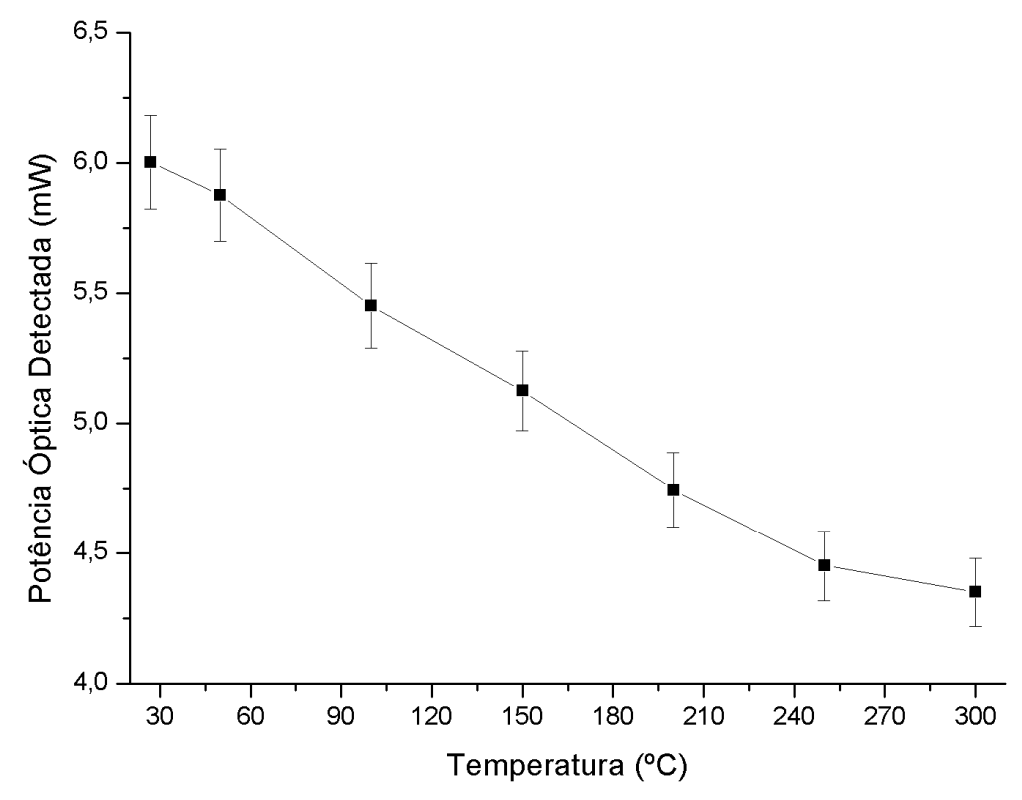

Figura 4.18 -Potência luminosa medida pelo fotodiodo em função da temperatura do filtro 4.

Podemos observar uma boa variação da potência óptica detectada em função da temperatura $\left(0,007 \mathrm{~mW} /{ }^{\circ} \mathrm{C}\right.$ ) (Figura 4.18). Este sensor pode ser usado neste ângulo específico para detectar variações de temperatura. Para um ângulo diferente ao utilizado na curva anterior terá uma variação menor, pois a transmitância será menos influenciada pela variação da temperatura. 


\subsubsection{Filtro SusPenso COMO SENSOR de ANGULAR}

O filtro suspenso construído sobre silício fino também foi submetido a testes angulares, a montagem utilizada para testá-lo na bancada óptica foi a mesma utilizada para testar o filtro 4 construído sobre vidro (Figura 4.16). O dispositivo utilizado para realizar a variação angular dentro do espectrofotômetro também é o mesmo (Figura 4.12 e Figura 4.13), como este filtro foi construído utilizando-se um substrato de silício ele está adaptado à utilização de outras técnicas de micro eletrônica como $\mathrm{KOH}$ corrosão e fotogravação diferentemente dos filtros construídos sobre Corning Glass. Abaixo estão mostrados os resultados dos testes angulares realizados com este filtro. Como podemos perceber ele se comporta atenuando comprimentos de onde menores à medida que o ângulo entre o feixe de luz e a normal ao seu plano aumenta.

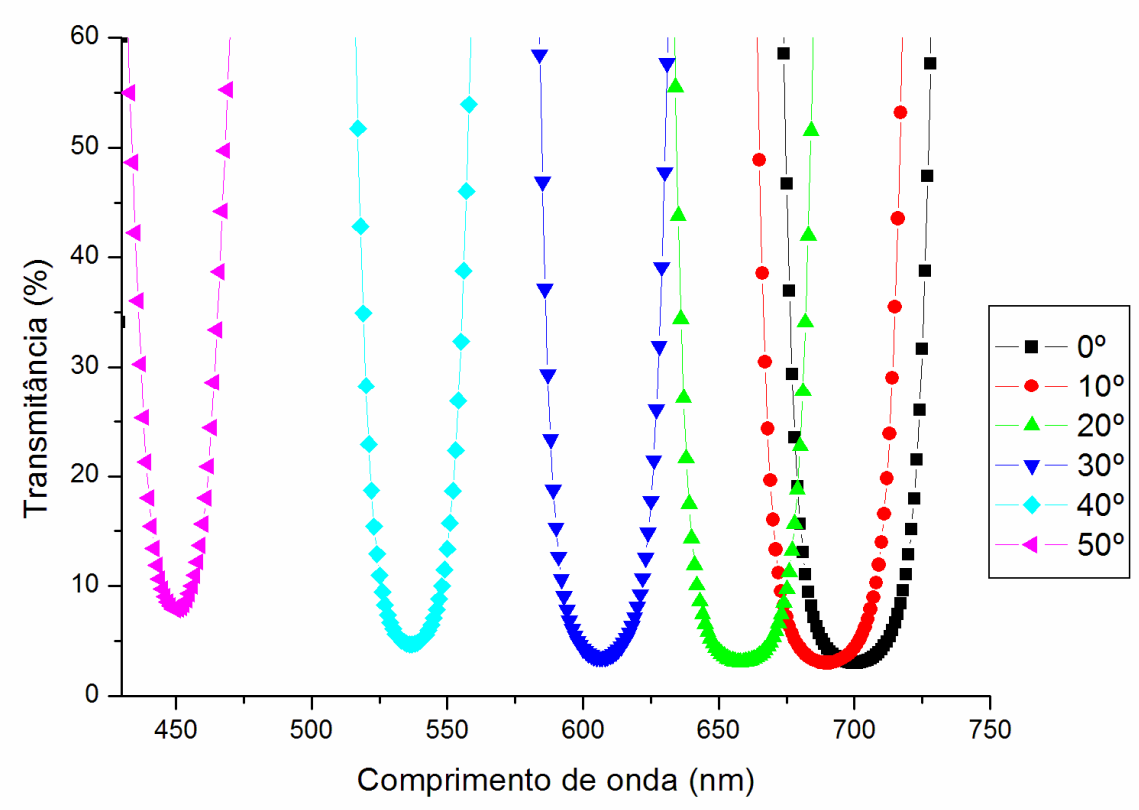

Figura 4.19 -Dados experimentais da transmitância do filtro suspenso sob diferentes ângulos de incidência da luz utilizando-se o espectrofotômetro.

Na Figura 4.20 vemos a simulação de como se comporta a transmitância da luz quando um laser de 633nm incide sob diferentes ângulos. Como podemos perceber, o lóbulo principal se encontra em torno de 25 graus de inclinação, ou seja, seria em 
torno deste ângulo a melhor posição para realizar o teste térmico, pois desta forma qualquer variação de índice de refração devido a uma variação de temperatura (efeito termo-óptico) provocaria uma maior variação na potência transmitida pelo filtro o que pelas simulações para 20 graus de inclinação chega à $27 \%$.

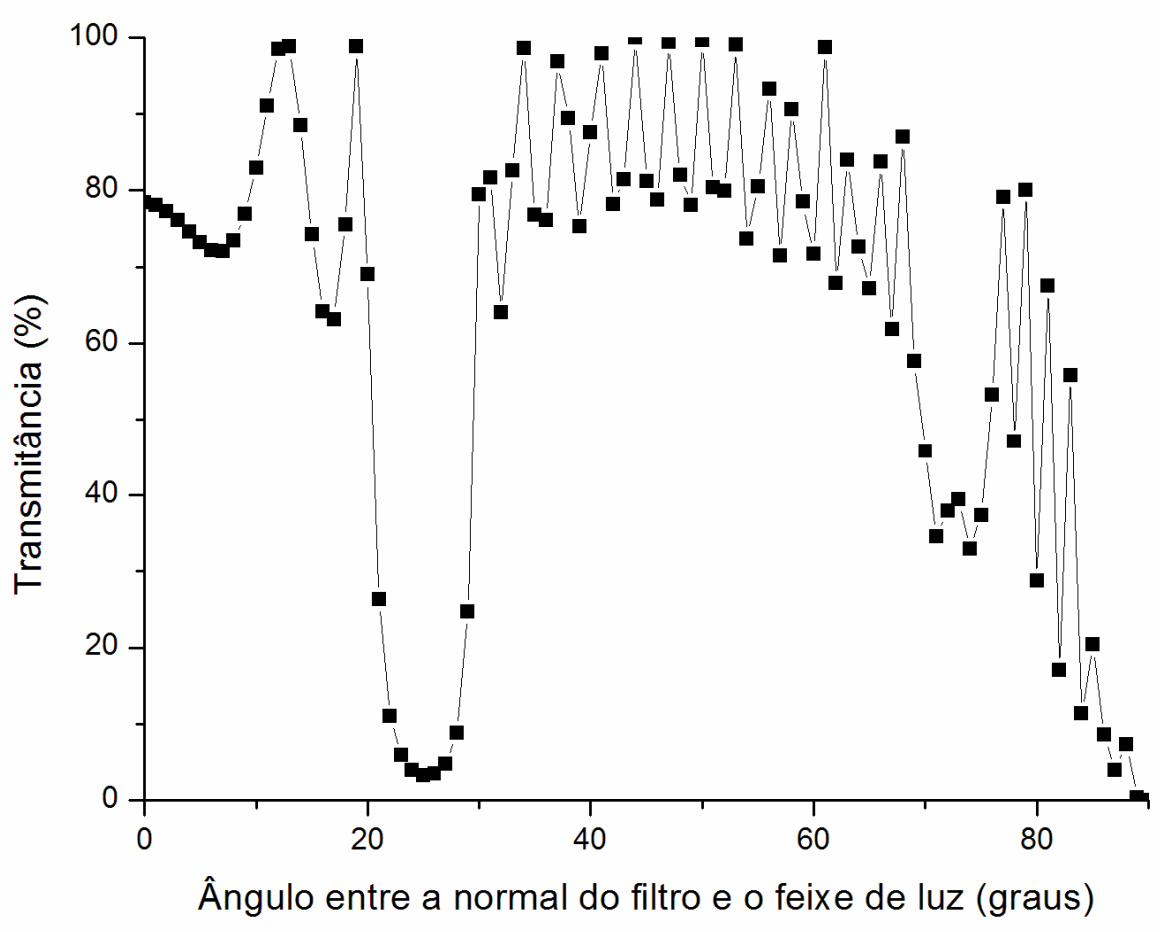

Figura 4.20 -Simulação da transmitância do filtro suspenso em função do ângulo entre a normal e o feixe de luz monocromático de $633 \mathrm{~nm}$.

A medida de transmitância em função do ângulo de incidência é mostrada na Figura 4.21 


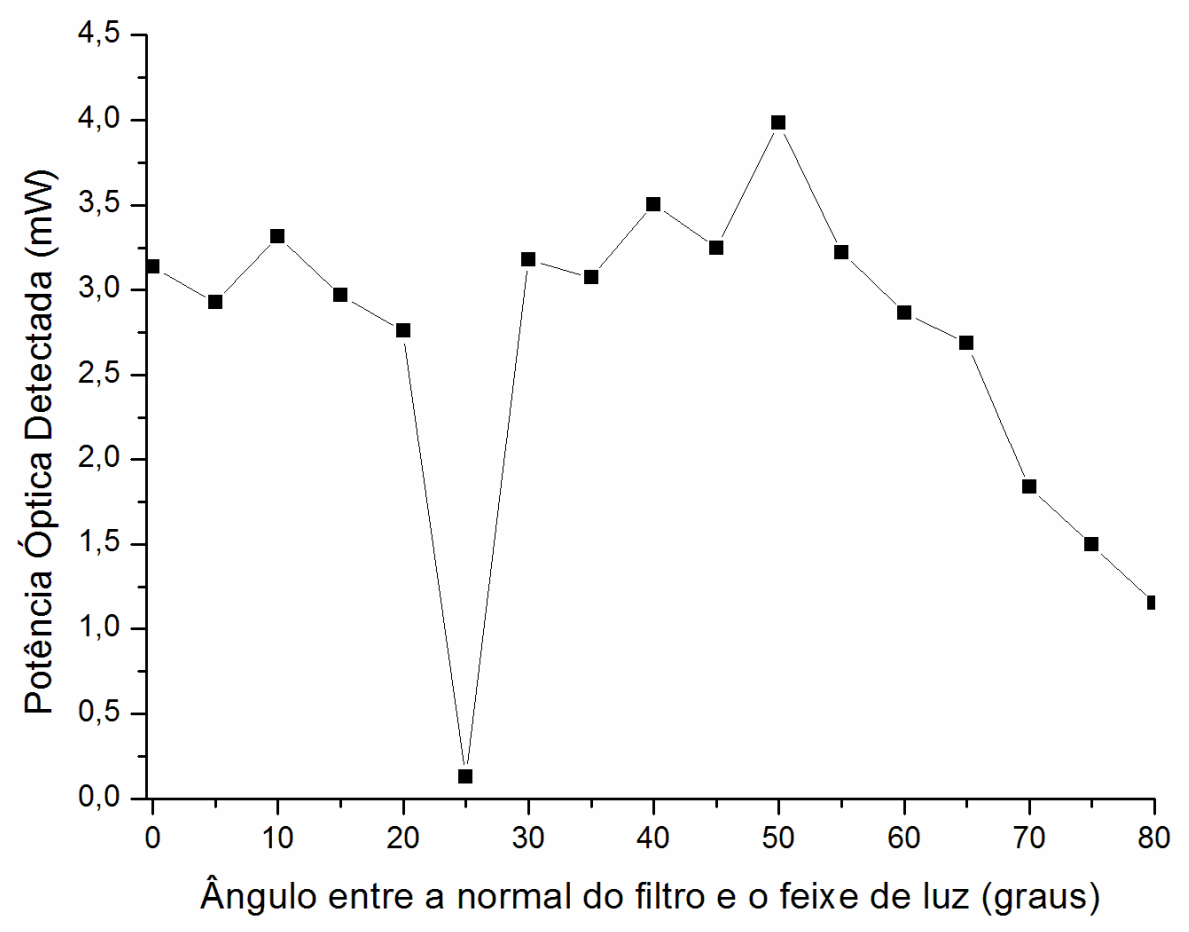

Figura 4.21 -Dados experimentais obtidos pelo teste angular, para o comprimento de onda de $633 \mathrm{~nm}$ no filtro suspenso.

Percebe-se a semelhança entre o simulado (Figura 4.20) e o real (Figura 4.21), variações na espessura das camadas e a resolução do experimento são a causa da maior parte das diferenças. O dispositivo pode funcionar como um sensor angular desde que é possível observar a variação da potência detectada em função do ângulo. Contudo o filtro 4 apresenta uma variação mais suave aproximadamente $0,17 \mathrm{~mW}$ por grau de inclinação em comparação com o filtro suspenso que varia aproximadamente $0,6 \mathrm{~mW}$ por grau de inclinação.

\subsubsection{FILTRO SUSPENSO COMO SENSOR DE TEMPERATURA}

O teste térmico no filtro suspenso foi realizado com uma inclinação de 20 graus entre o feixe de laser e a normal do filtro, pois nesta angulação a variação de potência que pode ser obtida em função da variação de temperatura é maior $(0,004 \mathrm{~mW} / \stackrel{\circ}{ } \mathrm{C})$, como foi visto na Figura 4.20 . 


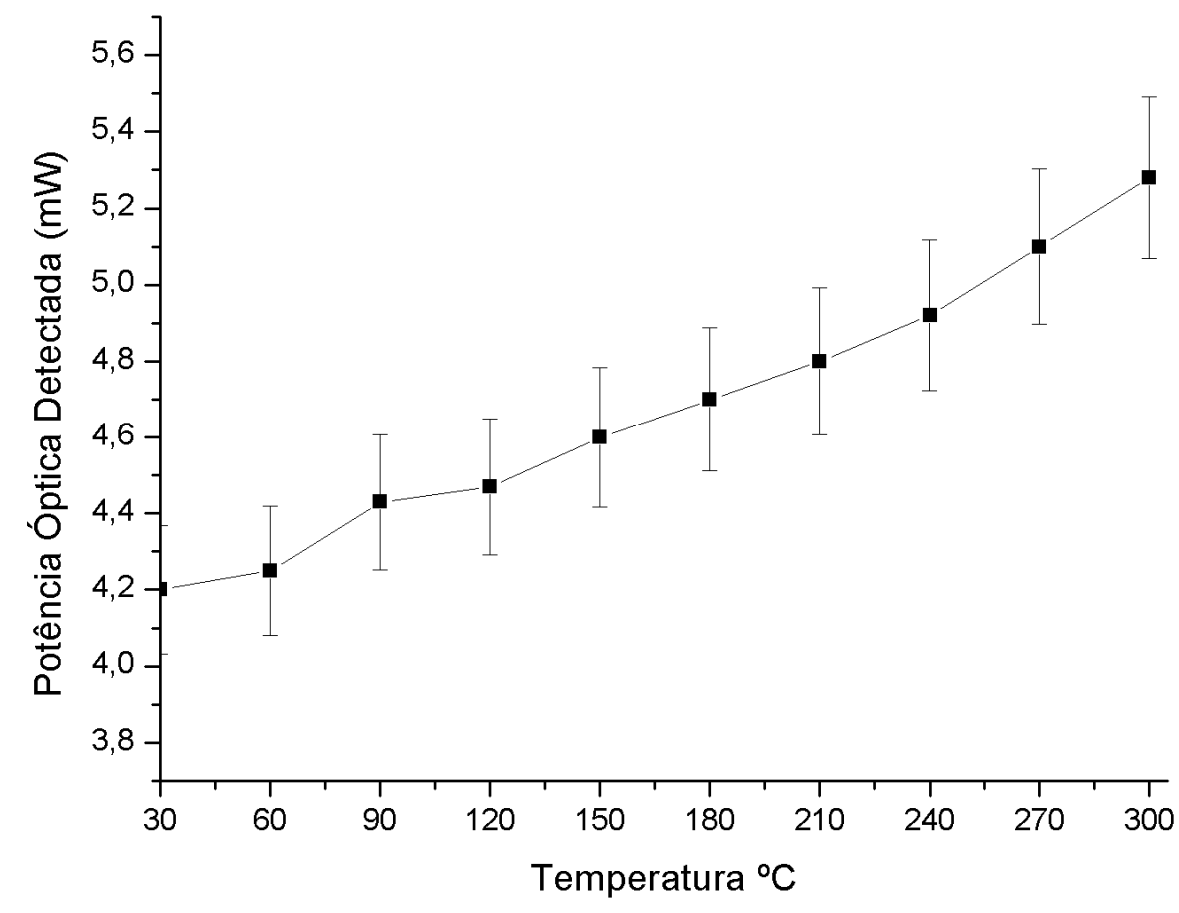

Figura 4.22 -Potência luminosa medida pelo fotodiodo em função da temperatura do filtro suspenso.

Pode-se perceber pela Figura 4.22 uma variação de 4 à $5,2 \mathrm{~mW}$ aproximadamente sendo possível utilizar o filtro como um sensor térmico assim como foi feito com o filtro 4. Contudo para este filtro podem-se utilizar outras técnicas de microfabricação para se construir sobre a parte não corroída do substrato outras estruturas deixando o dispositivo mais funcional e complexo; isto não é possível de se realizar com um substrato de vidro.

\subsubsection{Filtro Horizontal COMO SENSOR DE TEMPERATURA}

O filtro horizontal construído sobre silício também foi submetido a testes térmicos de acordo com a montagem mostrada na Figura 4.23. 


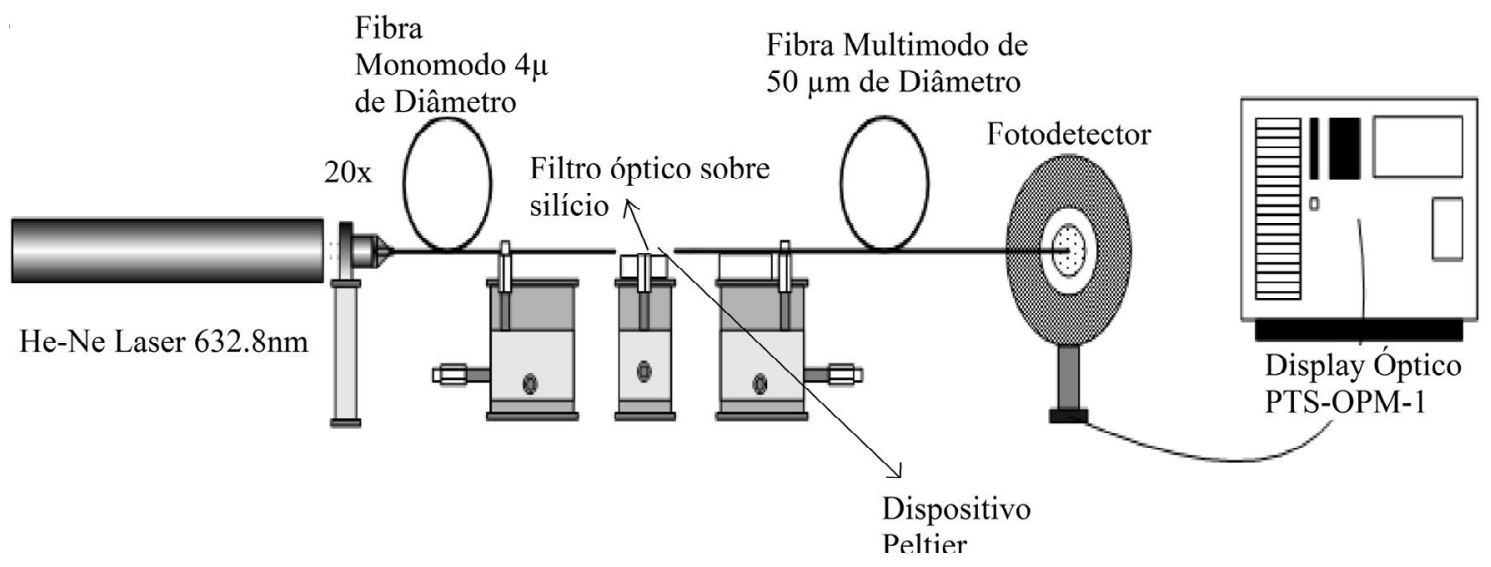

Figura 4.23 -Montagem para teste térmico do filtro sobre silício.

O filtro foi colocado entre duas fibras ópticas sendo que a fibra de entrada estava ligada a um laser de $633 \mathrm{~nm}$ e a fibra de saída a um fotodetector, as fibras foram posicionadas de forma que ocorresse máximo acoplamento com o filtro. Para o aquecimento do filtro foi utilizado um dispositivo Peltier sob a lâmina de silício, este dispositivo era controlado por uma fonte de corrente e a temperatura sobre ele foi medida com um termopar.

O resultado do teste é mostrado na Figura 4.24 e podemos observar a potência óptica detectada em função da temperatura.

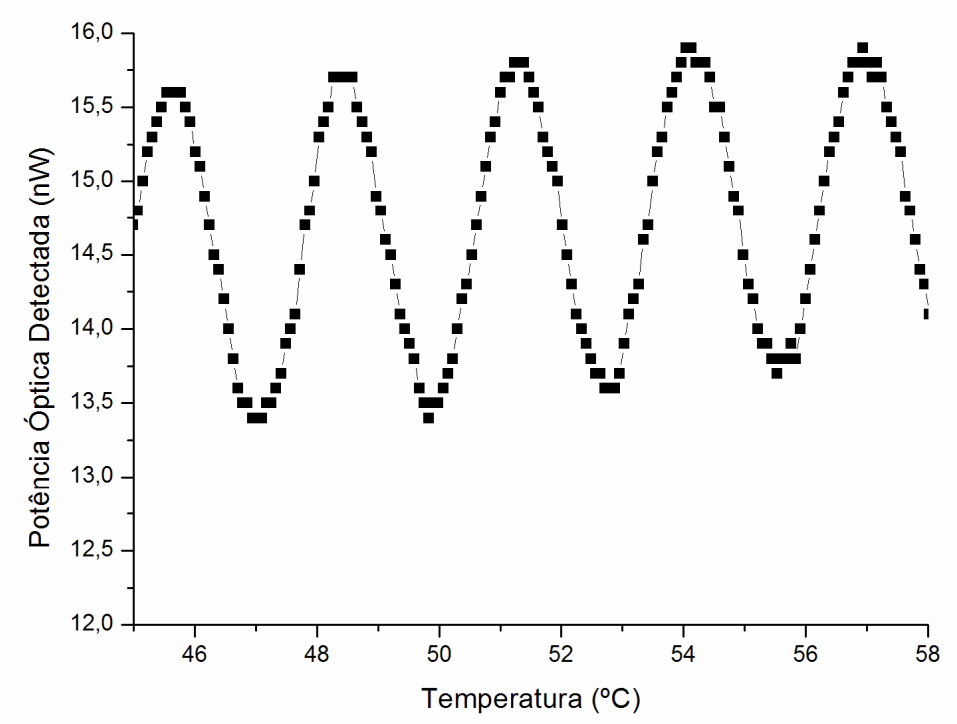

Figura 4.24 -Potência luminosa medida pelo fotodiodo em função da temperatura do filtro horizontal. 
A oscilação senoidal característica de cavidades óptica é confirmada nesta estrutura o efeito observado ocorre devido às múltiplas reflexões da luz nas camadas e entre as estruturas depositadas, ao ser aquecida a estrutura varia o índice de refração pelo efeito termo-óptico e as propriedades da cavidade se alteram gerando alteração na potencia óptica detectada na saída como na região de ar ocorre um fluxo dinâmico entre ar quente e ar frio a sua variação de índice de refração não foi considerada nas simulações que seguiram o mesmo padrão das simulações para os filtros verticais. Estes resultados são relativos às cavidades de $1000 \mu \mathrm{m}$ e a simulação da ressonância realizada nas cavidades de ar com variação da reflexão das paredes laterais destas cavidades em função da temperatura.

A simulação deste filtro é mostrada no Figura 4.25 onde podemos observar a variação da transmitância em função da temperatura aplicada ao filtro horizontal.

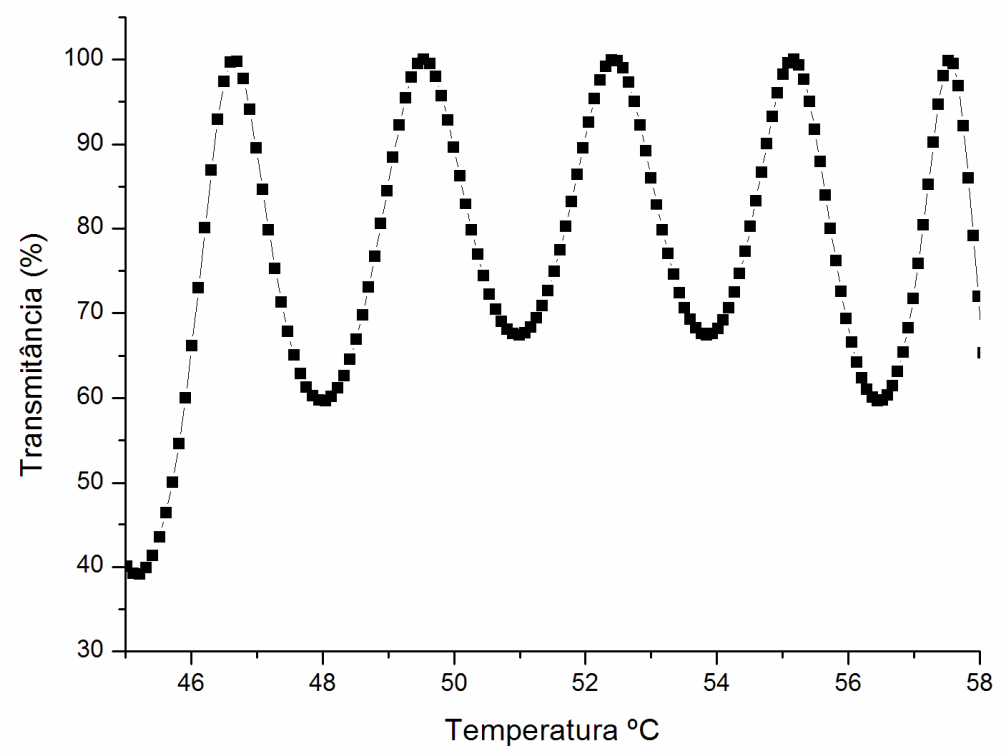

Figura 4.25 -Simulação da transmitância em função da temperatura do filtro horizontal.

Como podemos perceber nas Figura 4.24 e Figura 4.25, as curvas calculada e experimental são muito similares. A comparação entre estes gráficos foi realizada na Figura 4.26 onde foi colocado o gráfico experimental normalizado juntamente com o gráfico simulado. 


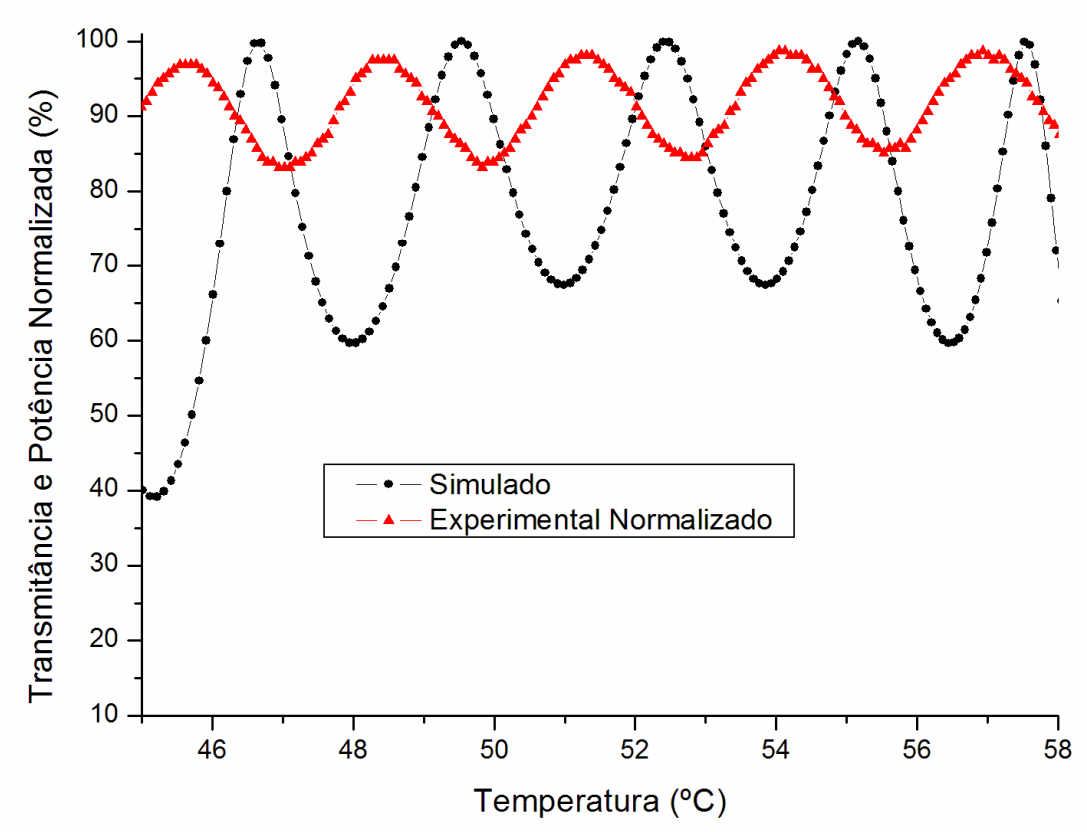

Figura 4.26 -Comparação entre o gráfico simulado e o gráfico experimental normalizado.

Pode-se observar que e o período (mudança de temperatura necessária para obter dois picos adjacentes) é praticamente idêntico (2,9 ${ }^{\circ} \mathrm{C}$ para a curva experimental e $3 \stackrel{\circ}{\circ}$ para a curva simulada). Contudo, uma menor variação na transmitância é observada para a curva experimental, isso se deve às perdas ópticas na inserção e propagação da luz através do filtro óptico interferencial. Um deslocamento é observado em relação às curvas e isso se deve a dois fatores: o primeiro deles é o erro na medida de temperatura. Isto ocorre, pois a temperatura foi medida diretamente na superfície do dispositivo termoelétrico Peltier e, na realidade, a temperatura no filtro deve ser menor que a temperatura medida, causando um deslocamento de aproximadamente $2^{\circ} \mathrm{C}$ entre as curvas simulada e experimental. $\mathrm{O}$ outro fator é a imprecisão da fotogravação do filtro. Como a máscara não possui resolução nanométrica, pequenas variações no tamanho do filtro e imperfeições da corrosão RIE podem também ter contribuído para este deslocamento. 


\section{Capítulo 5 - CONSIDERAÇÕES FINAIS}

\subsection{CONCLUSÕES}

Neste trabalho foi apresentada a simulação, fabricação e caracterização de filtros ajustáveis empregando películas dielétricas amorfas depositadas pela técnica de deposição a vapor assistida por plasma (PECVD) sobre silício $<100>$ e sobre Corning Glass (7059). Os dispositivos ópticos foram construídos usando-se processos padrões de microeletrônica e consistiram em camadas periódicas com espessura e comprimentos apropriados para produzir picos da atenuação na transmitância da luz na região visível. Simulações numéricas precedentes foram realizadas baseando-se nas características óticas das películas dielétricas, que foram extraídas da elipsometria. Os filtros interferenciais depositados sobre Corning Glass apresentaram-se muito condizentes com as simulações (com diferenças entre o lóbulos principais simulado e experimental com valores menores que $0,1 \%$ para o filtro suspenso) permitindo-se construir filtros de alta precisão onde os problemas técnicos com a deposição no reator de PECVD foram resolvidos. O filtro construído sobre silício fino (chamado de filtro suspenso) foi criado utilizando-se as novas técnicas de deposição, com garras mais finas para prendê-lo no reator, que foram desenvolvidas nos filtros de vidro, este filtro possui uma região suspensa que permite a passagem da luz e ao mesmo tempo um substrato de silício onde podem ser utilizadas técnicas de microeletrônica para que sejam desenvolvidos dispositivos mais complexos. Para a caracterização dos filtros interferenciais sobre Corning Glass e do filtro suspenso uma luz monocromática de um laser de $\mathrm{He}-\mathrm{Ne}$, foi injetada nos filtros e a luz obtida na saída foi conduzida então a um detector. O filtro 4 depositado sobre Corning Glass e o filtro suspenso foram montados sobre dispositivos térmicos e angulares e foi mostrada a possibilidade da utilização dos mesmos como sensores de temperatura e sensores de ângulos. O melhor filtro para sensor angular apresentando maior sensibilidade à variação angular foi o filtro suspenso (0,6 mW por grau de inclinação) e o melhor filtro para sensor térmico foi o filtro 4 que apresentou maior variação da potencia luminosa detectada com a 
variação da temperatura $(0,007 \mathrm{~mW} / \stackrel{\circ}{ } \mathrm{C})$, para uso como filtro de banda de comprimento de onda em função do ângulo de incidência da luz e uso como WDM o filtro suspenso apresentou melhores resultados pois para um maior conjunto de ângulos sua banda filtrada não se cruza como pode ser visto na Figura 4.19.

O filtro interferencial (filtro horizontal) depositado sobre silício apresentou perdas muito maiores em relação ao filtro com substrato de Corning Glass e o filtro suspenso devido ao maior caminho que a luz precisa percorrer e devido às perdas ópticas na inserção da luz na guia; as imprecisões da fotogravação do filtro e o fato de a máscara não possuir resolução nanométrica, causaram pequenas variações no tamanho do filtro que contribuíram para a menor similaridade entre o simulado e o real. Contudo mesmo com estas diferenças ele apresentou uma boa variação na potência luminosa de saída em relação à temperatura, permitindo seu uso como um sensor de térmico.

\subsection{SUGESTÕES PARA TRABALHOS FUTUROS}

Para futuros trabalhos segue como sugestão a associação de 2 ou mais filtros verticais através de mecanismos de soldagem de lâminas de silício ou de vidro de forma a possibilitar a construção de filtros com maior número de camadas e com camadas mais espessas permitindo um sensoriamento térmico melhor e mais preciso.

Outra sugestão é o uso de cavidades ressonantes construídas sobre silício do mesmo modo do filtro horizontal, contudo com a separação do mesmo feixe de luz em vários guias onde a luz entraria por diferentes ângulos numa mesma estrutura de cavidades ressonantes; em sua saída é esperado que ocorra maior ou menor atenuação para as saídas de diferentes ângulos de entrada, contudo essa atenuação iria variar de maneira continua para ângulos próximos em função da temperatura permitindo o roteamento da luz para as diferentes saídas. 


\subsection{TRABALHOS DECORRENTES}

- Martins, G.S.P.; Mina, A.M.; Alayo, M.I. Fabrication of an Electro-Optical Temperature Sensor Based on Silicon Oxynitride Films Deposited by PECVD. 2006. Apresentado no congresso SBMicro 2006 em Ouro Preto, 28 de agosto à 1 de setembro.

- Martins, G.S.P.; Carvalho, D.O.; Alayo, M.I. Tunable Bragg Filter Using Silicon Compound Films. 2007. Apresentado no congresso ICANS22 em Breckenridge, Colorado (EUA) de 19 a 24 de agosto e publicado no Journal of Non-Crystalline Solids. Vol. 354, 1 Maio de 2008, páginas 2816-2820.

- Martins, G.S.P.; Baez, H.; Alayo, M.I. Simulation, Fabrication and Characterization of a Tunable Bragg Reflector Based on Silicon Oxide and Silicon Nitride Dielectric Films Deposited by PECVD. 2007. Apresentado no congresso SBMicro 2007 no Rio de Janeiro de 3 a 6 de setembro .

- MINA, A.M. ; Baez, H. ; Martins, G.S.P. ; Alayo, M.I. Developing and Fabrication of an Optimized Thermo-Electro-Optic Device Using a Mach-Zehnder Interferometer. 2007. Apresentado no congresso ICANS22 em Breckenridge Colorado (EUA) de 19 a 24 de agosto e publicado no Journal of NonCrystalline Solids. Vol. 354, 1 Maio de 2008, páginas 2565-2570. 
Referências

[1] SUHIR, E. Microelectronics and photonics - the future. Bell laboratories, Lucent Technologies Inc. Physical Sciences and Engineering Research Division.

[2] CHATterJeE, P. K.; DOERING, R. R. The Future of Microelectronics, Invited Paper IEEE, 2000.

[3] HILLENIUS, S. The Future of Silicon Microelectronics. INTEGRATED CIRCUIT DEVICE TECHNOLOGY IEEE, 2004.

[4] Bona, G. L.; Germann, R.; Offrein B. J. SiON high-refractive-index waveguide and planar lightwave circuits. IBM J. RES. \& DEV., v. 47, n. 2/3, Mar. 2003.

[5] AHN, J. T. et al. A stabilised fibre-optic Mach-Zehnder interferometer filter using an independent stabilisation light source, Basic Research Laboratories, Electronics and Telecommunications Research Institute, 1998.

[6] COCORULLO, G. et al. SENSORS AND ACTUACTORS, 1997. 267 p.

[7] OKAMOTO, K. Fundamentals of Optical Waveguides, ACADEMIC PRESS, 1992.

[8] REED, T., NATURE,v.427, 595 p., Fev. 2004.

[9] YROKY, J. et al. Bragg waveguide grating as a 1D photonic band gap structure: COST 268 modelling task, Optical and Quantum Electronics, KLUWER ACADEMIC PUBLISHERS, 2002. 455 p.

[10] COCORULLO, G. et al., A Temperature All-Silicon Micro-Sensor Based on the Thermo-Optic Effect, IEEE TRANSACTIONS ON ELECTRON DEVICES, 1997. 
[11] LI, C.B. et al. Thermally tunable optical filter with crystalline silicon as cavity, Institute of Semiconductors, China: Chinese Academy of Science, 2005. 167 p.

[12] DOMASH, L. et al. Tunable Thin Film Filters , Aegis Semiconductor Inc., OFC, 2003. $522 \mathrm{p}$.

[13] DOMASH, L. et al. Switchable thin film add/drop filter, Reg\& Semiconductor, OPTICAL SOCIETY OF AMERICA, 2003.

[14] COCORULLO, G.; IODICE M.; RENDINA I. All-silicon Fabry-Perot modulator based on the thermo-optic effect, Italia: OPTICS LETTERS, v. 19, n. 6, Mar. 1994.

[15] HOHLFELD, D.; ZAPPE, H. An all-dielectric tunable optical filter based on the thermo-optic effect, JOURNAL OF OPTICS: PURE AND APPLIED OPTICS, v. 6, p. 504-511, 2004.

[16] RUMPF, R. C. et al. Design and optimization of space-variant photonic crystal filters, APPLIED OPTICS, v. 46, n. 23, Ago. 2007.

[17] GOTTSCHALCH, V. et al. Plasma-enhanced chemical vapor deposition of SiOxySiNx Bragg reflectors, THIN SOLID FILMS v. 416, p. 224-232, 2002.

[18] HUMBLET, P. A.; HAMDY, W. M. Crosstalk Analysis and Filter Optimization of Single- and Double-Cavity Fabry-Perot Filters, IEEE JOURNAL ON SELECTED AREAS IN COMMUNICATIONS, v. 8, n. 6, ago. 1990.

[19] MATSUMOTO, S. et al. Tunable Wavelength Filter Using Nano-Sized Droplets of Liquid Crystal, IEEE PHOTONICS TECHNOLOGY LETTERS, v. 11, n. 4, Abr. 1999. 
[20] DIMMICK T. E. et al. Compact All-Fiber Acoustooptic Tunable Filters with Small Bandwidth-Length Product, IEEE PHOTONICS TECHNOLOGY LETTERS, v. 12, Set. 2000.

[21] TAYEBATI P. et al. Microelectromechanical tunable filter with stable half symmetric cavity, ELECTRONICS LETTERS, v. 34, n. 20, Out. 1998.

[22] M. LEQUIME. et al. Toward tunable thin-film filters for wavelength division multiplexing applications, APPLIED OPTICS, v. 41, n. 16, Jun. 2002.

[23] PARMENTIER R.; LEQUIME M. Substrate-strain-induced tunability of dense wavelength-division multiplexing thin-film filters, OPTICS LETTERS, v. 28, n. 9, Mai. 2003.

[24] LAMPERSKI J. Discretely Tunable Multi Cavity FFP Filter for Standard WDM Frequency Grid, ELECTRONIC COMPONENTS AND TECHNOLOGY CONFERENCE, 2000.

[25] UEHARA N. et al. Advanced thin-film filter for passive optical networks, OPTICAL SOCIETY OF AMERICA, 2004.

[26] ALAYO, M.I.; CRIADO, D.; CARREÑO, M.N.P.; PEREYRA, I. Fabrication and Characterization of PECVD silicon oxynitride based waveguides, INTERNATIONAL SOCIETY FOR OPTICAL ENGINEERING - INTEGRATED OPTICS: DEVICES, MATERIALS AND TECHNOLOGIES VIII, EUA: n. 5355, 2004, 198 p.

[27] ALAYO, M.I.; CRIADO D.; GONÇALVES L.C.D.; PEREYRA I. JOURNAL OF NON-CRYSTALLINE SOLIDS, v. 76, p. 338-340, 2004.

[28] ALAYO M.I.; D. CRIADO; CARREÑO M.N.P.; PEREYRA I. Materials Science and Engineering B - Solid State Materials for Advanced Technology, v. 123, 2004. $112 \mathrm{p}$. 
[29] ALAYO M.I.; CARREÑO M.N.P.; CRIADO D.; PEREYRA I. Optical and Structural Characterization of PECVD-Silicon Oxynitride films for waveguide device applications, INTERNATIONAL SOCIETY FOR OPTICAL ENGINEERING OPTOELECTRONIC INTEGRATION ON SILICON III, EUA: v. 250, 2005. 5730 p.

[30] ALAYO M.I.; CARREÑO M.N.P.; CRIADO D.; PEREYRA I. PECVD Silicon oxynitride films for application in optical waveguide, III ENCONTRO DA SOCIEDADE BRASILEIRA DE PESQUISA EM MATERIAIS, Paraná: v. 148, 2004.

[31] ALAYO M.I.; PEREYRA I.; CRIADO D.; GONÇALVES L.C.D. Deposition and Characterization for Integrated Optical Applications, 20TH INTERNATIONAL CONFERENCE ON AMORPHOUS AND MICROCRYSTALLINE SEMICONDUCTORS, PTU-1, 2003.

[32] ALAYO M.I.; CARREÑO M.N.P.; CRIADO D.; PEREYRA I. PECVD-Silicon Oxynitride Films for Fabrication of Optical Waveguides, II ENCONTRO DA SOCIEDADE BRASILEIRA DE PESQUISA EM MATERIAIS, Rio de Janeiro: v. 50, 2003.

[33] AZZAM R. M. A.; BASHARA N. M. Ellipsometry and polarized light, New York: North-Holland Pub. Co.: sole distributors for the U.S.A. and Canada, Elsevier NorthHolland, 1977

[34] CARRENO M.N.P.; Pereyra I. JORNAL OF NON-CRYSTALINE SOLIDS v. 201, p.110, 1996.

[35] TOLOSA F. E. F.; Carbono amorfo hidrogenado (a-C:H) tipo diamante, tese apresentada no instituto de física Glew Wataghin, Universidade Estadual de Campinas, Out 1991.

[36] YU G.Q. et al. Properties of fluorinated amorphous diamond like carbon films by PECVD, APPLIED SURFACE SCIENCE, v. 219, p. 228-237,2003. 
[37] DOMÍNGUEZ C.et al. Plasma enhanced CVD silicon oxide films for integrated optic applications, VACUUM, v. 52, p. 395-400, 1999.

[38] KIM Y.T. et al, Refractive index control of core layer using PECVD and FHD for sílica optical waveguide, SURFACE AND COATINGS TECHNOLOGY, v. 171, p. 3498, 2003.

[39] TEMPLE-BOYER P. et al. Properties of $\mathrm{SiO}_{x} \mathrm{~N}_{\mathrm{y}}$ films deposited by LPCVD from $\mathrm{SiH}_{4} / \mathrm{N}_{2} \mathrm{O} / \mathrm{NH}_{3}$ gaseous mixture, SENSORS AND ACTUATORS, v. 74, p. 52-55, 1999.

[40] CRIADO D.; PEREYRA I.; ALAYO M.I. MATERIALS CHARACTERIZATION, v. 50, 2003. p. 167.

[41] PEREYRA I.; ALAYO M.I. JOURNAL OF NON-CRYSTALLINE SOLIDS, v. 212, p. 225, 1997.

[42] BATES R.; Optimizing Parameters for Profiling Measurements, Microelectronic Manufacturing and Testing, p.7 9,1990.

[43 ] MANDOU M. J.FUNDAMENTALS OF MICROFABRICATION, The science of miniaturization CRC Press, 2002 